Universidade Federal do Rio Grande do Norte Centro de Tecnologia Programa de Pós-Graduação em Engenharia Elétrica e de Computação Baseada em Redes Neurais Artificiais

Victor Leonardo Cavalcante Melo da Silva

Natal - RN 


\section{Predição da Incrustação em um Trocador de Calor Baseada em Redes Neurais Artificiais}

Victor Leonardo Cavalcante Melo da Silva

Orientador: Prof. Dr. Jorge Dantas de Melo

Dissertação de Mestrado apresentada ao Programa de Pós-Graduação em Engenharia Elétrica e de Computação da UFRN (área de concentração: Engenharia de Computação) como parte dos requisitos para obtenção do título de Mestre em Ciências

Natal - RN

2013 
UFRN / Biblioteca Central Zila Mamede

Catalogação da Publicação na Fonte

Silva, Victor Leonardo Cavalcante Melo da.

Predição da incrustação em um trocador de calor baseada em redes neurais artificiais. / Victor Leonardo Cavalcante Melo da Silva. - Natal, $\mathrm{RN}, 2013$.

60 f.; il.

Orientador: Prof. Dr. Jorge Dantas de Melo.

Dissertação (Mestrado) - Universidade Federal do Rio Grande do Norte. Centro de Tecnologia. Programa de Pós-Graduação em Engenharia Elétrica e de Computação.

1. Redes neurais artificiais - Dissertação. 2. Predição - Dissertação. 3. Identificação de sistemas - Dissertação. 4. Inferência - Dissertação. 5. Sensor de software - Dissertação. 6. Incrustação - Petróleo - Dissertação. 7. Permutador de calor - Dissertação. I. Melo, Jorge Dantas de. II. Universidade Federal do Rio Grande do Norte. III. Título. 


\title{
Predição da Incrustação em um Trocador de Calor Baseada em Redes Neurais Artificiais
}

\author{
Victor Leonardo Cavalcante Melo da Silva
}

Dissertação de Mestrado aprovada em 19 de abril de 2013 pela banca examinadora composta pelos seguintes membros:

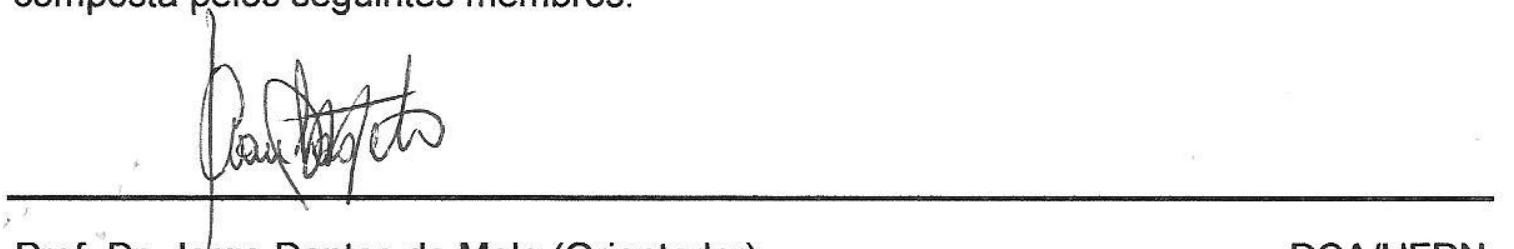

Prof. Dr. Jorge Dantas de Melo (Orientador) . . . . . . . . . . DCA/UFRN

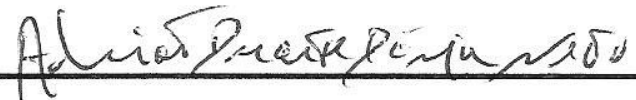

Prof. Dr. Adrião Duarte Dória Neto (Coorientador) . . . . . . . . . . . . DCA/UFRN Wuate

Prof. Dr. Márcia Maria Lima Duarte (Examinador Interno) . . . . . . . . DEQ/UFRN Lacete de M Borres seinin Dr. Laerte de Medeiros Barros Júnior (Examinador Externo) . . . . . . . . Petrobras 


\section{Agradecimentos}

Em primeiro lugar gostaria de agradecer à minha família. Aos meus pais e irmãos pelos exemplos, ensinamentos de vida e apoio durante os estudos. À minha namorada Andréa Karla pela compreensão, motivação e incentivo para a realização de meus objetivos.

Aos meus colegas que fizeram parte da minha jornada durante o mestrado, trocando ideias, auxiliando nos estudos e na realização de trabalhos. Aos integrantes do projeto CSIMD, que forneceram informações de grande ajuda no desenvolvimento desta dissertação.

Ao meu orientador, Jorge Dantas de Melo, por ter acompanhado meu desenvolvimento acadêmico desde a graduação. Aos professores Adrião Duarte Doria Neto, Márcia Maria Lima Duarte e ao Engenheiro Laerte de Medeiros Barros Júnior, pelos comentários, sugestões e ensinamentos.

Aos professores e funcionários do Programa de Pós-Graduação em Engenharia Elétrica e de Computação, pelos ensinamentos e pela ajuda.

Ao Conselho Nacional de Desenvolvimento Científico e Tecnológico (CNPq) pelo apoio financeiro. 


\section{Resumo}

Um sério problema que afeta unidades de refino de petróleo é a deposição e incrustação de sólidos nos equipamentos. Esses resíduos estão naturalmente presentes no petróleo ou são produtos de reações químicas durante o seu transporte. Um permutador de calor, quando sujo, perde sua capacidade de aquecer adequadamente o petróleo, precisando, periodicamente, ser retirado de operação, para que possa ser realizada uma limpeza. Informações prévias do melhor período para realizar as paradas podem melhorar a eficiência energética e de produção da planta. Esse trabalho desenvolveu um sistema de predição da incrustação em um permutador da Refinaria Potiguar Clara Camarão, com base em dados coletados em parceria com a Petrobras. Foram utilizadas redes neurais recorrentes que preveem a vazão no permutador em instantes futuros. Essa variável é o principal indicador da incrustação, pois seu valor diminui gradualmente à medida que os depósitos nas paredes dos tubos reduzem seu diâmetro. A predição pode ser usada para dizer quando a vazão terá caído abaixo de um valor satisfatório, indicando quando será necessário retirar o equipamento de operação.

Palavras-chave: redes neurais artificiais, predição, identificação de sistemas, inferência, sensor de software, incrustação, permutador de calor. 


\begin{abstract}
A serious problem that affects an oil refinery's processing units is the deposition of solid particles or the fouling on the equipments. These residues are naturally present on the oil or are by-products of chemical reactions during its transport. A fouled heat exchanger loses its capacity to adequately heat the oil, needing to be shut down periodically for cleaning. Previous knowledge of the best period to shut down the exchanger may improve the energetic and production efficiency of the plant. In this work we develop a system to predict the fouling on a heat exchanger from the Potiguar Clara Camarão Refinery, based on data collected in a partnership with Petrobras. Recurrent Neural Networks are used to predict the heat exchanger's flow in future time. This variable is the main indicator of fouling, because its value decreases gradually as the deposits on the tubes reduce their diameter. The prediction could be used to tell when the flow will have decreased under an acceptable value, indicating when the exchanger shutdown for cleaning will be needed.
\end{abstract}

Keywords: artificial neural networks, prediction, system identification, inference, soft sensors, fouling, heat exchanger. 


\section{Lista de Figuras}

Figura 1 - Esquema de um trocador de calor "casco e tubos" típico ..........................................4

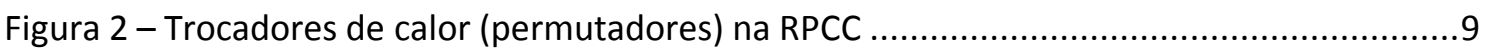

Figura 3 - Modelo de um Neurônio Artificial.............................................................................18

Figura 4 - Perceptron de Múltiplas Camadas com duas camadas ocultas e uma de saída .........19

Figura 5 - Topologia de MLP com entradas atrasadas no tempo .............................................22

Figura 6 - Topologia de MLP com saídas realimentadas às entradas .....................................23

Figura 7 - Diagrama de blocos do procedimento de identificação ..........................................27

Figura 8 - Arquitetura do sistema de predição da incrustação ................................................31

Figura 9 - Arquitetura do sistema de predição de dias até a parada .........................................32

Figura 10 - Vazão entre novembro e dezembro com alguns problemas em destaque ...............36

Figura 11 - Vazão após tratamento de erros e separação de ciclos .........................................38

Figura 12 - Dados tratados do segundo ciclo de operação do trocador de calor ........................39

Figura 13 - Efetividade de ciclos de operação do permutador..................................................40

Figura 14 - Índice de incrustação de ciclos de operação do permutador ...................................41

Figura 15 - Definição do sistema de predição da incrustação ...................................................44

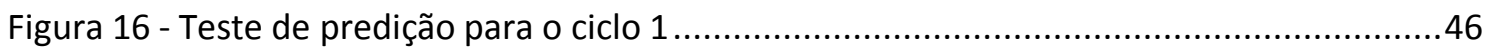

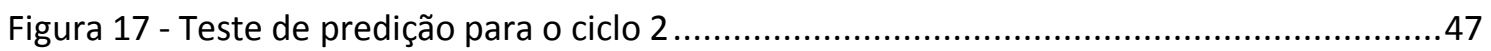

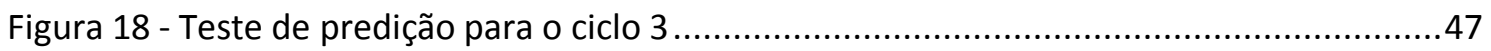

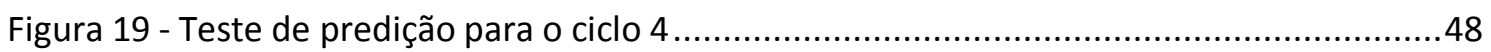

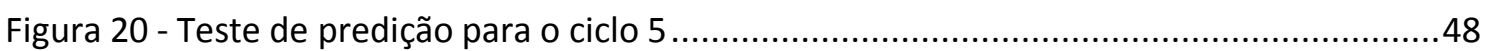

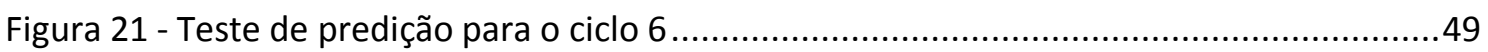

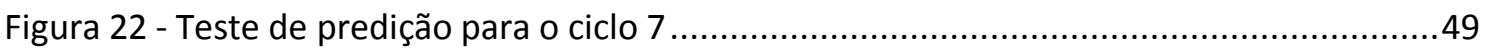

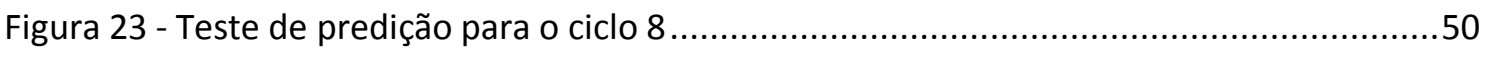

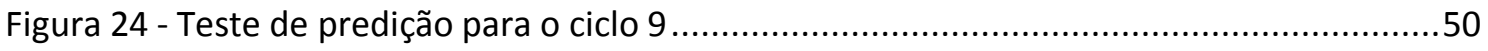

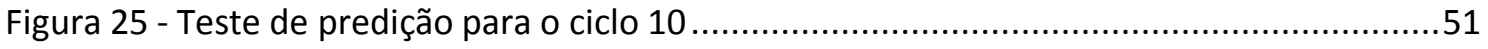




\section{Lista de Tabelas}

Tabela 1 - Lista de algoritmos de treinamento do Matlab......................................................20

Tabela 2 - Exemplo de conjunto de treinamento para rede neural TDNN de ordem $3 \ldots \ldots \ldots \ldots . . .22$

Tabela 3 - Exemplo de conjunto de treinamento para rede recorrente ......................................24

Tabela 4 - Exemplos de regressores experimentados .............................................................. 32

Tabela 5 - Matriz de correlação dos dados coletados .................................................................

Tabela 6 - Resumo da análise dos ciclos de operação do P-27002 ….....................................42

Tabela 7 - Informações e erros das melhores redes selecionadas .............................................45

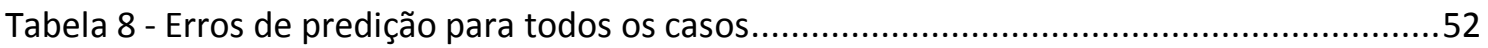




\section{Sumário}

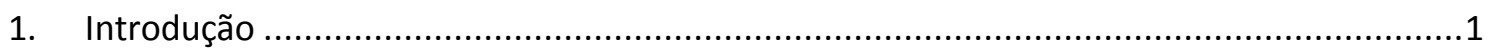

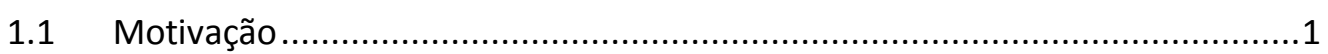

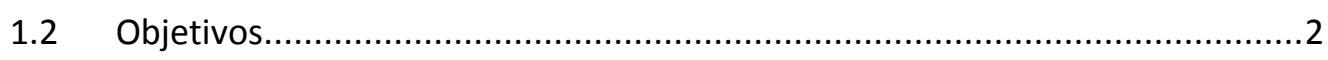

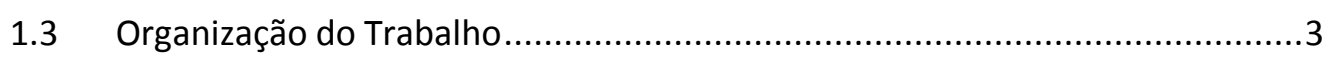

2. Deposição e Incrustação na Indústria do Petróleo …......................................................

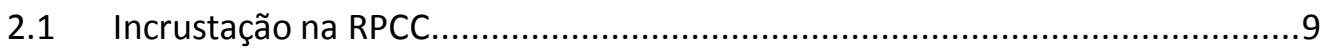

2.2 Detecção e Predição da Incrustação em Trocadores de Calor .......................10

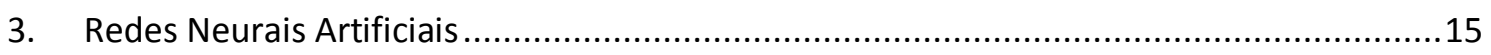

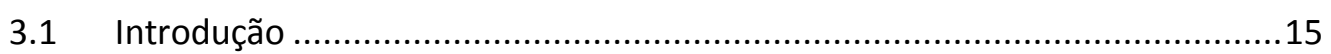

3.2 Propriedades das Redes Neurais Artificiais .................................................16

3.3 Modelo de um Neurônio Artificial ..........................................................17

3.4 Perceptron de Múltiplas Camadas ........................................................18

3.5 Identificação de Sistemas e Predição Usando Redes Neurais ........................20

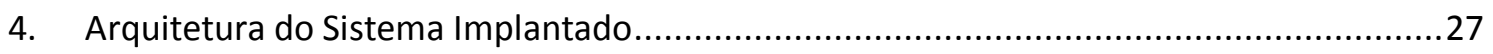

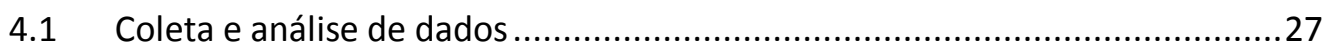

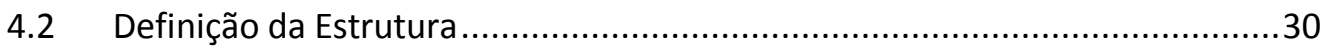

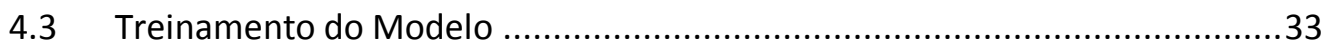

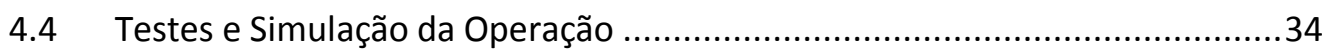

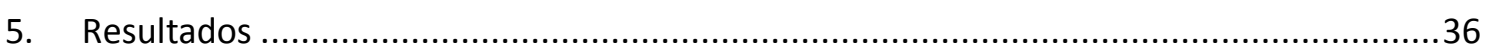

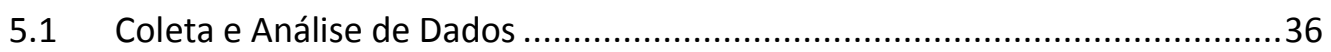

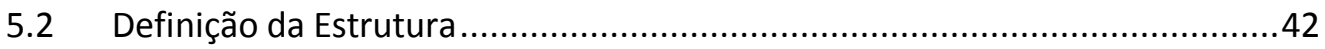

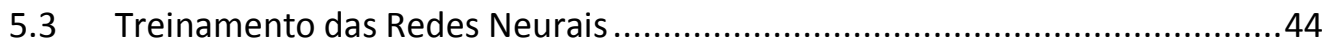

5.4 Testes e Simulação da Operação ...............................................................45

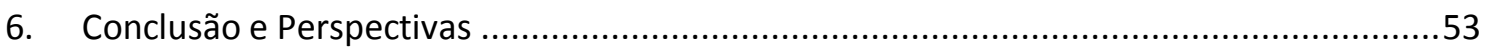

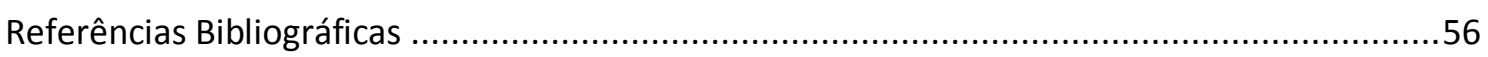




\section{Introdução}

\subsection{Motivação}

O Rio Grande do Norte é um dos maiores produtores de petróleo em terra do Brasil e boa parte desse petróleo é refinada localmente, na Refinaria Potiguar Clara Camarão (RPCC), localizada no município de Guamaré. O petróleo produzido no estado é de boa qualidade, com elevado grau API, mas não está isento de um problema que ocorre em qualquer refinaria: tendência à formação de incrustação, principalmente nas correntes dos derivados produzidos na coluna de destilação. Esse problema consiste na deposição de produtos de reações químicas, sais, restos orgânicos e sujeiras em geral, o que diminui gradativamente a eficiência do processo de refino, até um ponto em que é necessário retirar equipamentos de operação para realizar a sua limpeza. Na produção de querosene de aviação (QAV) da RPCC, a incrustação ocorre em particular nos permutadores (ou trocadores) de calor da bateria de préaquecimento.

No processo de refino do petróleo, a quantidade de energia envolvida é muito grande. Trocadores de calor são usados com o propósito de recuperar energia do processo e, portanto, reduzir o consumo energético da planta. A presença da incrustação em trocadores de calor, utilizados no pré-aquecimento do óleo cru, representa uma resistência à transferência de calor e, com o passar do tempo, reduz a performance térmica destes equipamentos. A capacidade de monitorar o desempenho térmico dos trocadores de calor e de suas redes é de fundamental importância para o sucesso econômico de uma refinaria. Métodos de monitoramento simples e seguros permitem que a performance atual dos equipamentos seja conhecida e o momento ideal para limpeza do trocadores de calor seja estabelecido (TONIN e NEGRÃO, 2003). No entanto, alguns parâmetros relacionados à incrustação são difíceis de serem medidos em tempo real devido a limitações como custo, confiabilidade e grande zona morta. Assim, alguns modelos empíricos e sensores de software são utilizados para estimar a incrustação (HOU e ZHOU, 2005).

Os danos causados pela incrustação nos permutadores são grandes. Pesquisas de SHANRANG, ZHIMING e LINGFANG, 2004, indicam uma perda de até 0,3\% da produção de um país. Eles apontam para a importância de um agendamento adequado das paradas para 
limpeza. Essa é a maior motivação para essa área de pesquisa, que atualmente está dividida em três frentes: predição, monitoramento e contramedidas. O trabalho a ser realizado pretende trazer contribuições para as duas primeiras.

Em visita técnica à Refinaria Potiguar Clara Camarão, descobriu-se que atualmente não existe um método oficial para monitoramento da incrustação. Os operadores da planta observam que, à medida que o permutador sofre mais incrustação, é necessário aumentar a energia no forno da coluna de destilação, pois o petróleo não entra aquecido o suficiente pelo permutador. Além disso, a qualidade dos destilados, principalmente dos produtos de topo, é prejudicada devido à redução da carga térmica retirada da coluna. Para manter a especificação dos produtos é necessário reduzir o rendimento. Para evitar maiores perdas de produção, o equipamento precisa ser retirado de operação para que seja realizada uma limpeza. Em suma, o monitoramento da incrustação é realizado pelos próprios operadores, analisando o desempenho do processo.

\subsection{Objetivos}

O objetivo principal desse trabalho é criar um sistema capaz de prever o nível da incrustação no trocador ou permutador de calor. Essa predição tem a função de permitir um melhor planejamento das paradas, pois com ela, os operadores podem saber a priori se a incrustação terá ou não atingido um nível inaceitável em um intervalo de tempo arbitrário. 0 melhor planejamento das paradas por consequência melhorará a eficiência geral do processo. Além disso, os operadores poderiam alimentar o sistema com condições de operação hipotéticas, permitindo analisar em quais casos a incrustação ocorre mais ou menos rapidamente.

Dados reais de operação do permutador P-27002 foram obtidos em parceria com a Petrobras. Os dados correspondem a diversos ciclos de operação do equipamento, incluindo várias paradas para manutenção. Foi feita uma investigação para definir quais variáveis são afetadas e de que forma a incrustação pode ser indicada com base nesses dados.

Foram experimentadas possíveis arquiteturas de redes neurais artificiais para realizar a predição. $\mathrm{O}$ erro resultante do sistema também será considerado. Foram analisados os limites de tempo até os quais a predição é confiável. Se a incrustação for entendida como uma variável oculta que pode ser inferida a partir de outros dados de processo, é possível formular o problema como uma tarefa de identificação de sistemas. 


\subsection{Organização do Trabalho}

O restante do trabalho está organizado em capítulos. No segundo capítulo haverá uma descrição mais detalhada do problema da deposição e incrustação em trocadores de calor em geral. Em particular, será explicado o que ocorre nos trocadores da Refinaria Potiguar Clara Camarão. Será feita também uma revisão bibliográfica com base em trabalhos recentes da literatura referentes à deteç̧ão e à predição da incrustação em trocadores de calor.

No terceiro capítulo será feita uma revisão bibliográfica sobre redes neurais artificiais (RNA) e, em particular, sobre a utilização de redes dinâmicas para predição e identificação de sistemas.

O quarto capítulo descreverá a metodologia e a arquitetura do sistema proposto e desenvolvido neste trabalho, com a descrição detalhada das tarefas e técnicas utilizadas no desenvolvimento do sistema para predição da incrustação com base em RNA.

No quinto capítulo serão apresentados e discutidos os resultados obtidos pelo sistema através de testes que simulam a sua utilização em um ambiente real.

O texto se encerra no sexto capítulo com a conclusão e perspectivas futuras desse trabalho, seguido das referências bibliográficas consultadas. 


\section{Deposição e Incrustação na Indústria do Petróleo}

Os problemas de deposição e incrustação de materiais são frequentes e ocorrem nas mais diversas atividades industriais. Entre as atividades em que a deposição é um fator muito importante, destacam-se as atividades de refino e processamento de petróleo. O tratamento do óleo cru em uma torre de destilação é a primeira etapa do refino e processamento do óleo e, consequentemente, estas unidades são as mais afetadas por problemas de deposição. 0 processo de destilação consiste na fragmentação e separação do óleo cru em determinados produtos de acordo com a diferença do ponto de ebulição dos componentes individuais. Durante o processo de destilação, materiais, sujeiras e produtos químicos presentes no óleo podem se depositar nos equipamentos e tubulações e causar problemas de incrustação. Esses problemas são muito custosos, pois aumentam o gasto com combustíveis (maior consumo nos fornos de aquecimento, por exemplo), causam interrupções na operação, perda na produção e gastos com manutenção.

O óleo cru que alimenta uma unidade de destilação atmosférica em geral é submetido a um processo de pré-aquecimento, passando por trocadores de calor antes de entrar na torre. Um trocador de calor é um equipamento onde ocorre uma troca térmica entre dois fluidos, normalmente sem haver um contato físico entre eles. Há diversos tipos construtivos, dentre os quais um dos mais usados industrialmente é o de feixe tubular, constituído por um conjunto de tubos envolto por um casco. Um dos fluidos circula no interior dos tubos (fluido de tubo) e o outro fluido escoa no lado externo (fluido de casco), como mostra a Figura 1.

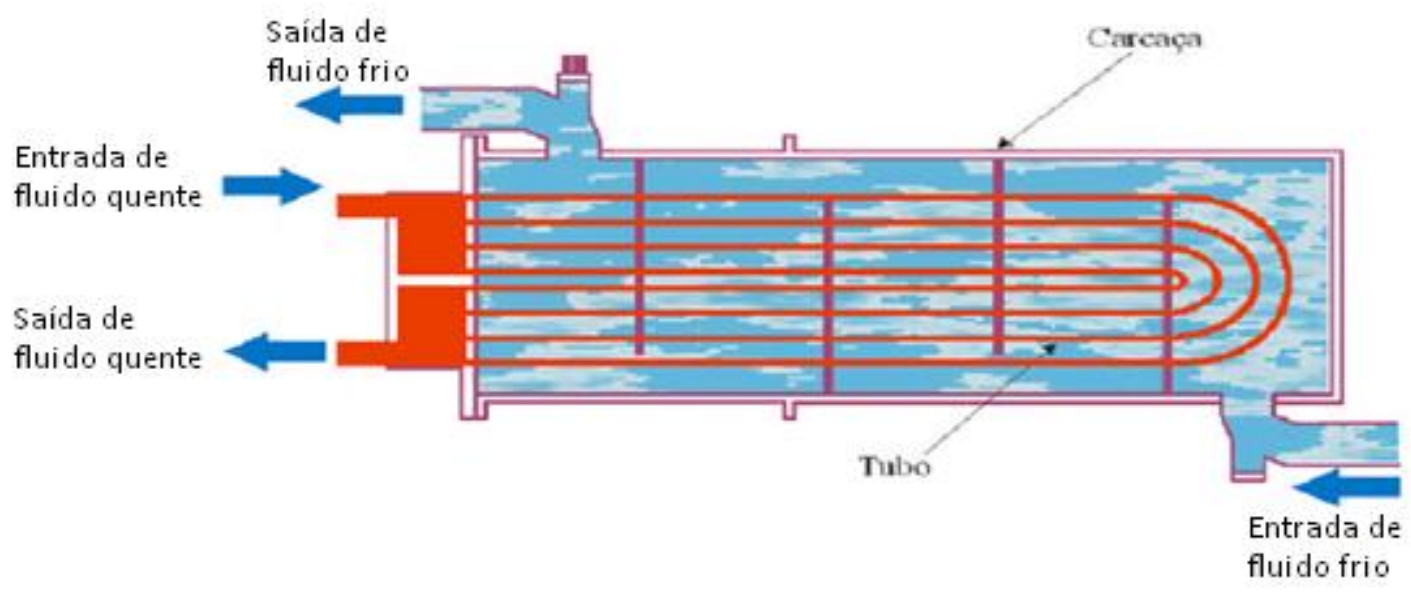

Figura 1 - Esquema de um trocador de calor "casco e tubos" típico 
Trocadores de calor utilizados em plantas industriais são fortemente prejudicados pela incrustação. O material particulado indesejável trazido pelo óleo cru, ou formado por meio de reações entre produtos químicos e o petróleo, se deposita nos tubos internos do trocador. Esse depósito aumenta a resistência à transferência de energia, diminuindo a eficiência de troca térmica, de forma que a temperatura de saída do óleo será menor do que a esperada e ele entrará mais frio na torre, o que diminui a eficiência do processo como um todo. Além disso, o depósito pode obstruir a passagem do fluido, aumentando a sua perda de carga.

Um dos modos adotados na prática para saber o grau de depósito num trocador de calor em operação é acompanhar, ao longo do tempo de uso, as temperaturas e as pressões terminais do trocador. À medida que o depósito aumenta, a eficiência de troca térmica cai (observado através das temperaturas) e a diferença de pressões cresce (SONG, 1997). Por definição, a eficiência (ou efetividade) do trocador pode ser calculada pela Equação 1:

$$
\varepsilon=\frac{T_{c 2}-T_{c 1}}{T_{h 1}-T_{c 1}}\left(\frac{C_{c}}{C_{\min }}\right)
$$

em que $T_{c 1}$ e $T_{c 2}$ são as temperaturas de entrada e de saída do fluido frio, respectivamente, $T_{h 1}$ é a temperatura de entrada do fluido quente, $C_{c}$ é a capacitância térmica do fluido frio e $C_{\min }$ é a menor capacitância térmica dentre os fluidos. Supondo que o fluido frio tem menor capacidade térmica, a equação 1 se simplifica para a Equação 2:

$$
\varepsilon=\frac{T_{c 2}-T_{c 1}}{T_{h 1}-T_{c 1}}
$$

JERONIMO et al. (1997) definem um índice de incrustação como sendo a Equação 3:

$$
I F=\frac{\varepsilon_{\text {limpo }}-\varepsilon_{\text {medido }}}{\varepsilon_{\text {limpo }}-\varepsilon_{\text {sujo }}}
$$

em que $\varepsilon_{\text {limpo }}$ é a eficiência do trocador limpo, $\varepsilon_{\text {medido }}$ é a eficiência do trocador num instante de tempo qualquer (real), e $\varepsilon_{\text {sujo }}$ é a eficiência na condição de extrema incrustação (teórico). Assim, o cálculo desses índices é o método mais simples para se monitorar a incrustação em um trocador de calor.

O processo de formação da deposição é em geral complexo. Alguns dos principais mecanismos são:

- Cristalização: ocorre devido à supersaturação, decorrente da variação da temperatura do fluido, com a consequente deposição de sais presentes no mesmo. 
- Decomposição de produtos orgânicos ou coqueamento: as superfícies do trocador podem ficar cobertas com alcatrão ou coque, produzidos por reações químicas. Essas reações ocorrem próximas à superfície quente e produzem partículas sólidas ou alcatrão muito viscoso que se acumulam nos tubos.

- Reações químicas: depósitos que são formados como resultado de reações químicas que se desenvolvem no meio fluido ou diretamente na superfície de transferência de calor. O material da superfície do trocador de calor não atua como reagente, embora possa agir como catalisador. Esse é um dos principais mecanismos presentes na formação da incrustação em correntes de hidrocarbonetos. Em particular, polimerizações ou oxidações consistem em reações que formam uma camada plástica cuja remoção pode ser complexa.

- Sedimentação: consiste no depósito de partículas sólidas nas superfícies do trocador. Muitos fluidos, como o petróleo bruto produzido no Rio Grande do Norte, contém diversas partículas sólidas em suspensão. Alguns tipos de partículas podem inclusive "assar" na superfície do trocador, complicando ainda mais sua limpeza.

- Deposição biológica: algas, fungos e bactérias podem consumir nutrientes em suspensão e formar limos que se prendem à superfície do trocador. Os limos podem ainda servir como ponto de partida para bactérias anaeróbicas causadoras de corrosão.

- Corrosão: esse processo consiste na oxidação de metais, causada por oxigênio ou ácidos dissolvidos no fluido. A corrosão causa a formação de camadas de ferrugem nas tubulações.

Esses mecanismos podem ocorrer independente ou paralelamente. A taxa de depósito é afetada pelas condições de processo do trocador tais como a natureza dos fluidos, a velocidade de escoamento, as temperaturas dos fluidos, a temperatura na parede, o material de construção do equipamento, o grau de acabamento da superfície, como a rugosidade ou o tipo de revestimento interno. A deposição é mais expressiva nos tubos do fluido frio, pois as impurezas se dissolvem com mais dificuldade a baixas temperaturas. Isto ocorre porque a solubilidade da maior parte das substâncias cresce proporcionalmente à temperatura.

Para facilitar a quantificação do efeito da deposição, costuma-se usar um parâmetro definido como fator de incrustação ou fator de sujeira (fouling factor). Dimensionalmente é o inverso do coeficiente de transporte de energia por convecção. Logo, quanto maior o fator de incrustação, maior o depósito, maior a resistência à troca térmica. O fator de incrustação deve ser considerado a priori num projeto de trocador de calor, pois a área de troca térmica 
calculada deve ser suficiente para as necessidades do processo quando o trocador está novo (limpo) e quando está em operação há algum tempo (já com sujeira). Como o valor desse fator é difícil de ser previsto, essa deficiência constituirá uma das causas principais da imprecisão no projeto de um trocador de calor (SONG, 1997).

Em um processo de produção de derivados do petróleo, é comum a prática de medidas para evitar e combater possíveis problemas de deposição. A dessalgação é uma das mais importantes etapas do processo de destilação para o controle da corrosão e da deposição. A dessalgação consiste na remoção de sais, água e suspensões de partículas sólidas, permitindo assim maior flexibilidade operacional em relação aos tipos de petróleos processados e, principalmente, evitando que problemas de corrosão se agravem com a geração de ácido clorídrico. Em um processo de dessalgação, o petróleo preaquecido recebe uma corrente de água de processo para misturar com a água residual, sais e sólidos presentes na carga. Uma válvula misturadora provoca o contato íntimo entre a água injetada, os sais e os sedimentos. A seguir, a mistura de petróleo, água e impurezas, já na dessalgadora, passa por um campo elétrico de alta voltagem, mantido entre pares de eletrodos metálicos existentes no equipamento de dessalgação. As forças de campo assim criadas provocam a formação de muitas gotas grandes que, pelo aumento de sua densidade, se precipitam no fundo da dessalgadora, carregando sais e sedimentos (GONÇALVES, 2007).

O grande limitante ao processo de dessalgação é o fato de petróleos oriundos dos tanques estarem muito carregados com resíduos sólidos devido ao baixo tempo de residência adotado na operação. Esse fator prejudica muito o processo de dessalgação, em que parte da solução aquosa, que deveria ser efluente da dessalgadora, pode continuar no processo, gerando problemas de corrosão nas etapas posteriores. Os ácidos formados a partir da hidrólise dos sais que não foram retidos na dessalgadora vão para o topo da torre, provocando reações químicas que corroem o ferro. Outro problema também presente no sistema é a formação de incrustações devido à presença de sais que se depositam em áreas próximas ao permutador de calor, na linha de topo e no condensador. Algumas refinarias utilizam duas dessalgadoras em série exatamente para aumentar a eficiência na remoção dos sais. Entretanto, mesmo com eficiente dessalgação, normalmente resíduos de sais ainda são encontrados no topo, em níveis que podem causar deposição de incrustações e problemas de corrosão (GONÇALVES, 2007).

Quando a incrustação atinge um nível crítico, é necessário retirar o trocador de operação para a realização de atividades de manutenção. Eles podem ser limpos com jatos de 
água pressurizados, ácidos de limpeza, jatos de areia, entre outros. Para evitar as perdas devido às paradas para manutenção, é importante estudar métodos para inibir ou atenuar o efeito da deposição e da incrustação, e o que pode ser alterado na malha de controle para compensar esses efeitos, garantindo uma maior produtividade e diminuindo a frequência das paradas.

De uma maneira geral, uma refinaria tem um número limitado de opções para controle das incrustações, sendo elas (TONIN, 2003): a modificação das condições operacionais; a modificação do equipamento; a limpeza com maior frequência dos trocadores de calor; o aumento da quantidade de aditivos químicos.

Embora estas opções possam ser usadas para o controle do problema da incrustação, é importante ser capaz de monitorar o efeito da incrustação nestes trocadores de calor de uma maneira simples e econômica (TONIN, 2003).

O desempenho de um trocador de calor pode ser observado de duas maneiras: através da observação da transferência de calor e da perda de pressão ao longo do tempo. A incrustação deve causar redução da transferência de calor e aumento da queda de pressão nas correntes de fluidos do trocador. A diminuição da transferência de calor deverá ser compensada por um aquecimento nos fornos e por consequência, um consumo maior de combustível. Para que o aumento da queda de pressão não cause redução de vazão, deverá haver um aumento na potência de bombeamento dos fluidos. Como o aumento do consumo de combustível é mais significativo nos custos operacionais, a ênfase tem sido no monitoramento da transferência de calor. Monitorar a transferência de calor pode significar acompanhar: os coeficientes de transferência de calor, a temperatura de entrada do petróleo nos fornos, o consumo de combustível nos fornos e/ou a quantidade de calor trocado (TONIN, 2003).

O grande número de trocadores de calor presentes na rede de preaquecimento de petróleo, a variação nas condições operacionais e na carga de petróleo processada dificultam o monitoramento diário e individual de cada trocador. Nestas condições, as vazões e as propriedades termofísicas das correntes (petróleo e produtos) que passam pelos trocadores geralmente diferem das condições estabelecidas no projeto. Portanto, o desempenho de cada trocador medido diariamente não pode ser comparado com o desempenho previsto nas condições de projeto. Por exemplo, os coeficientes de transferência de calor devem ser recalculados introduzindo sempre que necessário os novos valores das vazões e das 
propriedades termofísicas dos fluidos. Este é o método tradicional de se avaliar o desempenho térmico de um trocador (TONIN, 2003).

Neste trabalho serão estudados métodos não tradicionais para prever a incrustação, utilizando redes neurais artificiais recorrentes para identificar o processo e fornecer um indicador da sujeira no trocador de calor.

\subsection{Incrustação na RPCC}

O petróleo proveniente dos campos produtores do RN e CE chega à RPCC através de oleodutos levando grande quantidade de $\mathrm{H}_{2} \mathrm{~S}$, sais, restos orgânicos, limalhas de ferro e sujeiras em geral. Além disso, produtos químicos são dosados no tratamento do óleo desde os poços produtores até as estações de tratamento. São dosados principalmente sequestrante de $\mathrm{H}_{2} \mathrm{~S}$, biocidas e desemulsificantes. O sequestrante de $\mathrm{H}_{2} \mathrm{~S}$ tem a função de evitar a corrosão dos dutos de transporte de petróleo. Os especialistas da planta verificam que esses produtos químicos, principalmente o sequestrante de $\mathrm{H}_{2} \mathrm{~S}$, são os maiores causadores da incrustação e se depositam nos equipamentos, sobretudo nos tubos internos do trocador P-27002, provavelmente por terem um ponto de fragmentação similar ao do fluido quente que alimenta este equipamento. Os trocadores de calor tem a função de pré-aquecer o petróleo na linha de alimentação da coluna de destilação de QAV, aproveitando a energia do óleo quente que sai como produto da coluna. Alguns desses equipamentos são destacados na Figura 2.

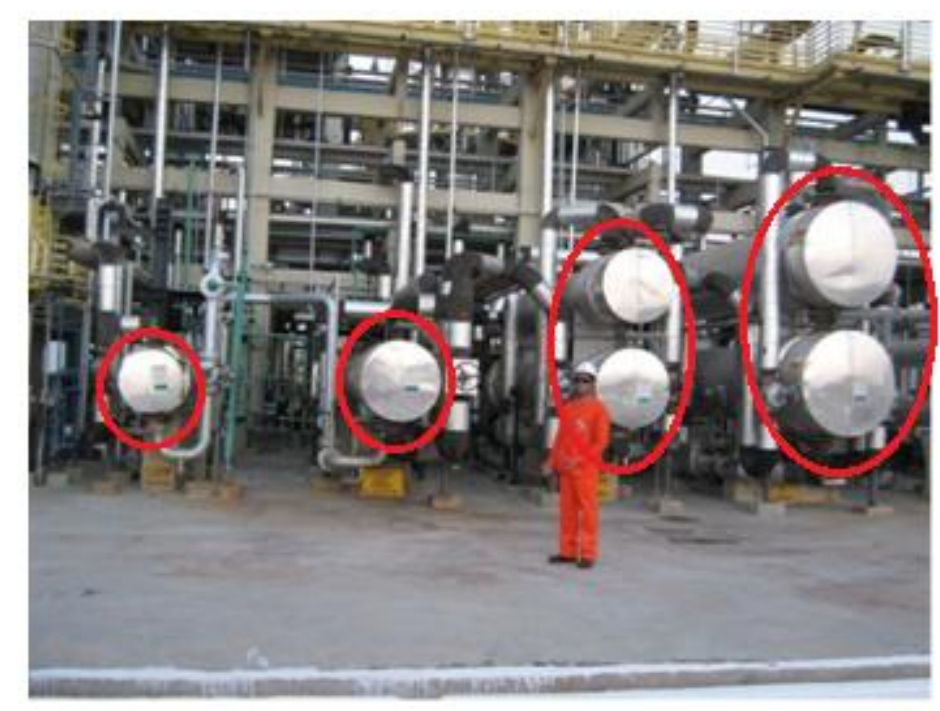

Figura 2 - Trocadores de calor (permutadores) na RPCC 
A incrustação causa uma série de problemas, como um menor rendimento de destilados, obtenção do produto com menor teor de pureza, dificuldade de controle e aumento do consumo de combustível no forno da coluna de destilação.

Com a incrustação, ocorre uma diminuição da troca de energia no permutador, fazendo com que o óleo cru seja alimentado para a coluna a uma temperatura menor do que a esperada. Assim, é necessário gastar mais energia no forno para aquecer o óleo até a temperatura ideal. Além disso, a temperatura de topo da coluna se eleva, pois há uma redução da carga térmica retirada da coluna. Consequentemente, ocorre uma alteração na composição dos produtos, sendo necessário diminuir a produção para manter a especificação exigida. 0 rendimento pode cair até $3 \%$ e é o principal problema da incrustação.

O desempenho do trocador decai gradualmente. Quando a incrustação atinge um nível muito alto, não é mais viável compensar o problema com um aumento da energia fornecida pelo forno. Os operadores então realizam um bypass nos trocadores, a fim de limpá-los.

Atualmente, a deposição na refinaria é combatida com o uso de dessalgadoras e filtros convencionais, para reter parte da sujeira. No entanto, a deposição ainda atinge níveis preocupantes, sendo necessário realizar manutenções frequentes nos equipamentos. 0 monitoramento da incrustação é realizado pelos próprios operadores, que analisam o desempenho da coluna de destilação, decidindo quando é necessário realizar a limpeza. Em visita técnica, foi informado que a principal variável monitorada pelos operadores é a vazão de QAV através do permutador, pois ela decresce ao longo do tempo, devido à incrustação nos tubos.

\subsection{Detecção e Predição da Incrustação em Trocadores de Calor}

A formação da incrustação é um processo químico e físico complicado, que é influenciado por muitos fatores, de forma que a pesquisa inicial na predição de incrustação, baseada no entendimento exato dos mecanismos de formação, não é ideal. Nos anos recentes, a inteligência artificial foi largamente aplicada em processos industriais, e alcançou resultados muito bons. Redes neurais têm grande capacidade de aprendizado, processamento paralelo e resolução de problemas multidisciplinares, de forma que a predição indireta com redes neurais é o novo caminho que pode ser tomado (SUN, ZHANG, ZHENG, YANG e QIN, 2008). 
JONSSON et al. (2007) apontam os métodos clássicos para detecção da incrustação. São eles: a análise do coeficiente de troca de calor (ou efetividade); a observação de quedas de pressão e vazão mássica; medições de temperaturas para calcular a proporção entre as ideais e as observadas no processo; medições ultrassônicas e medições elétricas.

De acordo com WALLHÄUßER, HUSSEIN e BECKER (2012), dependendo do processo e dos objetivos requeridos, diferentes métodos de detecção podem ser mais vantajosos que outros. É implausível buscar um único método que seja capaz de satisfazer todos os requerimentos. Seria mais prático combinar diferentes métodos buscando aproveitar os pontos fortes de cada um. Os autores apontam que os objetivos do estudo da incrustação em trocadores de calor podem ser os seguintes: determinação do local exato da incrustação; determinação da quantidade ou da espessura exata da incrustação; determinação simplesmente da presença ou ausência da incrustação; monitoramento e adaptação do processo de limpeza (por quanto tempo limpar?); monitoramento do desenvolvimento da incrustação (quando começa e quando termina?).

Uma combinação de diferentes métodos pode melhorar a estabilidade da deteç̧ão e a probabilidade dos objetivos serem alcançados. O primeiro passo é determinar os objetivos e o limite de detecção dos métodos, e saber quais os tipos de incrustações presentes. É importante para a indústria ter um método não invasivo, rápido, confiável, robusto e não muito caro. Vários dos métodos conhecidos não são invasivos, mas não podem ser facilmente aplicados a trocadores de calor já existentes. Outros são muito sensíveis e invasivos, mas poderiam ser incluídos em novos trocadores de calor.

WALLHÄUßER, HUSSEIN e BECKER (2012) ainda exemplificam que, se for necessário apenas determinar a presença da incrustação, a análise de pressões e temperaturas é suficiente. Para determinar o local e a quantidade da incrustação, pode ser feita a monitoração dos coeficientes de troca de calor. Se for interessante detectar camadas muito finas ou qual mecanismo de incrustação está ocorrendo, métodos acústicos são os mais adequados. Se for desejado um auxílio na tomada de decisão referente à limpeza, são adequados métodos numéricos e simulações, utilizando por exemplo redes neurais artificiais.

JONSSON et al. (2007), com o objetivo de detectar a incrustação em tempo real, sugerem a utilização de técnicas de identificação para modelar o equipamento e então procurar discrepâncias entre o que é previsto pelo modelo e o que realmente ocorre. Seguindo essa abordagem, os autores criaram um modelo em espaço de estados do trocador de calor, utilizando filtros de Kalman para calcular os parâmetros desconhecidos. Os dados necessários 
para a aplicação do filtro foram temperaturas e vazões dos fluidos quente e frio, obtidos através de um software simulador de trocador de calor. Foram incluídos no software rotinas para permitir também a simulação de incrustação no equipamento. Os autores mostraram que o modelo desenvolvido é bastante sensível à presença de incrustação e pode ser bem aplicado na deteç̧ão da sujeira em tempo real.

O trabalho de SUN et al. (2008b) utilizou redes de função de base radial (Radial Basis Function - RBF) e máquinas de vetor de suporte (Support Vector Machines - SVM) para prever a incrustação em um trocador de calor. Os autores usaram redes com seis variáveis de entrada, todas elas coletadas de sensores conectados diretamente ao trocador de calor, sendo elas a temperatura de entrada, a temperatura de saída e a vazão do fluido causador da incrustação, e outras três temperaturas das paredes do equipamento. Os dados foram coletados com um tempo de amostragem de um minuto, normalizados, e separados em conjuntos de treinamento e validação. A variável de saída utilizada foi a resistência térmica, que nesse caso pode ser chamada de "resistência da incrustação". Os autores dispunham de uma medição em tempo real dessa variável, que quantifica a resistência à transferência de calor no trocador, causada pela incrustação. A rede projetada obteve excelentes resultados, sendo capaz de prever com bastante exatidão a resistência do trocador a partir da sua condição de operação. Uma extensão desse trabalho pode ser vista em SUN, ZHANG e SAQI (2009), onde os autores utilizaram máquinas de vetor de suporte combinadas com técnicas heurísticas de algoritmos genéticos e de enxame de partículas para realizar a mesma predição. Redes neurais wavelet otimizadas com o algoritmo de Levenberg-Marquardt foram utilizadas com esse mesmo propósito no trabalho de SUN et al. (2008a), apresentando bons resultados.

TONIN e NEGRÃO (2003) usaram equações de fluxo de calor para calcular a efetividade de trocadores de calor com base nas vazões e temperaturas das suas correntes quente e fria. Os autores calcularam as efetividades do trocador limpo, sujo, e na condição de operação. Um índice de incrustação pôde então ser calculado a partir de uma relação entre essas efetividades. O trabalho de VIJAYSAI et al. (2006) utilizou equações similares para calcular em tempo real o "fator de limpeza" de um trocador de calor e desenvolver um sistema de monitoramento da incrustação. Além disso, os autores também utilizaram modelos matemáticos do tipo filtro de Kalman para prever a incrustação em tempos futuros. O sistema foi capaz de detectar a incrustação com sucesso, desde que fossem eliminados todos os outros fatores que influenciassem as variáveis de entrada. Além disso, o sistema permitiu gerar uma boa aproximação da data em que seria necessário parar o equipamento para limpeza. 
SHAOSHENG e JU (2007) aplicaram redes neurais recorrentes diagonais na medição da incrustação em um condensador. Eles utilizaram um algoritmo backpropagation adaptativo, que inicia com apenas um neurônio na camada oculta e aumenta o número de neurônios de acordo com o erro no treinamento. Outra particularidade da rede neural utilizada pelos autores é que os neurônios da camada oculta são auto-recorrentes. O sistema foi capaz de fornecer corretamente uma medição em tempo real da incrustação no condensador, mais precisa do que aquela obtida por métodos clássicos do cálculo da resistência térmica ou do coeficiente de transferência de calor.

O trabalho de HOU e ZHOU (2005) teve o objetivo de prever a incrustação de um trocador de calor por lotes. Esse equipamento, diferente dos trocadores tradicionais, não opera continuamente com os mesmos fluidos quente e frio. Ele opera sob demanda, com diferentes fluidos e diferentes condições de operação. Isso dificulta o uso de equações tradicionais para calcular algum índice da incrustação, pois o fenômeno ocorre de modo diferenciado a cada ciclo de operação. Os autores utilizaram Redes Neurais Fuzzy combinadas com o algoritmo de agrupamento Fuzzy c-means para aprender essas tendências de incrustação. Os experimentos mostraram que o esquema de medição proposto foi capaz de fornecer uma predição mais correta para a incrustação nesses trocadores.

RADHAKRISHNAN et al. (2007) apresentaram um trabalho utilizando redes neurais clássicas do tipo perceptron de múltiplas camadas para prever o comportamento de um trocador de calor. O objetivo era descobrir quando a eficiência cairia abaixo de um nível aceitável para possibilitar um pré-agendamento da manutenção. Foram coletados dados de três anos de operação de um permutador real, que passou por diversas paradas para limpeza durante esse período. A rede neural foi construída com 25 entradas e 2 saídas. As variáveis de entrada consistiam de variáveis operacionais, como temperaturas e vazões dos fluidos quente e frio do trocador, além de variáveis relativas à composição do óleo, como proporção de água, acidez, quantidade de sais, enxofre, entre outros. As variáveis de saída consistiam da temperatura de saída dos fluidos quente e frio no trocador. A rede neural mostrou bons resultados para os conjuntos de teste e validação. Em um estudo de caso, os autores forneceram à rede neural condições de operação típicas do trocador para prever o seu comportamento durante os 200 dias seguintes. Os autores também testaram uma arquitetura recorrente, realimentando dois instantes anteriores das temperaturas de saída. A realimentação aumentou a exatidão do preditor. 
KASHANI et al. (2012) realizaram um trabalho de predição da incrustação usando redes neurais artificiais recorrentes. Os autores coletaram 5 variáveis, sendo elas as temperaturas de entrada e de saída dos fluidos quente e frio e a vazão de um trocador de calor de uma refinaria de petróleo. Os dados foram referentes a um período de 6 meses com uma taxa de amostragem de 2 horas. O objetivo era calcular a resistência da incrustação para as próximas horas, utilizando apenas os dados anteriores conhecidos e supondo que as temperaturas de entrada permaneceriam em um nível conhecido. Uma janela móvel foi utilizada para formar os conjuntos de dados utilizados no treinamento de RNA recorrentes preditoras. Foram experimentados diversos algoritmos de treinamento com diferentes números de neurônios na camada oculta da rede neural artificial. Os autores verificaram que o algoritmo LevenbergMarquardt apresentou os melhores resultados, tanto no tempo de treinamento quanto no erro obtido. Também foi verificado que a melhor arquitetura foi aquela composta por apenas uma camada oculta com 5 neurônios. O sistema final foi capaz de prever, com base nos dados operacionais das últimas 500 horas, a resistência da incrustação para as próximas 50 horas com um erro médio quadrático de $8 \%$ e para as próximas 200 horas com um erro médio quadrático de $11 \%$. Foi observado que a precisão da predição diminuía com o tempo. Isso pode ser devido a mudanças no comportamento do processo em longo prazo e a variações em parâmetros não incluídos no modelo. 


\section{Redes Neurais Artificiais}

\subsection{Introdução}

O desenvolvimento das redes neurais artificiais foi motivado pelo reconhecimento de que o cérebro humano processa informações de uma forma inteiramente diferente do computador digital convencional. O cérebro é um sistema de processamento de informação altamente complexo, não linear e paralelo. Ele tem a capacidade de organizar seus constituintes estruturais, conhecidos por neurônios, de forma a realizar certos processamentos muito mais rapidamente que o mais rápido computador digital hoje existente (HAYKIN, 2000).

Na sua forma mais geral, uma rede neural artificial é uma máquina construída inspirada na maneira como o cérebro realiza uma tarefa ou função em particular. Essa rede é geralmente implementada a partir de componentes eletrônicos ou simulada através da programação em um computador digital. Para alcançarem um bom desempenho, as redes neurais empregam uma interligação maciça de células computacionais simples, denominadas neurônios artificiais. Essa tecnologia é multidisciplinar, com raízes na neurociência, matemática, estatística, física, ciência da computação e engenharia (HAYKIN, 2000).

Uma rede neural artificial pode ser definida como um processador paralelo distribuído, composto de unidades de processamento simples, que tem a propensão natural para armazenar conhecimento experimental. Essas estruturas se assemelham ao cérebro humano em dois aspectos (HAYKIN, 2000): possuem a capacidade de adquirir conhecimento a partir do ambiente, através de um processo de aprendizagem; o conhecimento é armazenado nos pesos sinápticos, as forças de conexões entre os neurônios que constituem a rede.

O processo de aprendizagem de uma rede neural artificial consiste no ajuste dos seus pesos sinápticos, utilizando um algoritmo de aprendizagem. A partir do aprendizado, as redes neurais artificiais são capazes de estabelecer relações não lineares entre suas entradas e saídas e podem generalizar e se adaptar a novas situações. São utilizadas em diversas áreas do processamento inteligente da informação, como na classificação de padrões, filtragem de sinais, compressão de dados, processamento de imagens e identificação de sistemas. 
É preciso reconhecer que ainda existe um longo caminho até o desenvolvimento de uma rede neural artificial capaz de imitar o cérebro humano. Os modelos atuais são apenas inspirados em um conhecimento primitivo das funções do sistema nervoso e são extremamente simplificados quando comparados ao cérebro biológico.

\subsection{Propriedades das Redes Neurais Artificiais}

As RNA devem o seu poder computacional a duas características principais: primeiro, sua estrutura paralela e distribuída; segundo, sua habilidade de aprender e, consequentemente, de generalizar. A generalização refere-se ao fato de uma rede neural artificial produzir saídas adequadas para entradas que não fizeram parte do conjunto de treinamento (aprendizagem). Essas duas propriedades de processamento de informação tornam possível para as RNA tratarem de forma vantajosa problemas complexos (de grande escala) que são atualmente intratáveis. Na prática, as RNA não são utilizadas isoladamente para fornecer uma solução, o problema é decomposto em diversas subtarefas para as quais elas possam ser bem aplicadas. Outras das suas propriedades são enumeradas a seguir (HAYKIN, 2000):

- Não linearidade: Uma RNA formada por neurônios não lineares permite efetuar relacionamentos não lineares entre entradas e saídas.

- Mapeamento de entrada-saída: a aprendizagem supervisionada, ou aprendizagem com um "professor", envolve a modificação dos pesos sinápticos de uma RNA pela aplicação de um conjunto de amostras de treinamento rotuladas ou exemplos da tarefa. Cada exemplo consiste de um sinal de entrada único e de uma resposta desejada correspondente. Apresenta-se para a rede um exemplo escolhido ao acaso do conjunto, e os pesos sinápticos (parâmetros livres) da rede são modificados para minimizar a diferença entre a resposta desejada e a resposta real da rede, produzida pelo sinal de entrada, de acordo com um critério estatístico apropriado. $O$ treinamento da rede é repetido por muitos exemplos do conjunto até que a rede alcance um estado estável em que não haja mais modificações significativas nos pesos sinápticos. Os exemplos de treinamento previamente aplicados podem ser reaplicados durante a sessão de treinamento, mas em uma ordem diferente. Assim, a rede aprende dos exemplos ao construir um mapeamento entrada-saída para o problema considerado.

- Adaptabilidade: as redes neurais artificiais tem uma capacidade inata de adaptar seus pesos sinápticos a modificações do meio ambiente. Em particular, uma rede treinada 
para atuar em um ambiente específico pode ser facilmente retreinada para lidar com pequenas modificações nas condições operativas do ambiente. Além disso, quando está operando em um ambiente não estacionário, uma rede neural pode ser projetada para modificar seus pesos sinápticos em tempo real.

- Resposta a evidências: no contexto da classificação de padrões, uma rede neural artificial pode ser projetada para fornecer informação não somente sobre qual padrão particular selecionar, mas também sobre a confiança ou crença na decisão tomada. Esta informação pode ser utilizada para rejeitar padrões ambíguos, caso eles estejam presentes, e com isso melhorar o desempenho de classificação da rede.

- Tolerância a falhas: uma rede neural artificial, implementada na forma física (em hardware) é inerentemente tolerante a falhas, ou capaz de realizar computação robusta, no sentido de que seu desempenho se degrada suavemente sob condições de operação adversas. Se um neurônio ou suas conexões são danificados, por exemplo, a recuperação de um padrão armazenado é prejudicada em qualidade. Contudo, devido à natureza distribuída da informação armazenada na rede, o dano deve ser extenso para que a resposta global da rede seja degradada seriamente. O que deve ser observado nessas condições é uma degradação suave do desempenho em vez de uma falha seriamente comprometedora.

- Analogia neurobiológica: o projeto de uma RNA é motivado pela analogia com o cérebro, uma prova real de que processamento paralelo tolerante a falhas é possível, rápido e poderoso. Neurobiologistas veem redes neurais artificiais como ferramentas de pesquisa para a interpretação de fenômenos neurobiológicos. Engenheiros se inspiram na neurobiologia para resolverem problemas complexos que não podem ser resolvidos pelos métodos convencionais.

\subsection{Modelo de um Neurônio Artificial}

O neurônio artificial é a unidade de processamento fundamental da rede neural. Cada neurônio artificial é composto de quatro unidades básicas, como mostra a Figura 3:

1. Um conjunto de sinapses ou conexões, acompanhadas de pesos sinápticos. Cada entrada do neurônio é multiplicada pelo peso sináptico correspondente.

2. Um combinador que gera a soma de todos os sinais de entrada, multiplicados pelos pesos sinápticos correspondentes. Essas operações constituem um combinador linear. 
3. Uma função de ativação que é aplicada à saída do combinador linear, resultando na saída final do neurônio. Essa função geralmente limita a amplitude da saída para intervalos entre $[0,1]$ ou $[-1,1]$. Em alguns casos os neurônios não apresentam função de ativação ou ela é puramente linear, apenas repetindo a saída do combinador.

4. Um neurônio pode possuir também um bias, valor que é adicionado à saída do combinador linear e que também é ajustado durante o treinamento.

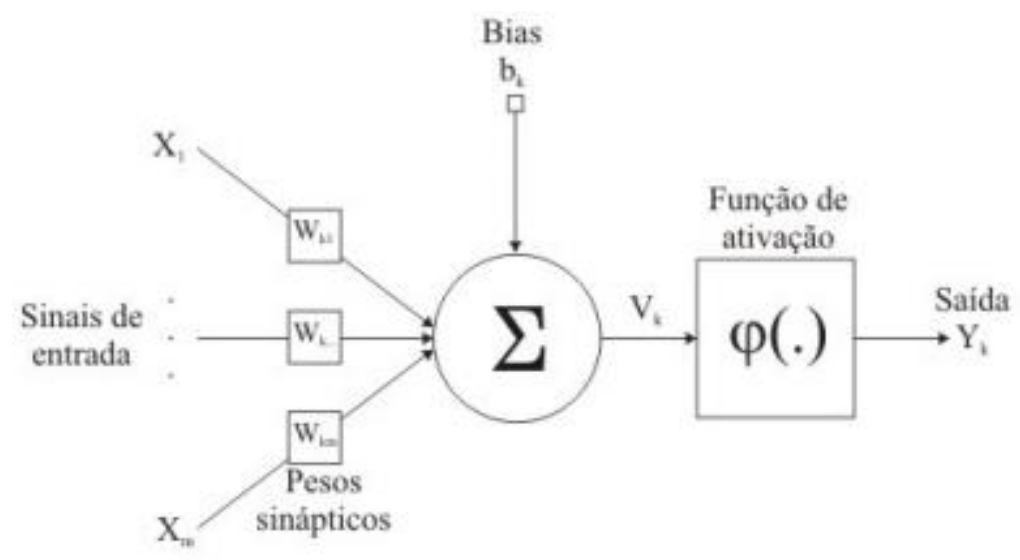

Figura 3 - Modelo de um Neurônio Artificial

\subsection{Perceptron de Múltiplas Camadas}

Existem diversas arquiteturas de RNA. Dentre elas, os perceptrons de múltiplas camadas (Multi-layer Perceptron - MLP) obtiveram grande sucesso nas mais variadas áreas, como por exemplo reconhecimento de padrões, processamento de sinais, compressão de dados, identificação de sistemas e predição de séries temporais.

Essa arquitetura se caracteriza pelo seu alto grau de conectividade, com neurônios dispostos em uma série de camadas, com pelo menos uma camada oculta e uma camada de saída. Os nós da camada de entrada da rede fornecem os sinais de entrada aos neurônios da primeira camada oculta cujas saídas serão, por sua vez, usadas como entradas dos neurônios da próxima camada, e assim por diante para o resto da rede. O conjunto de sinais de saída dos neurônios da última camada constitui a resposta global da rede. As redes do tipo MLP são conhecidas também como redes de alimentação direta (redes feedforward), pois a informação é propagada em apenas um sentido, da primeira para a última camada. A MLP exibida na Figura 4 pode ser definida como uma rede 2:3:3:2, pois possui duas entradas, duas camadas ocultas com três neurônios cada e uma camada de saída com dois neurônios. 


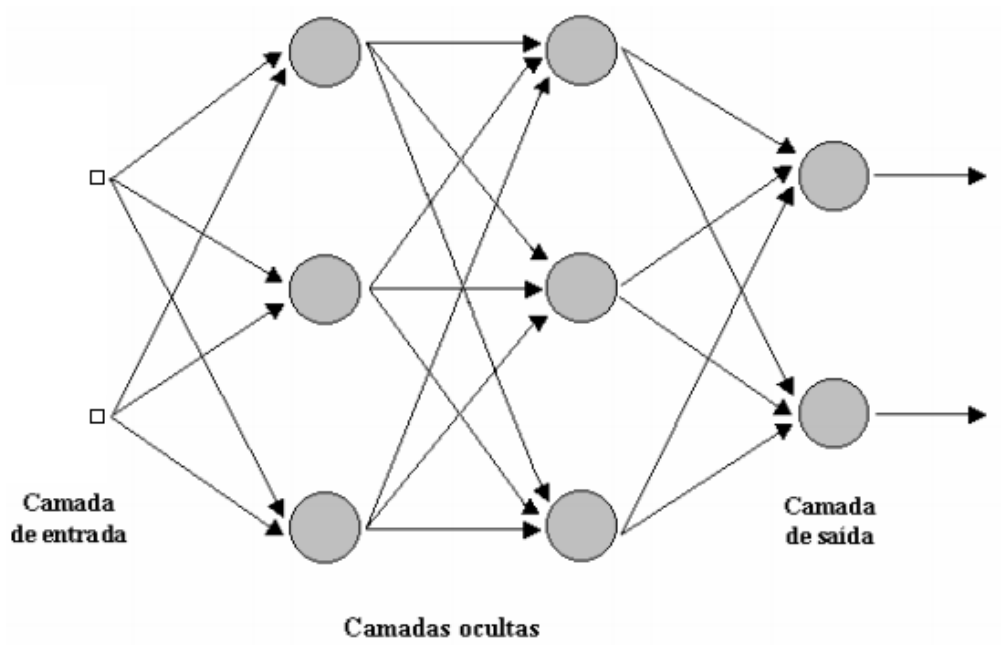

Figura 4 - Perceptron de Múltiplas Camadas com duas camadas ocultas e uma de saída

Uma característica importante das redes MLP é a sua capacidade de aproximação universal. Qualquer função contínua pode ser aproximada por uma rede MLP que possua uma camada oculta com funções de ativação sigmoide ou tangente hiperbólica (HAYKIN, 2000).

O algoritmo backpropagation é capaz de treinar redes MLP com diferentes funções de ativação e permite o mapeamento de relações lineares e não lineares entre os vetores de dados de entrada e saída para a solução de problemas de aproximação de funções, classificação de padrões, identificação de sistemas, entre outros. O backpropagation é um processo realizado em duas fases. Na primeira fase, as entradas são apresentadas à rede e propagadas até que a saída seja gerada. Essa saída é comparada com a saída desejada, gerando um sinal de erro. Na segunda fase, o erro é retropropagado pela rede e a sua derivada é utilizada para ajustar os pesos sinápticos, de modo a reduzi-lo.

O backpropagation pode operar de dois modos: sequencial (ou on-line) ou batelada (batch). No modo sequencial, o ajuste dos pesos sinápticos ocorre após a apresentação de cada ponto de treinamento. Assim, se o conjunto de treinamento possui $\mathrm{N}$ exemplos, serão feitos $\mathrm{N}$ ajustes nos pesos sinápticos após uma época de treinamento. Já no modo batelada, todos os $\mathrm{N}$ pontos de treinamento são apresentados e o erro é acumulado. $\mathrm{O}$ ajuste dos pesos sinápticos ocorre apenas uma vez, no final da época de treinamento (HAYKIN, 2000).

Existem diversos algoritmos que utilizam o backpropagation como base para 0 treinamento. Eles são variações de técnicas de otimização como gradiente, Newton, QuasiNewton, entre outros. Diferem em velocidade de convergência e requisitos computacionais de processamento e de memória. O software matemático Matlab ${ }^{\circledast}$ dispõe de vários desses 
algoritmos para o treinamento de redes MLP, descritos brevemente na Tabela 1 (ZANATA, 2005).

Tabela 1 - Lista de algoritmos de treinamento do Matlab

\begin{tabular}{|c|c|}
\hline Função & Descrição \\
\hline traingd & $\begin{array}{l}\text { Gradiente descendente básico. Apresenta resposta lenta e pode ser utilizado } \\
\text { em treinamentos de modo incremental. }\end{array}$ \\
\hline traingdm & $\begin{array}{l}\text { Gradiente descendente com momento. Geralmente é mais rápido do que o } \\
\text { básico. Pode ser utilizado em treinamentos de modo incremental. }\end{array}$ \\
\hline traingdx & $\begin{array}{l}\text { Gradiente com taxa de aprendizado adaptativa. Convergência mais rápida do } \\
\text { que o básico, porém só pode ser utilizado em treinamento de batelada. }\end{array}$ \\
\hline trainrp & $\begin{array}{l}\text { Retropropagação resiliente. Algoritmo simples de treinamento por lote com } \\
\text { rápida convergência e pouca memória requisitada. }\end{array}$ \\
\hline traincgf & $\begin{array}{l}\text { Algoritmo de gradiente conjugado de Fletcher-Reeves. Possui os menores } \\
\text { requisitos de memória dentre os algoritmos de gradiente conjugado. }\end{array}$ \\
\hline traincgp & $\begin{array}{l}\text { Algoritmo de gradiente conjugado de Polak-Ribiére. Requer um pouco mais } \\
\text { de memória que o traincgf, porém apresenta convergência rápida para } \\
\text { alguns problemas específicos. }\end{array}$ \\
\hline traingb & $\begin{array}{l}\text { Algoritmo do gradiente conjugado de Powell-Beale. Requer um pouco mais } \\
\text { de memória que o traincgp, mas geralmente apresenta uma convergência } \\
\text { mais rápida. }\end{array}$ \\
\hline trainscg & $\begin{array}{l}\text { Algoritmo de gradiente conjugado em escala. Adapta-se com facilidade a } \\
\text { uma grande variedade de problemas. }\end{array}$ \\
\hline trainbfg & $\begin{array}{l}\text { Método Quasi-Newton BFGS. Necessita do armazenamento da aproximação } \\
\text { da matriz Hessiana e requer mais recurso computacional a cada iteração do } \\
\text { que os algoritmos de gradiente conjugado, porém geralmente converge em } \\
\text { poucas iterações. }\end{array}$ \\
\hline trainoss & $\begin{array}{l}\text { Método one step secant. Meio termo entre métodos de gradiente conjugado } \\
\text { e métodos Quasi-Newton. }\end{array}$ \\
\hline trainlm & $\begin{array}{l}\text { Algoritmo de Levenberg-Marquardt. É o algoritmo de treinamento mais } \\
\text { rápido para redes de tamanho moderado. Possui a função de redução de } \\
\text { memória para ser utilizada quando possuir muitos dados para treinamento. }\end{array}$ \\
\hline trainbr & $\begin{array}{l}\text { Utiliza Regularização Bayesiana dentro do algoritmo de Levenberg- } \\
\text { Marquardt para gerar redes com melhor generalização. Minimiza uma } \\
\text { combinação linear de erros quadráticos e pesos e também modifica a } \\
\text { combinação de forma que, no final do treinamento, a rede resultante tenha } \\
\text { boas qualidades de generalização (MACKAY, 1992). }\end{array}$ \\
\hline
\end{tabular}

\subsection{Identificação de Sistemas e Predição Usando Redes Neurais}

A identificação de sistemas é a abordagem experimental para modelar um processo ou uma planta com parâmetros desconhecidos. Envolve os seguintes passos: planejamento experimental, seleção de uma estrutura para o modelo, estimação de parâmetros e validação do modelo. O procedimento da identificação de sistemas é naturalmente iterativo, ou seja, 
pode ser necessário repetir esses passos até que um modelo satisfatório seja construído (HAYKIN, 2000).

Em contraste aos problemas de aproximação de funções e reconhecimento de padrões (considerados estáticos), as saídas dos sistemas denominados dinâmicos, assumindo um instante de tempo qualquer, dependem de seus valores anteriores de saída e de entrada (AGUIRRE, 2004; LUNG, 1998).

Há várias formas de classificar as técnicas de modelagem. Levando-se em conta o nível de conhecimento do sistema que se deseja identificar, podem-se agrupar os métodos em três grupos: modelagem caixa branca, modelagem caixa preta e modelagem caixa cinza. Se a identificação baseia-se exclusivamente em dados obtidos do sistema, assumindo nenhum ou pouco conhecimento sobre os princípios físicos do sistema, o processo de identificação é conhecido como modelagem caixa preta. Em contrapartida, o termo modelagem caixa branca é aplicado quando é realizada uma modelagem puramente física do sistema. A modelagem caixa cinza é um conjunto de técnicas que poderia ser classificado como estando entre a modelagem caixa branca e a caixa preta. As técnicas desse grupo caracterizam-se por usar informação auxiliar, que não se encontra no conjunto de dados utilizado durante a identificação. O tipo de informação auxiliar e a forma com que ela é usada variam muito entre as diversas técnicas disponíveis (AGUIRRE, 2004). Neste trabalho serão focadas técnicas de modelagem caixa preta, pois não serão utilizados modelos físicos do sistema.

Duas configurações principais podem ser utilizadas na identificação de sistemas baseadas em redes neurais artificiais: redes com entradas atrasadas no tempo (TDNN - time delayed neural network) e redes com saídas recorrentes (SILVA et al., 2010). As redes de entradas atrasadas no tempo, idealizadas pioneiramente por LANG e HINTON (1988) para reconhecimento de voz, possuem estrutura semelhante à de um perceptron de múltiplas camadas (MLP). A saída da rede é, em um determinado instante, função das entradas em instantes anteriores, como mostra a Equação 4:

$$
y(t+1)=f\left(x(t), x(t-1), \ldots, x\left(t-n_{p}\right)\right)
$$

A ordem desse modelo é dada por $1+n_{p}$. A função $f$ está sendo realizada por uma rede neural do tipo MLP, como mostra a Figura 5. 


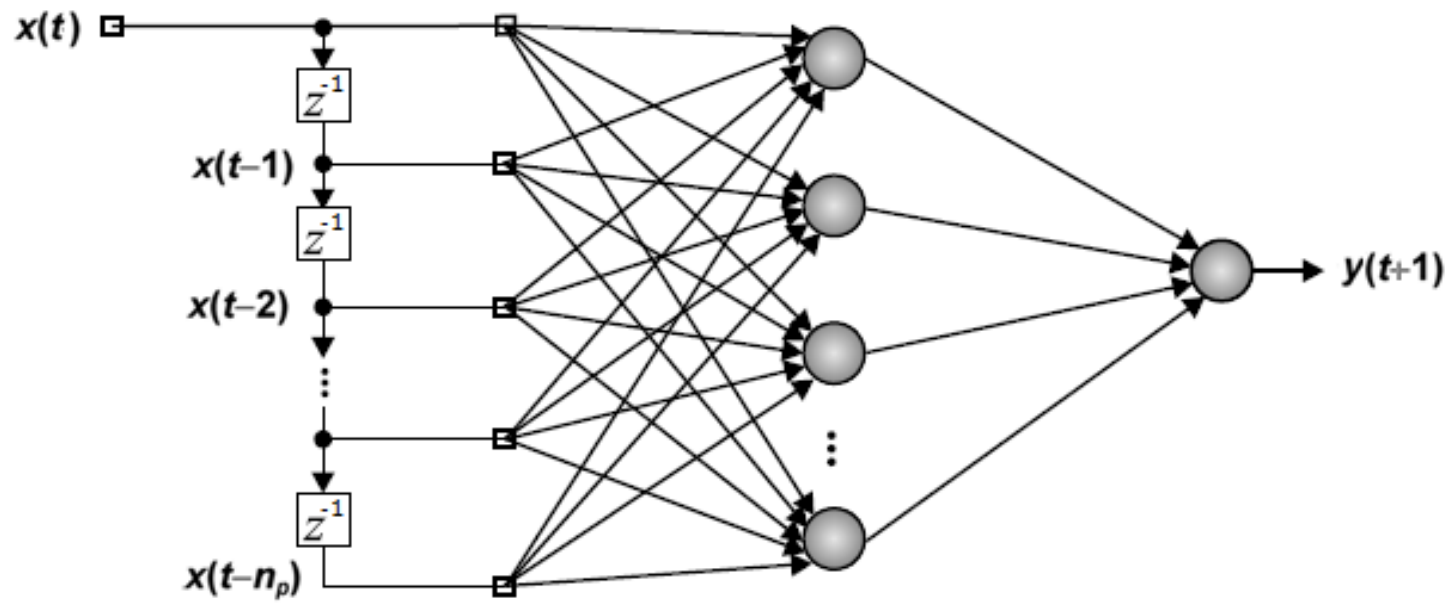

Figura 5 - Topologia de MLP com entradas atrasadas no tempo

A partir ainda da Figura 5, verifica-se que a rede recebe $1+n_{p}$ entradas, que representam o comportamento do processo, e fornece a saída $y(t+1)$, que representa a resposta estimada do processo um passo à frente. Durante o seu treinamento, a rede deverá minimizar o erro entre o valor de $y(t+1)$ estimado e a resposta real do processo. A rede pode ser treinada como uma MLP comum, desde que o conjunto de treinamento seja formado de maneira adequada. A Tabela 2 mostra a construção de cinco exemplos de treinamento para essa topologia. A rede sempre realiza uma estimação de um passo à frente, calculando sequencialmente o seu valor futuro a partir das suas $1+n_{p}$ últimas entradas.

Tabela 2 - Exemplo de conjunto de treinamento para rede neural TDNN de ordem 3

\begin{tabular}{|l|l|l|l|l|}
\hline Entradas & $\mathbf{x}_{\mathbf{1}}$ & $\mathbf{x}_{\mathbf{2}}$ & $\mathbf{x}_{\mathbf{3}}$ & $\begin{array}{c}\text { Saída } \\
\text { Desejada }\end{array}$ \\
\hline $\mathbf{t}=\mathbf{3}$ & $x(3)$ & $x(2)$ & $x(1)$ & $y(4)$ \\
\hline $\mathbf{t}=\mathbf{4}$ & $x(4)$ & $x(3)$ & $x(2)$ & $y(5)$ \\
\hline $\mathbf{t}=\mathbf{5}$ & $x(5)$ & $x(4)$ & $x(3)$ & $y(6)$ \\
\hline $\mathbf{t}=\mathbf{6}$ & $x(6)$ & $x(5)$ & $x(4)$ & $y(7)$ \\
\hline $\mathbf{t}=\mathbf{7}$ & $x(7)$ & $x(6)$ & $x(5)$ & $y(8)$ \\
\hline
\end{tabular}

A arquitetura apresentada não é adequada para a identificação de sistemas dinâmicos, pois estes normalmente possuem saídas que dependem, além dos seus valores passados, também dos valores de outras variáveis de entrada no instante atual e em instantes passados. Nesses casos, são utilizadas redes recorrentes ou realimentadas, que implementam a seguinte função $f$ mostrada na Equação 5:

$$
y(t+1)=f\left[x(t), x(t-1), \ldots, x\left(t-n_{p}\right), y(t), y(t-1), \ldots, y\left(t-n_{q}\right)\right]
$$


Tal configuração, mostrada na Figura 6, possibilita que a rede recorrente execute, de maneira implícita, o mapeamento entre entradas e saídas de processos que sejam tanto nãolineares como também variantes no tempo, tornando-se uma ferramenta bem flexível para aplicações envolvendo identificação de sistemas (SILVA et al., 2010). Em terminologia da área de identificação de sistemas, a rede recorrente configurada dessa maneira funciona como um modelo auto-regressivo não linear com entradas exógenas (Nonlinear Auto-Regressive with eXogenous inputs - NARX), cuja aplicabilidade direciona-se ao mapeamento de sistemas com dinâmicas tipicamente não lineares (NELLES, 2005).

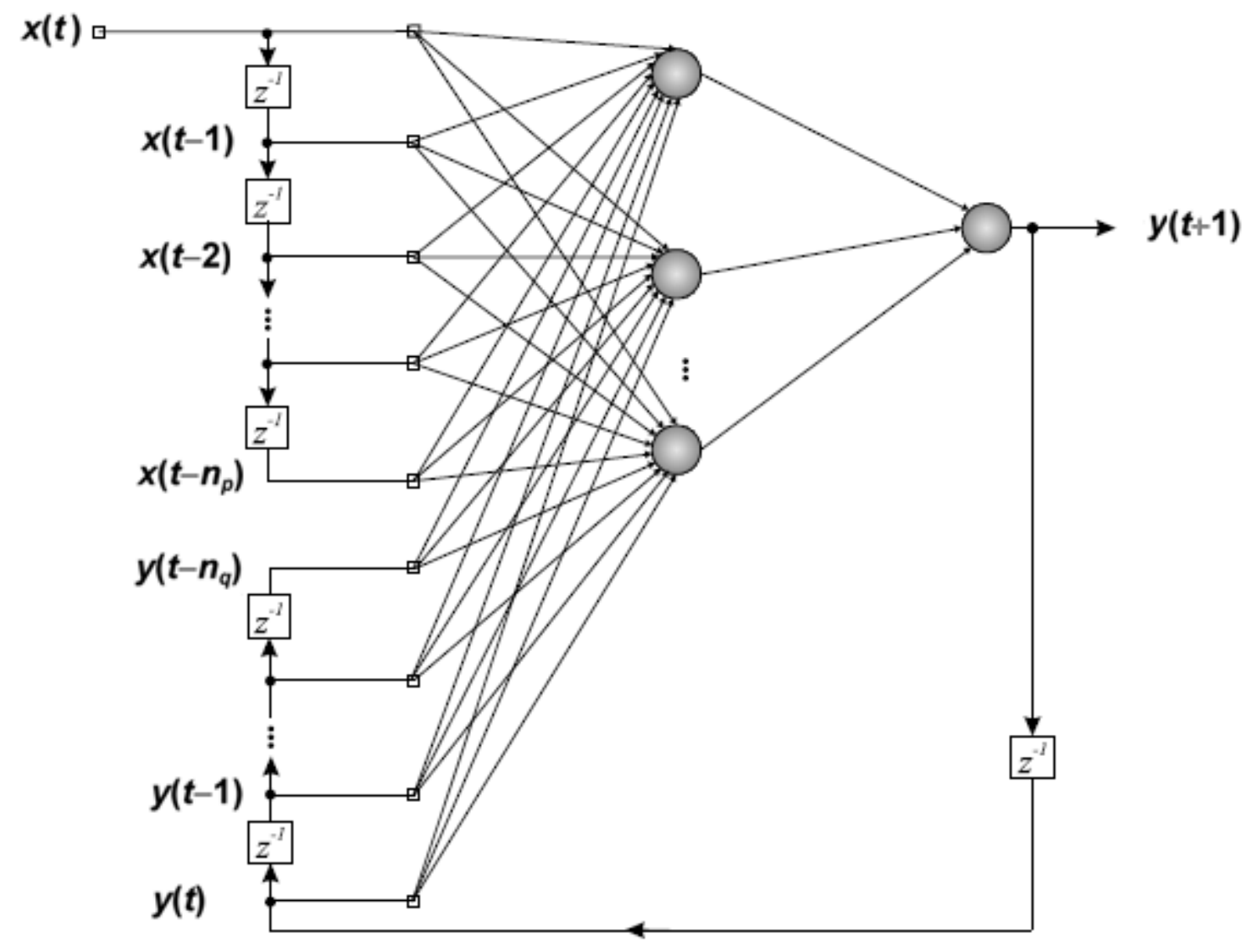

Figura 6 - Topologia de MLP com saídas realimentadas às entradas

O treinamento ainda pode ser realizado de forma similar ao MLP comum, desde que o conjunto de treinamento seja construído de maneira adequada. A Tabela 3 mostra um exemplo de construção do conjunto de treinamento. 
Tabela 3 - Exemplo de conjunto de treinamento para rede recorrente

\begin{tabular}{|l|l|l|l|l|l|l|l|}
\hline Entradas & $\mathbf{x}_{\mathbf{1}}$ & $\mathbf{x}_{\mathbf{2}}$ & $\mathbf{x}_{\mathbf{3}}$ & $\mathbf{x}_{\mathbf{4}}$ & $\mathbf{x}_{\mathbf{5}}$ & $\mathbf{x}_{\mathbf{6}}$ & $\begin{array}{c}\text { Saída } \\
\text { Desejada }\end{array}$ \\
\hline $\mathbf{t}=\mathbf{3}$ & $\mathrm{x}(3)$ & $\mathrm{x}(2)$ & $\mathrm{x}(1)$ & $\mathrm{y}(3)$ & $\mathrm{y}(2)$ & $\mathrm{y}(1)$ & $\mathrm{y}(4)$ \\
\hline $\mathbf{t}=\mathbf{4}$ & $\mathrm{x}(4)$ & $\mathrm{x}(3)$ & $\mathrm{x}(2)$ & $\mathrm{y}(4)$ & $\mathrm{y}(3)$ & $\mathrm{y}(2)$ & $\mathrm{y}(5)$ \\
\hline $\mathbf{t}=\mathbf{5}$ & $\mathrm{x}(5)$ & $\mathrm{x}(4)$ & $\mathrm{x}(3)$ & $\mathrm{y}(5)$ & $\mathrm{y}(4)$ & $\mathrm{y}(3)$ & $\mathrm{y}(6)$ \\
\hline $\mathbf{t}=\mathbf{6}$ & $\mathrm{x}(6)$ & $\mathrm{x}(5)$ & $\mathrm{x}(4)$ & $\mathrm{y}(6)$ & $\mathrm{y}(5)$ & $\mathrm{y}(4)$ & $\mathrm{y}(7)$ \\
\hline $\mathbf{t}=\mathbf{7}$ & $\mathrm{x}(7)$ & $\mathrm{x}(6)$ & $\mathrm{x}(5)$ & $\mathrm{y}(7)$ & $\mathrm{y}(6)$ & $\mathrm{y}(5)$ & $\mathrm{y}(8)$ \\
\hline
\end{tabular}

O modelo identificado permite que sejam estimadas as saídas futuras do sistema em questão. Para isso, basta alimentar o modelo com as condições iniciais, ou seja, com as entradas e saídas reais observadas mais recentemente, e deixar que o modelo forneça estimativas das próximas saídas a partir de sucessivas realimentações. O modelo identificado utilizado com esse objetivo pode ser chamado de preditor. Como a estrutura do modelo é do tipo NARX baseado em redes neurais artificiais, está sendo feita uma predição NARX. Isso é útil, por exemplo, para técnicas de controle preditivo e detecção de falhas. Alguns trabalhos na área de detecção de falhas foram feitos por FERNANDES (2007) e REBOUÇAS (2011), ambos utilizando redes MLP recorrentes.

Além da utilização como estimador de comportamento futuro de processos envolvendo sistemas dinâmicos, o preditor neural pode ser convertido em diversas configurações, tendo elevada aplicabilidade na temática de sistemas de controle. Um dos trabalhos pioneiros nesta direção foi realizado por NARENDRA e PARTHASARATHY (1990), sendo que investigações mais abrangentes e detalhadas encontram-se relatadas em LEONDES (2006), NORGAARD et al. (2006) e SUYKENS, VANDEWALLE e DE MOOR (2001).

O modelo identificado de um sistema pode ser utilizado para inferir uma variável de difícil medição a partir das variáveis de entrada do modelo, que em geral são facilmente obtidas. Sistemas que realizam essa inferência são chamados de sensores de software ou virtuais. Sensores de software comuns utilizam, por exemplo, medições de temperatura e pressão para inferir a composição de uma substância em um processo de destilação de petróleo. Sensores virtuais podem também ser utilizados na validação de sensores reais. Trabalhos realizados na área de sensores de software podem ser vistos em LINHARES (2010), REBOUÇAS (2009), WERLE (2009), e ZANATA (2005). Esses autores utilizaram diferentes estratégias com redes neurais para estimar a composição de produtos de colunas de destilação. 
$\mathrm{Na}$ análise de casos, um sistema identificado pode ser alimentado com entradas arbitrárias. Isso possibilita a análise do comportamento do sistema em situações de interesse para os operadores ou mesmo em situações incomuns ou hipotéticas.

Muitos autores modificam a arquitetura neural apresentada anteriormente, combinando diferentes técnicas. Para citar alguns exemplos, têm-se os trabalhos de THYAGARAJAN e MALAR (2009), que analisaram o desempenho de redes neuro-fuzzy na identificação de um sistema quádruplo de tanques, e WANG e PENG (2003), que utilizaram redes neurais recorrentes com neurônios ocultos realimentados para modelar e controlar um manipulador pneumático.

As redes neurais artificiais também continuam sendo relevantes em trabalhos recentes envolvendo trocadores de calor. Essa técnica foi utilizada no trabalho de VASICKANINOVÁ et al. (2011) para construir um modelo identificado de um pré-aquecedor que aquece petróleo usando água quente. O modelo foi utilizado como parte de um controlador preditivo que tinha o objetivo de minimizar o consumo de água, mantendo o petróleo aquecido a uma temperatura desejada. Os autores mostraram que o controlador preditivo foi mais eficiente que um controlador PID clássico. O trabalho de KHAN et al. (2012) também utilizou RNA como modelo de um trocador de calor de múltiplas correntes, com o objetivo de prever o comportamento futuro do sistema, auxiliando na tomada de decisão para melhorar o desempenho da planta. Similarmente, AKBARI, SIMONSON e BESANT (2012) utilizaram RNA para desenvolver um modelo capaz de prever o calor transiente e a transferência de umidade de um trocador de energia sob diversas condições climáticas.

GANG e WANG (no prelo, 2013) realizaram um trabalho de inferência da temperatura da água na saída de um trocador de calor. Eles estudaram um sistema de controle que deveria selecionar ou um trocador de calor ou uma torre de resfriamento de acordo com qual fornecesse água com temperatura mais baixa em sua saída. No entanto, nem sempre a medição da temperatura na saída do trocador estava disponível. Para resolver o problema, os autores utilizaram RNA do tipo perceptron de múltiplas camadas para inferir essa temperatura com base em outras variáveis disponíveis no processo, determinadas a partir de um teste de correlação. Foram experimentadas arquiteturas neurais estáticas, utilizando apenas informações atuais do processo pra inferir cada valor de temperatura, e dinâmicas, que também utilizavam dados passados na inferência. Os autores testaram três algoritmos para treinar as redes: o Levenberg-Marquardt, o gradiente conjugado escalado e o BFGS. Os autores verificaram que o Levenberg-Marquardt foi o mais rápido e mais preciso. Após o treinamento, 
ambas as arquiteturas foram capazes de inferir com boa exatidão a temperatura desejada. A arquitetura dinâmica foi mais complexa, mas forneceu um erro ainda menor. Os autores concluíram que a escolha entre o modelo estático ou dinâmico poderia ser feita com base nas exigências e limitações do sistema de controle do processo. 


\section{Arquitetura do Sistema Implantado}

A principal proposta deste trabalho consiste no desenvolvimento de um preditor capaz de prever o nível da incrustação no permutador de calor P-27002 da Refinaria Potiguar Clara Camarão. Isso pode ser interpretado como uma tarefa de identificação de sistemas, aplicada ao permutador em questão. Esse procedimento pode ser dividido em quatro etapas, como mostra a Figura 7. Cada etapa pode ser repetida a qualquer momento caso os resultados da fase seguinte não estejam satisfatórios. Os tópicos seguintes detalham o que é feito em cada bloco.

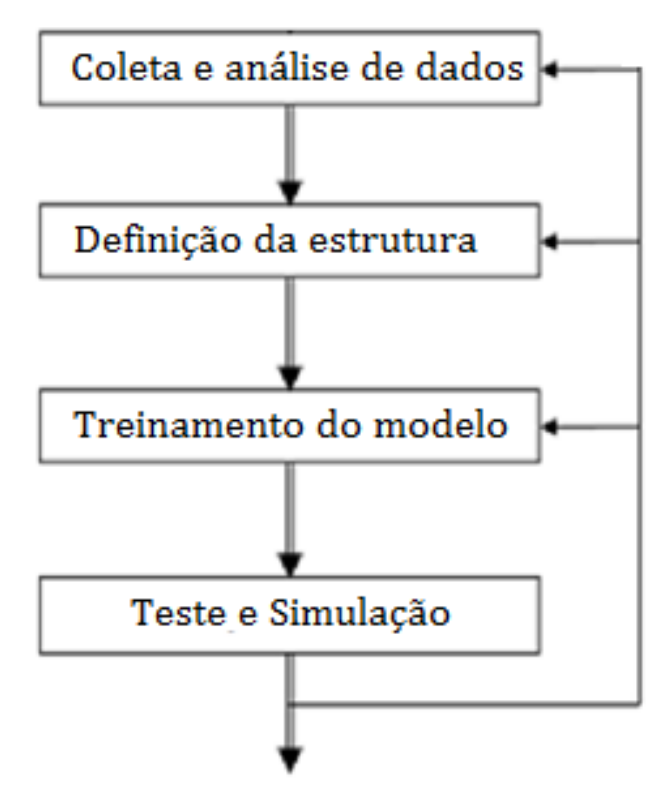

Figura 7 - Diagrama de blocos do procedimento de identificação

\subsection{Coleta e análise de dados}

A primeira etapa para o desenvolvimento do modelo identificado do trocador é a análise crítica dos dados disponíveis no banco de dados da planta para selecionar variáveis que influenciam e trazem informações sobre a dinâmica do sistema. Essa tarefa requer a cooperação de especialistas da planta, que conhecem as variáveis relevantes para o processo. Algumas das variáveis escolhidas podem ser descartadas posteriormente, se análises mostrarem que elas são desnecessárias. Em visita técnica à refinaria, descobriu-se que as principais variáveis relacionadas à incrustação são as temperaturas e vazões dos fluidos frio e quente que entram e saem do permutador. Portanto, inicialmente o trabalho será feito sobre esse conjunto de dados. 
Os dados foram obtidos em parceria com a Petrobras no banco de dados do Plant Information (PI), um sistema utilizado pela empresa para manter um histórico dos valores medidos pelos instrumentos de campo. O Plant Information utiliza o protocolo OPC para se comunicar com o sistema supervisório da refinaria, que por sua vez se comunica diretamente com os Controladores Lógicos Programáveis que recebem os sinais de medição enviados pelos instrumentos de campo.

Outro ponto de interesse é o período de amostragem. Os dados armazenados nos bancos de dados de plantas industriais são gerados a partir de amostras dos sinais medidos pelos instrumentos. Em geral, os técnicos das plantas são conservadores quanto ao tempo de amostragem, devido à grande memória de armazenamento disponível, o que resulta em dados armazenados com um período de amostragem muito menor do que o necessário para respeitar o teorema de Nyquist. Nesses casos, é interessante reamostrar os dados para evitar o manuseio de conjuntos de dados muito grandes e, principalmente, reduzir a colinearidade dos dados, ou seja, evitar que uma série de pontos consecutivos apresente o mesmo valor (FORTUNA et al., 2007). Em visita técnica, foi recomendado o período de amostragem de uma hora. Portanto, será usado inicialmente esse valor.

Para o presente trabalho, é necessário coletar dados relativos a um longo período de tempo de operação do permutador de calor, para que seja possível analisar a evolução do desempenho em diferentes condições de operação. Em particular, é interessante obter dados que mostrem diversos ciclos nos quais a eficiência do trocador inicia alta, degrada com o tempo devido à incrustação, e aumenta novamente após uma parada para limpeza e manutenção.

Os dados coletados devem ser investigados para que sejam detectados e tratados valores espúrios ou períodos de perda de dados, causados por problemas na medição ou nos sistemas de transmissão, desligamentos ou outras perturbações. Alguns desses problemas são registrados pelo próprio banco de dados $\mathrm{Pl}$ através de alguns rótulos como "Bad", "Not Connected", entre outros. Valores de topo ou de fundo de escala, como, por exemplo, temperaturas com valores de $0^{\circ} \mathrm{C}$ ou $100^{\circ} \mathrm{C}$ também são claros indícios de problemas. $\mathrm{O}$ primeiro passo da análise de dados é a busca por esses problemas de fácil detecção. Em seguida, é feita uma análise mais minuciosa com o auxílio de tabelas e gráficos para a detecção de outros valores espúrios ou sequências de valores congelados. Nem sempre é simples determinar o que é valor espúrio ou o que é uma alteração nas condições de operação. No segundo caso, os dados contém informação útil e não devem ser interpolados ou descartados. 
É interessante analisar as variáveis não individualmente, mas em conjunto, para facilitar a determinação de quais são os dados válidos.

Se apenas um ou poucos dados problemáticos forem registrados em sequência, pode ser feita uma interpolação linear para substituir os valores por estimativas plausíveis. Se houver um bloco de erros por um período de tempo maior, a interpolação não faz sentido e é necessário remover completamente os dados problemáticos, tratando o conjunto anterior e posterior aos erros como dois conjuntos de dados separados. Nem sempre é óbvio decidir quando a interpolação pode ou não ser realizada. Mais uma vez, é interessante analisar os dados em conjunto para auxiliar na decisão.

Outro problema comum na coleta de dados é a presença de ruídos ou perturbações. Filtros digitais podem ser utilizados para reduzir esses e outros efeitos temporários que podem comprometer a análise. Um tratamento simples para esse problema é a utilização de filtros de média móvel. Esse tipo de filtro pode ser entendido matematicamente como filtro passa baixa e tem o efeito de suavizar o sinal. Existem duas alternativas para a realização desse filtro, como pode ser visto nas Equações 6 e 7:

$$
\begin{gathered}
F_{1}[x(t)]_{j=n+1}=\frac{x(t-n)+\cdots+x(t-1)+x}{j} \\
F_{2}[x(t)]_{j=2 n+1}=\frac{x(t-n)+\cdots+x(t-1)+x+x(t+1)+\cdots+x(t+n)}{j}
\end{gathered}
$$

em que $j$ é o tamanho da janela do filtro.

O filtro definido por $\boldsymbol{F}_{1}$ substitui cada ponto de dado pela média dos últimos j pontos registrados. A vantagem dessa abordagem é que utiliza apenas valores passados e, portanto, pode ser implementado em tempo real.

O filtro $\boldsymbol{F}_{\mathbf{2}}$ calcula a média usando um número igual de pontos antes e depois do ponto central, necessitando assim de um número de janela ímpar. Esse filtro é mais adequado para a análise de um sinal já registrado no banco de dados, pois garante que as variações nas médias estejam alinhadas a variações nos dados ao invés de estarem atrasadas no tempo. A desvantagem é que não pode ser implementado em tempo real, por depender de valores futuros. $\mathrm{O}$ filtro $\boldsymbol{F}_{\mathbf{2}}$ foi usado nesse trabalho para suavizar a curva da efetividade e do índice de incrustação.

O filtro da mediana é outro filtro digital não linear utilizado para a redução de ruídos e, principalmente, eliminação de valores espúrios. O filtro substitui cada ponto de um sinal pela 
mediana (ponto central) dos pontos vizinhos. A vantagem deste filtro é que os pontos espúrios são eliminados sem influenciar de forma alguma o valor dos outros pontos.

É comum que os dados de uma planta apresentem magnitudes diferentes, dependendo da unidade escolhida e da natureza do processo. Isso pode fazer com que variáveis de maior magnitude se tornem dominantes sobre as variáveis de baixa magnitude durante, por exemplo, o processo de aprendizagem de uma rede neural. Por esse motivo, é necessário normalizar os dados antes de utilizá-los (FORTUNA et al., 2007). Um método comum é a normalização linear, também chamada de normalização min-max, dada pela Equação 8:

$$
x^{\prime}=\frac{x-\min _{x}}{\max _{x}-\min _{x}}\left(\max _{x^{\prime}}-\min _{x^{\prime}}\right)+\min _{x^{\prime}}
$$

em que:

$$
\begin{aligned}
& \text { x é a variável não normalizada; } \\
& \text { x' é a variável normalizada; } \\
& \min _{x} \text { é o valor mínimo da variável não normalizada; } \\
& \max _{x} \text { é o valor mínimo da variável não normalizada; } \\
& \min _{x^{\prime}} \text { é o valor mínimo da variável normalizada; } \\
& \max _{x^{\prime}} \text { é o valor mínimo da variável normalizada. }
\end{aligned}
$$

Neste trabalho a normalização será feita dessa forma para limitar todas as variáveis a valores no intervalo de $[-\mathbf{1}, \mathbf{1}]$. Todas as variáveis serão analisadas individualmente para que sejam escolhidos valores mínimos e máximos adequados em cada caso.

O objetivo final da coleta e análise dos dados é fornecer uma série de informações acerca dos ciclos de operação do permutador P-27002, como quais variáveis são mais influenciadas e permitem estimar o nível da incrustação, quais as alterações ocorridas após a limpeza ou após um longo período de operação e como os dados estão correlacionados. Isso permitirá definir as estruturas de redes neurais que serão experimentadas até que seja obtido um preditor satisfatório.

\subsection{Definição da Estrutura}

Neste trabalho foram utilizadas redes neurais artificiais como estrutura para modelar o sistema. Essa escolha se deve à sua comprovada eficácia em diversos trabalhos na literatura, como foi visto nos capítulos 2 e 4. 
O sistema consistirá basicamente de uma rede neural artificial com arquitetura recorrente treinada para aprender como a incrustação afeta o funcionamento do P-27002 e ser capaz de prever esse efeito. A rede neural artificial deverá receber em sua entrada uma estimativa das condições de operação do trocador mais uma indicação atual da incrustação. Com base nesses dados, o sistema deverá ser capaz de prever a evolução da incrustação nas próximas horas e dias, supondo que as condições de operação mantenham-se similares. A Figura 8 mostra essa arquitetura, em que $\mathbf{x}(\mathbf{k})$ são as variáveis que representam as condições estimadas de operação do trocador, $\mathbf{y}(\mathbf{k}+\mathbf{q})$ é um indicador da incrustação futura e $\{\mathbf{y}(\mathbf{k}), \mathbf{y}(\mathbf{k}-$ q), ... , y(k-nq)\} são os últimos indicadores da incrustação. Essa é a arquitetura de um preditor de 1 passo de tempo $\boldsymbol{q}$, mas a realimentação pode ser repetida quantas vezes for necessário, permitindo a predição de um período qualquer de tempo.

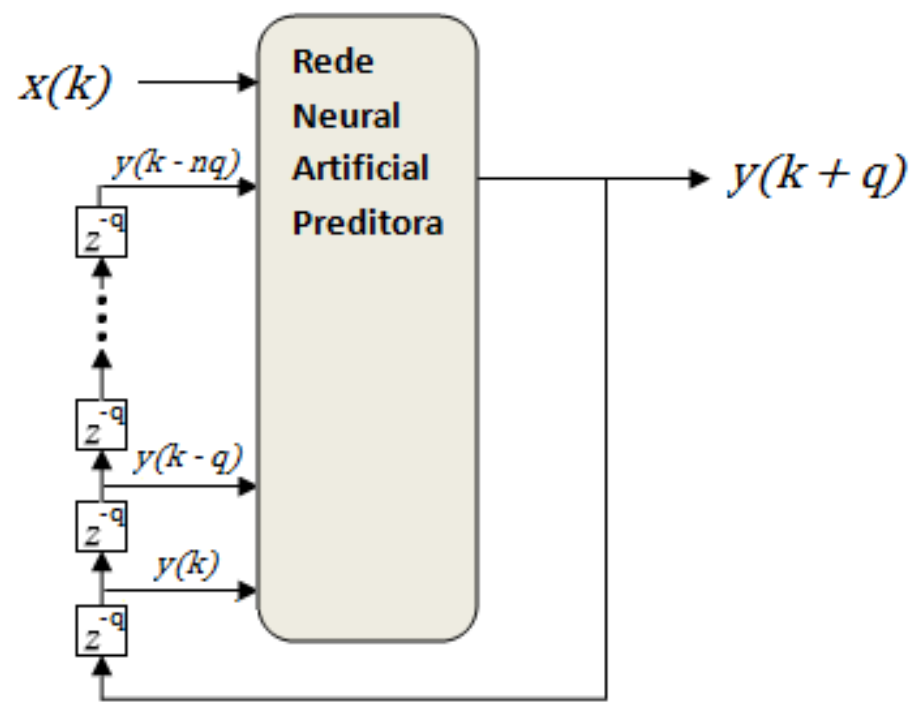

Figura 8 - Arquitetura do sistema de predição da incrustação

Não serão utilizados regressores nas entradas, ou seja, será fornecido apenas o seu valor em um instante de tempo fixo, pois é suposto que elas permanecerão aproximadamente constantes durante a predição. No caso das saídas, a escolha dos regressores será feita por tentativa e erro. Serão testadas arquiteturas com diferentes números de regressores e valores de $\boldsymbol{q}$. Será feita uma comparação do desempenho para determinar o número mais adequado. Alguns exemplos de regressores são mostrados na Tabela 4. O número de neurônios também será escolhido dessa forma. 
Tabela 4 - Exemplos de regressores experimentados

\begin{tabular}{lll}
\hline Maior regressor & Passo de predição (q) & Regressores \\
\hline $\mathbf{2}$ & 1 & $\mathrm{y}(\mathrm{k}-1), \mathrm{y}(\mathrm{k}-2)$ \\
$\mathbf{6}$ & 1 & $\mathrm{y}(\mathrm{k}-1), \mathrm{y}(\mathrm{k}-2), \mathrm{y}(\mathrm{k}-3), \ldots, \mathrm{y}(\mathrm{k}-6)$ \\
$\mathbf{1 2}$ & 2 & $\mathrm{y}(\mathrm{k}-2), \mathrm{y}(\mathrm{k}-4), \mathrm{y}(\mathrm{k}-6), \ldots, \mathrm{y}(\mathrm{k}-12)$ \\
$\mathbf{2 4}$ & 6 & $\mathrm{y}(\mathrm{k}-6), \mathrm{y}(\mathrm{k}-12), \mathrm{y}(\mathrm{k}-18), \mathrm{y}(\mathrm{k}-24)$ \\
$\mathbf{4 8}$ & 8 & $\mathrm{y}(\mathrm{k}-8), \mathrm{y}(\mathrm{k}-16), \mathrm{y}(\mathrm{k}-24), \ldots, \mathrm{y}(\mathrm{k}-48)$ \\
$\mathbf{6 4}$ & 8 & $\mathrm{y}(\mathrm{k}-8), \mathrm{y}(\mathrm{k}-16), \mathrm{y}(\mathrm{k}-24), \ldots, \mathrm{y}(\mathrm{k}-64)$ \\
\hline
\end{tabular}

Projetado dessa forma, o sistema pode ser entendido como um modelo de um permutador de calor que sofre uma deterioração gradual do seu desempenho, devido à incrustação. Esse modelo pode auxiliar a prever com antecedência se será necessário realizar uma nova parada para manutenção, ou pelo menos fornecer uma indicação do desempenho do permutador nos próximos dias.

Outro experimento consiste em realizar a predição diretamente de quantos dias restam até que seja necessário parar o permutador para limpeza. Nesse caso a rede neural terá entradas atrasadas no tempo que representem as condições de operação reais registradas mais recentemente pelos sensores. A saída não será realimentada, pois representa apenas o número de dias restantes até que algum indicador da incrustação atinja um valor inaceitável. Essa arquitetura é mostrada na Figura 9.

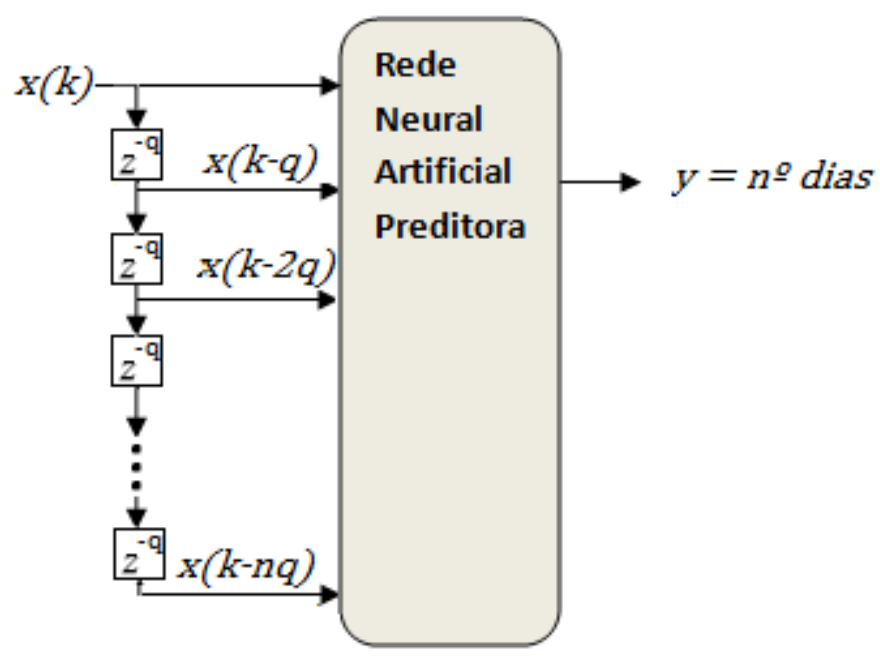

Figura 9 - Arquitetura do sistema de predição de dias até a parada

O número de regressores será escolhido por tentativa e erro com comparações de desempenho, da mesma forma explicada anteriormente. 
Enquanto que a primeira arquitetura é um modelo dinâmico capaz de prever a evolução da incrustação ao longo do tempo, esta última é um modelo estático que informa uma estimativa em dias de quando será necessário parar o permutador.

\subsection{Treinamento do Modelo}

Com a estrutura já definida é possível ajustar os parâmetros do modelo, ou seja, realizar o treinamento das redes neurais. As redes com realimentação foram treinadas segundo o esquema serial-paralelo (BEALE et al, 2007). Isso significa que, apenas durante o treinamento, a realimentação é feita com os dados reais, e não com a saída estimada a cada instante pela própria rede. A principal vantagem desse esquema é que a rede pode ser treinada com um algoritmo estático comum, como o backpropagation e suas variações. Inicialmente serão utilizados algoritmos clássicos de treinamento, como o gradiente conjugado ou o Levenberg-Marquardt. Se necessário, poderão ser investigados outros métodos de treinamento.

Serão separados conjuntos para treinamento, validação e teste. Os dados referentes aos primeiros ciclos de operação do permutador serão utilizados para treinamento, ou seja, serão usados diretamente nos cálculos de atualização dos pesos das redes neurais. Alguns ciclos na sequência serão usados para formar o conjunto de validação, ou seja, para parar antecipadamente o treinamento caso o erro para esse conjunto de dados esteja aumentando. Os dados referentes aos últimos ciclos serão utilizados para teste, ou seja, para verificar a capacidade de generalização da rede neural. Essa escolha sequencial, separando os primeiros ciclos para treinamento e os últimos para teste, foi feita para que se possa verificar se o preditor é capaz de generalizar o conhecimento aprendido a partir dos últimos ciclos de operação para os ciclos futuros.

Em busca da melhor arquitetura, serão treinadas redes neurais com diferentes regressores, passos de regressão e número de neurônios. As variáveis usadas nas entradas e saídas das redes neurais também serão variadas, desde que a arquitetura resultante faça sentido e possa ser implementada na realidade. Além disso, para redes neurais idênticas, o treinamento será repetido diversas vezes. Isso será feito porque, dependendo dos pesos iniciais, o resultado final do treinamento pode ser bastante diferente. A seleção das melhores redes seguirá o critério do menor erro médio quadrático para o conjunto de validação. 
Algumas das decisões tomadas nesse tópico são discutidas no trabalho de WIJAYASEKARA et al. (2011), direcionado ao uso de redes neurais artificiais na modelagem de trocadores de calor. Os autores propõem métodos para selecionar a melhor arquitetura neural destacando pontos importantes, tais quais: a separação dos conjuntos de treinamento, validação e teste para evitar o problema do overfitting, a criação de redes com diferentes números de neurônios e a repetição do treinamento diversas vezes mesmo para arquiteturas idênticas. Os autores também discutem técnicas para superar problemas devido a conjuntos de dados muito pequenos. Outra conclusão interessante é que, em alguns casos, arquiteturas maiores (com mais neurônios) fornecem melhores resultados, mas existem problemas para os quais redes mais simples não apenas são suficientes como fornecem resultados ainda melhores do que as mais complexas.

\subsection{Testes e Simulação da Operação}

Após o treinamento é necessário verificar se o modelo obtido é capaz de prever adequadamente o comportamento do permutador. Para isso, deve-se usar o conjunto de teste separado anteriormente para simular como o preditor funcionaria na realidade, diante de dados nunca vistos durante o treinamento, e avaliar os resultados.

Durante a simulação, as redes neurais estimam o comportamento futuro a partir apenas dos dados passados conhecidos. Cada iteração de cálculo da rede neural prevê um passo adiante. A realimentação pode ser feita quantas vezes for desejado, prevendo um número qualquer de horas adiante. O número de horas preditas é chamado de horizonte da predição. É interessante que o sistema proposto seja capaz de prever, com um erro aceitável, o maior horizonte possível. Porém, como a rede neural não é um modelo perfeito do sistema real, e como é impossível conhecer previamente as condições de operação (entradas da rede neural) exatas nos instantes futuros, cada valor predito contém um erro de predição. Esse erro é acumulado a cada realimentação e a tendência é que aumente a cada passo da predição. Um resultado importante dessa etapa é definir qual o maior horizonte de predição com erros aceitáveis.

Após o sucesso nessa fase do desenvolvimento, o modelo poderia ser implantado na realidade, sendo alimentado com os dados iniciais obtidos no processo real para fornecer uma indicação de como a incrustação irá afetar o seu desempenho no decorrer do tempo, conforme planejado. 
Se o desempenho verificado nessa etapa não for satisfatório as etapas anteriores devem ser refeitas. Talvez um novo treinamento com algumas alterações solucione o problema, ou talvez seja necessário modificar completamente a arquitetura proposta. Em último caso, o processo real deve ser reestudado para que seja realizada uma nova coleta e análise de dados. 


\section{Resultados}

\subsection{Coleta e Análise de Dados}

As seguintes variáveis, referentes ao permutador de calor P-27002, foram obtidas em parceria com a Petrobras:

- Vazão de QAV;

- Temperatura de entrada de QAV;

- $\quad$ Temperatura de saída de QAV;

- Vazão de óleo bruto;

- Temperatura de entrada de óleo bruto;

- Temperatura de saída de óleo bruto.

Os dados foram coletados com um período de amostragem de 1 hora e se referem aos meses de novembro de 2011 até março de 2012. No total, são 3620 pontos para cada uma das 6 variáveis.

Uma análise preliminar dos dados coletados mostrou os problemas esperados de ruído, valores espúrios e momentos de perdas de dados. A Figura 10, referente à vazão de QAV (com valores normalizados entre -1 e 1 ) entre os meses de novembro e dezembro, destaca alguns desses problemas.

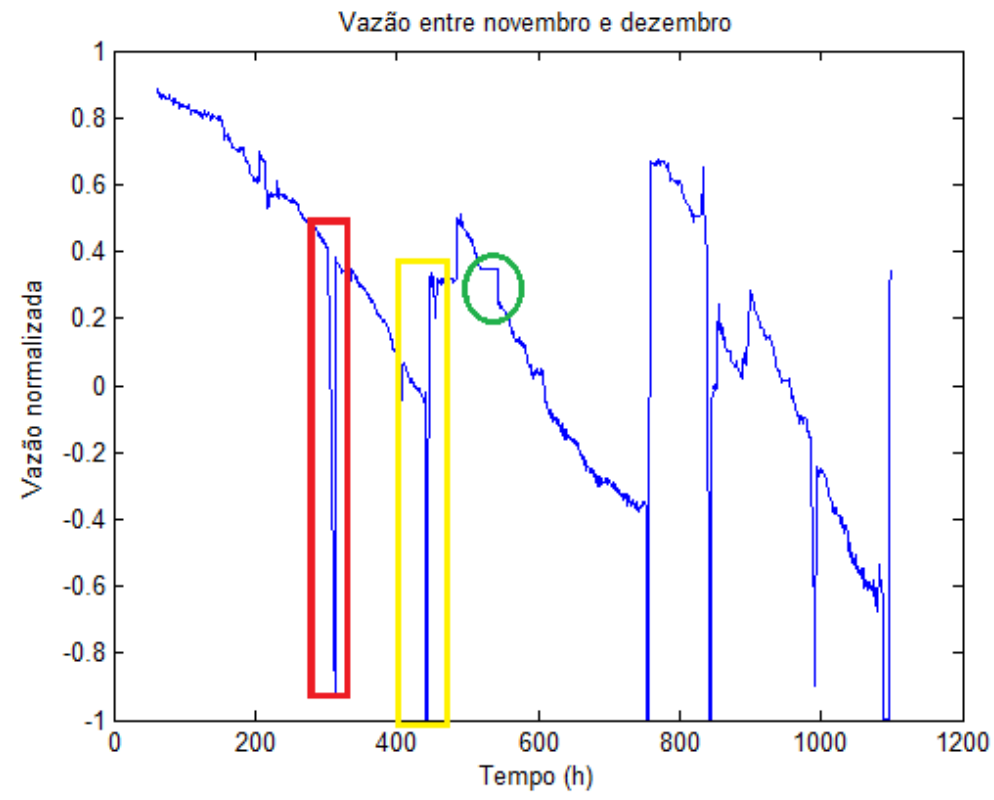

Figura 10 - Vazão entre novembro e dezembro com alguns problemas em destaque 
No instante destacado em vermelho, os dados da vazão apresentam uma grande queda de curta duração em seu valor. Esses pontos são chamados de espúrios e indicam claramente um problema no sistema de medição, transmissão e armazenamento dos dados. Em verde, tem-se um curto período de tempo onde os dados não se alteram, preservando o primeiro valor armazenado. Isso também é um problema provavelmente causado por um congelamento ou travamento no sistema. Todo o conjunto de dados foi analisado com o objetivo de identificar e tratar esses dois tipos de problemas. Como tratamento foi feita uma interpolação linear desde o último ponto válido antes dos pontos com problemas até o primeiro ponto válido obtido após o problema.

Em amarelo, temos um período no qual o valor da vazão cai para o fundo de escala e em seguida muda para outro patamar. Esses não são valores espúrios, pois em seguida a vazão muda completamente o seu ponto de operação. Na verdade, esses são exatamente os instantes em que o permutador de calor é parado para limpeza. Afinal, segundo os operadores da planta, a vazão no permutador decresce com o tempo devido à incrustação e aumenta de valor após a parada para limpeza. Seguindo essa lógica, é possível remover os valores com problemas e criar vários subconjuntos de dados referentes a ciclos de operação do permutador. Uma etapa crucial desse trabalho foi justamente a identificação e separação dos diversos ciclos de operação normal, incrustação e parada para limpeza do trocador de calor.

O tratamento dos valores espúrios e períodos de congelamento exibidos na Figura 10, permite obter a Figura 11, na qual é possível identificar facilmente 3 ciclos de operação. Nesse trabalho o tratamento foi feito a partir de interpolações lineares realizadas individualmente sobre cada um dos conjuntos de pontos problemáticos. Entretanto, quando o conjunto de dados a ser trabalhado é muito grande, pode ser mais viável aplicar o filtro da mediana para automatizar o processo de tratamento dos valores espúrios.

É possível observar também que, após a limpeza, a vazão não retorna exatamente aos mesmos valores do início do ciclo anterior. Isso ocorre porque o processo de limpeza, feito por jatos de água que percorrem os tubos e arrastam a sujeira, não é perfeito, sempre havendo variações na sua eficiência. 

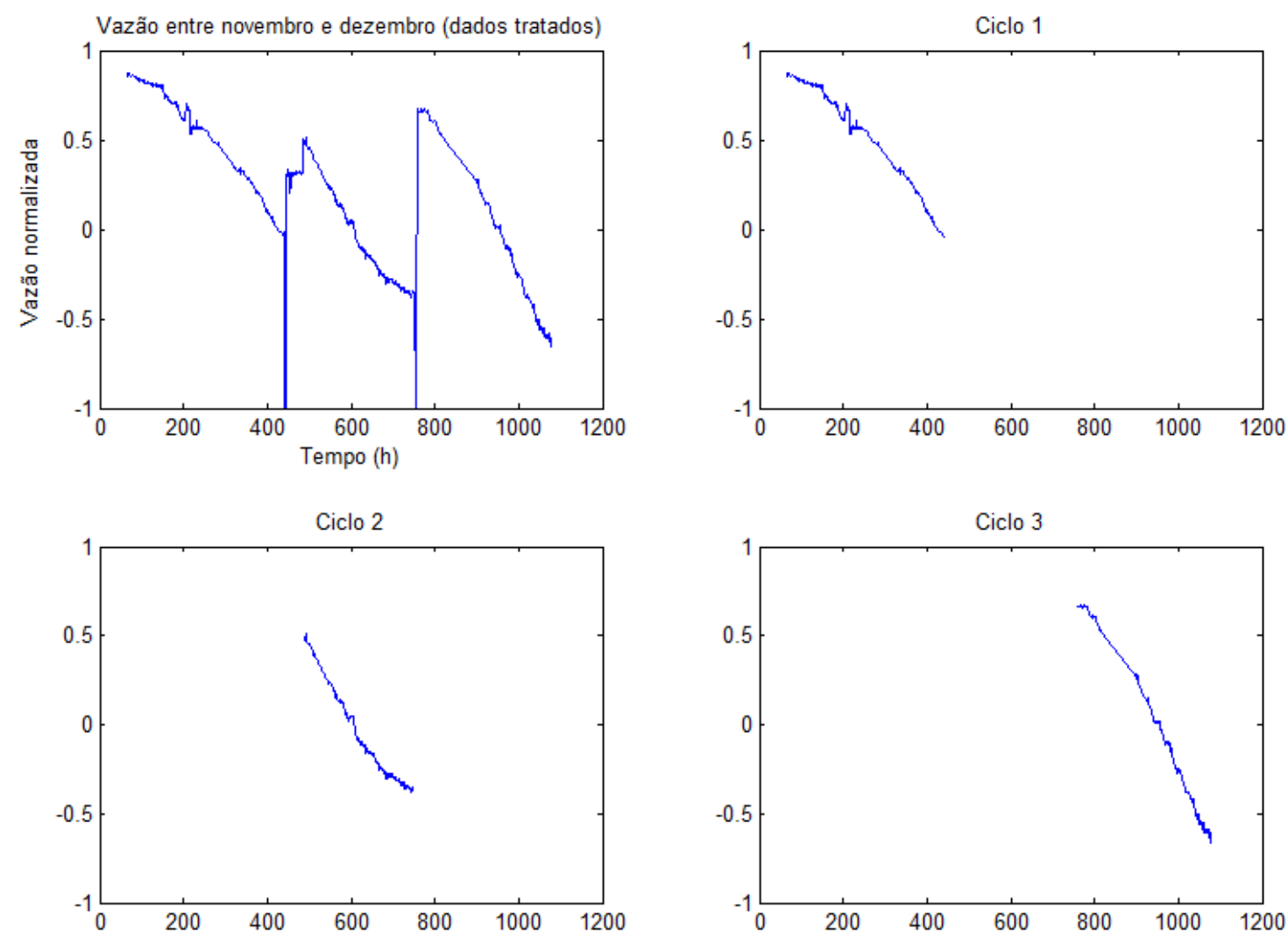

Figura 11 - Vazão após tratamento de erros e separação de ciclos

Até agora foram mostrados apenas os gráficos da vazão, mas a análise dos dados e o tratamento de erros foram feitos para todas as variáveis. Para exemplificar o resultado desse processo, a Figura 12 mostra todas as variáveis referentes ao segundo ciclo de operação do permutador, com valores normalizados entre -1 e 1 . 

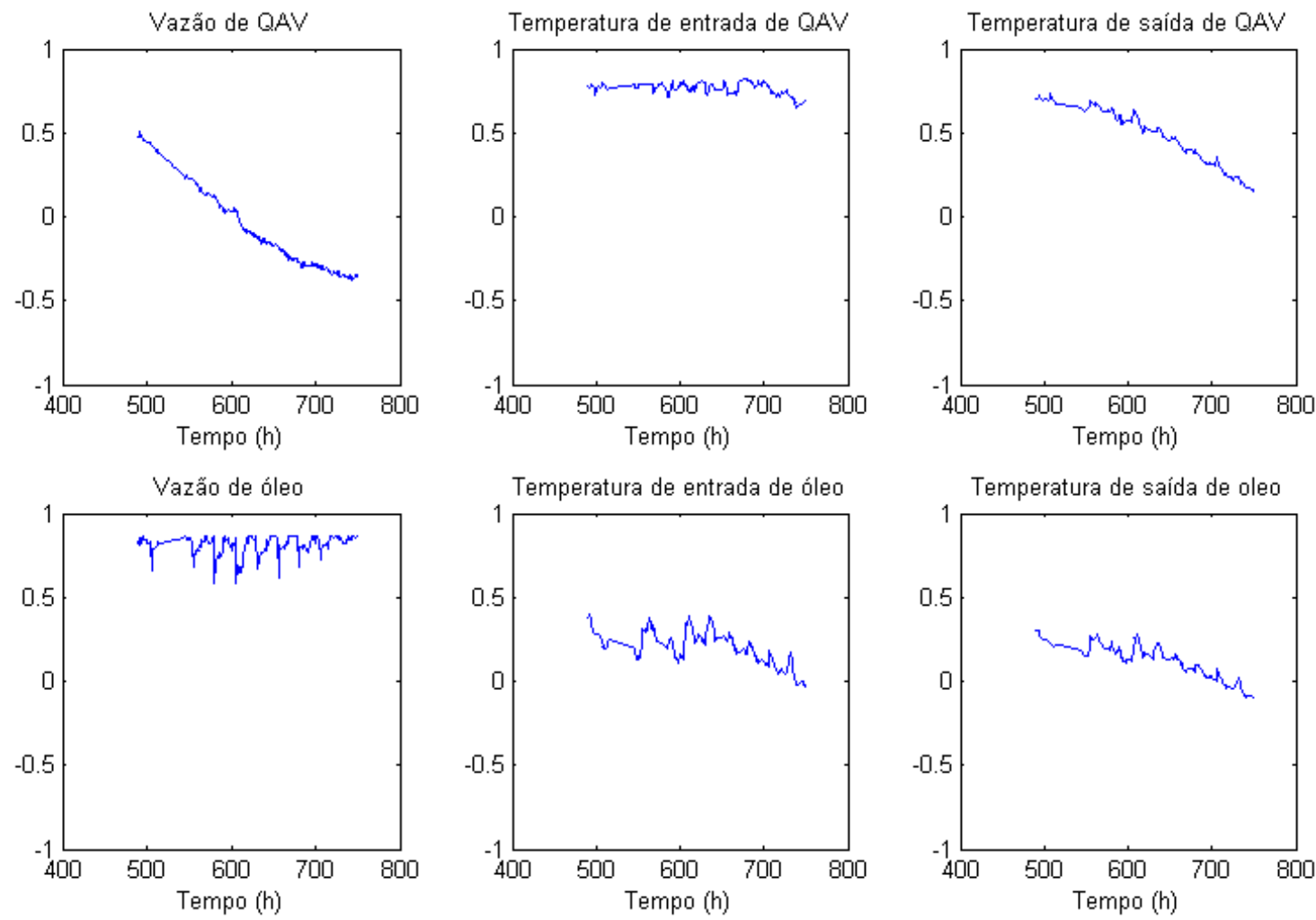

Figura 12 - Dados tratados do segundo ciclo de operação do trocador de calor

Prosseguindo com a análise, é possível utilizar os dados das temperaturas (após o tratamento para eliminação de erros) para calcular a efetividade do trocador, de acordo com a Equação 2 mostrada no capítulo 2. Foi ainda aplicado um filtro de média móvel com janela de 12 horas (Equação 6) para reduzir o efeito do ruído gerado na medição das temperaturas. Para exemplificar, a Figura 13 mostra a efetividade para os ciclos entre os meses de novembro e dezembro. 

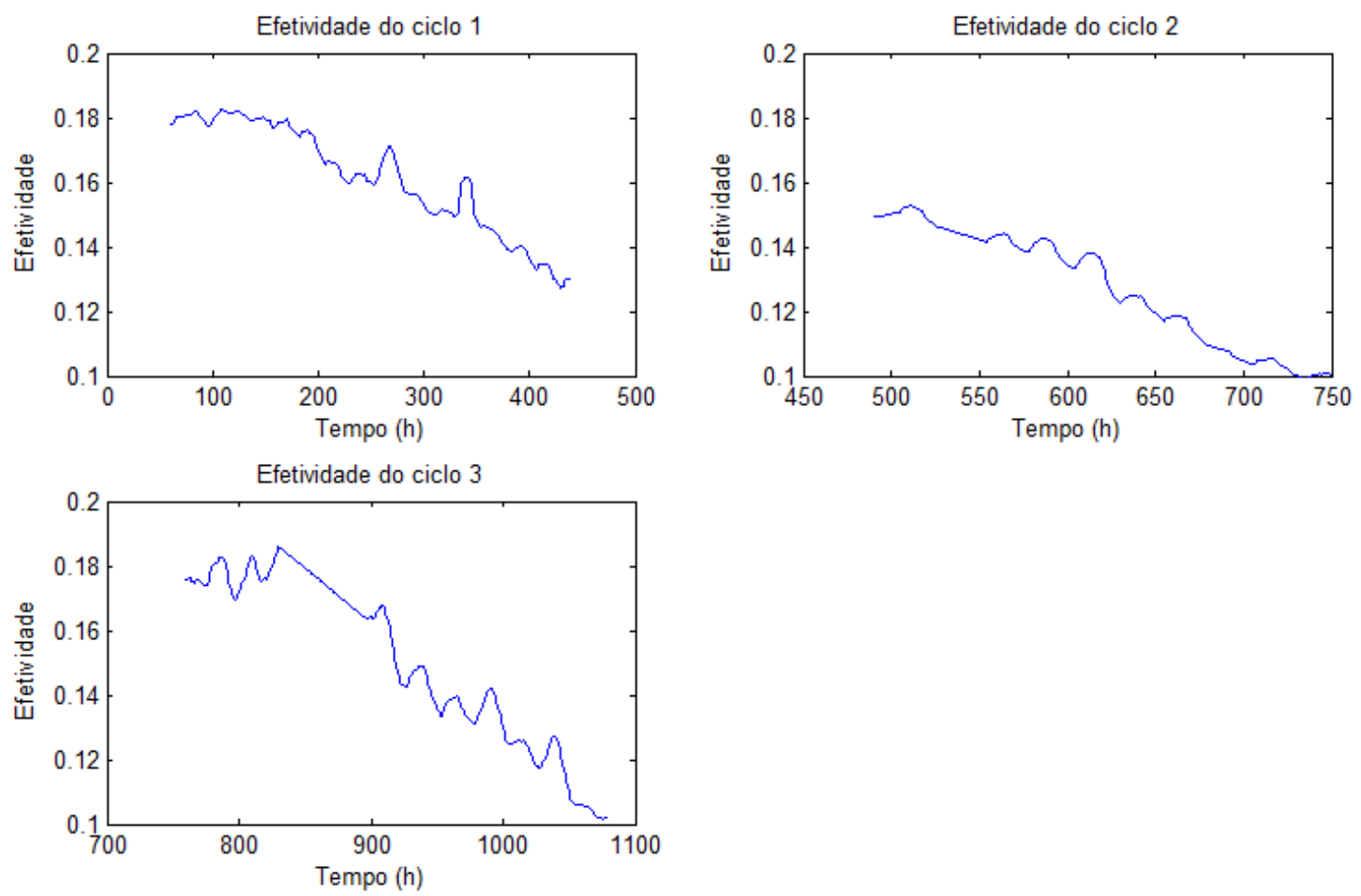

Figura 13 - Efetividade de ciclos de operação do permutador

Observa-se, como esperado, que a efetividade do permutador decai com o tempo, devido à incrustação. O cálculo da efetividade foi realizado para todos os ciclos identificados no conjunto de dados, e sempre foi observado o seu decaimento.

No capítulo 2 foi apresentada também a Equação 3 para cálculo do índice de incrustação de um permutador de calor. Para isso é necessário saber as efetividades do permutador no momento de operação, quando está limpo e quando está sujo. A maior efetividade observada em todo o período dos dados coletados foi de 0,18 , enquanto que a menor foi de 0,04. Utilizando esses valores para as efetividades de um permutador limpo e sujo respectivamente, podemos calcular um valor aproximado para o índice de incrustação a cada instante de operação. Para exemplificar, a Figura 14 mostra o índice calculado para os ciclos entre novembro e dezembro. 

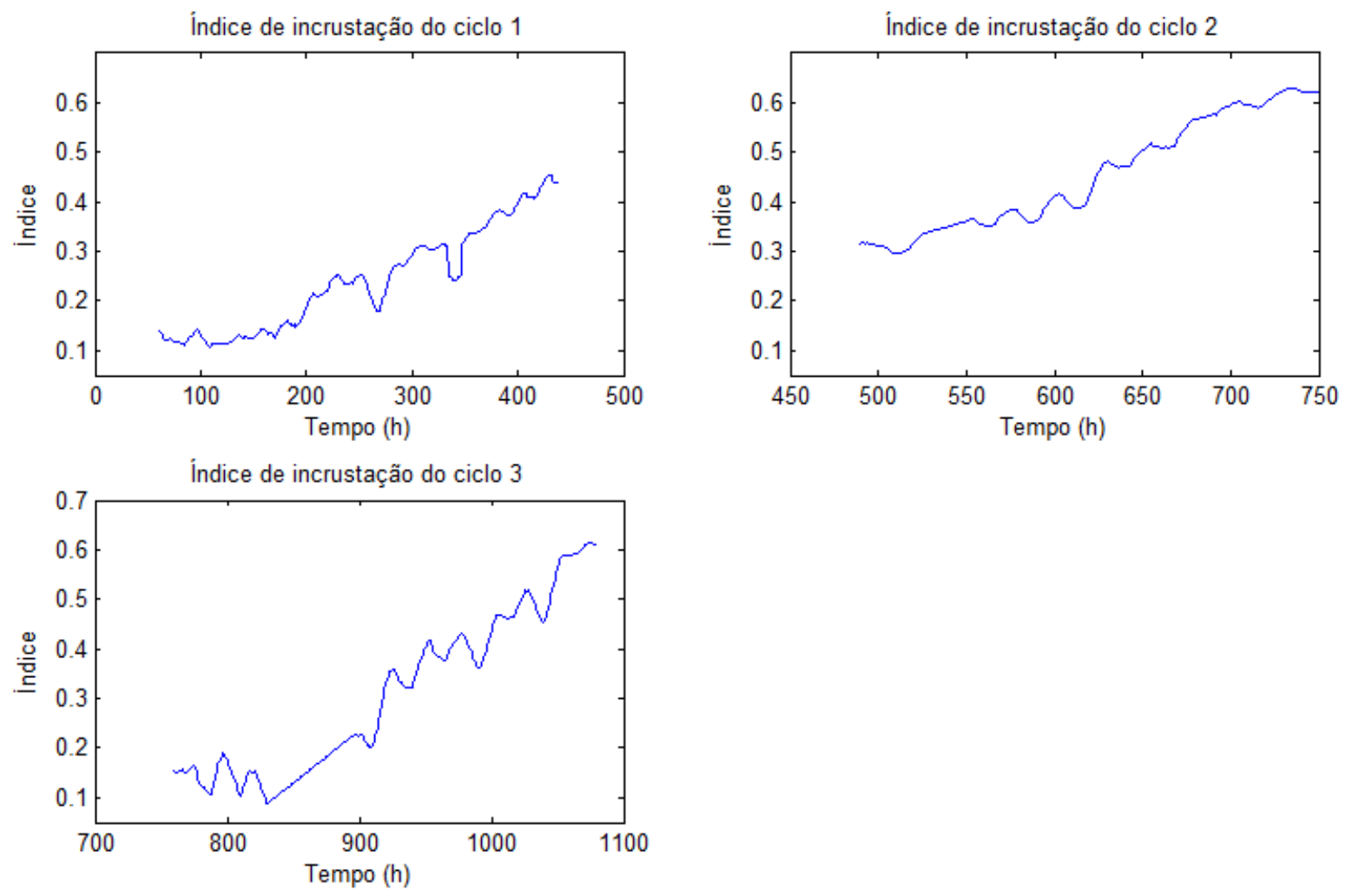

Figura 14 - Índice de incrustação de ciclos de operação do permutador

Observa-se, como esperado, um aumento do índice de incrustação ao longo do tempo. O índice foi calculado para todos os ciclos identificados no conjunto de dados, e sempre foi observada essa tendência.

Outras conclusões interessantes podem ser feitas a partir da matriz de correlação dos dados normalizados, registrada na Tabela 5.

Tabela 5 - Matriz de correlação dos dados coletados

\begin{tabular}{|c|c|c|c|c|c|c|}
\hline & $\begin{array}{c}\text { Vazão QAV } \\
\left(\mathbf{m}^{3} / \mathbf{h}\right)\end{array}$ & $\begin{array}{c}\text { Temp. } \\
\text { Entrada QAV } \\
\left({ }^{\circ} \mathrm{C}\right)\end{array}$ & $\begin{array}{c}\text { Temp. Saída } \\
\text { QAV }\left({ }^{\circ} \mathrm{C}\right)\end{array}$ & $\begin{array}{c}\text { Vazão óleo } \\
\left(\mathbf{m}^{3} / \mathbf{h}\right)\end{array}$ & $\begin{array}{c}\text { Temp. } \\
\text { entrada óleo } \\
\left({ }^{\circ} \mathrm{C}\right)\end{array}$ & $\begin{array}{c}\text { Temp. saída } \\
\text { óleo }\left({ }^{\circ} \mathrm{C}\right)\end{array}$ \\
\hline $\begin{array}{c}\text { Vazão QAV } \\
\left(\mathbf{m}^{3} / \mathbf{h}\right)\end{array}$ & $\mathbf{1 , 0 0}$ & 0,14 & 0,92 & $-0,03$ & 0,39 & 0,77 \\
\hline $\begin{array}{c}\text { Temp. } \\
\text { Entrada QAV } \\
\left({ }^{\circ} \mathrm{C}\right)\end{array}$ & $\mathbf{0 , 1 4}$ & $\mathbf{1 , 0 0}$ & 0,24 & $-0,03$ & 0,14 & 0,21 \\
\hline $\begin{array}{c}\text { Temp. Saída } \\
\text { QAV ( }\end{array}$ & $\mathbf{0 , 9 2})$ & $\mathbf{0 , 2 4}$ & $\mathbf{1 , 0 0}$ & $-0,08$ & 0,51 & 0,86 \\
\hline $\begin{array}{c}\text { Vazão óleo } \\
\left(\mathrm{m}^{3} / \mathrm{h}\right)\end{array}$ & $\mathbf{- 0 , 0 3}$ & $\mathbf{- 0 , 0 3}$ & $\mathbf{- 0 , 0 8}$ & $\mathbf{1 , 0 0}$ & $-0,06$ & $-0,12$ \\
\hline $\begin{array}{c}\text { Temp. } \\
\text { entrada óleo } \\
\left({ }^{\circ} \mathrm{C}\right)\end{array}$ & $\mathbf{0 , 3 9}$ & $\mathbf{0 , 1 4}$ & $\mathbf{0 , 5 1}$ & $-\mathbf{0 , 0 6}$ & $\mathbf{1 , 0 0}$ & 0,81 \\
\hline $\begin{array}{c}\text { Temp. saída } \\
\left.\text { óleo ( }{ }^{\circ} \mathrm{C}\right)\end{array}$ & $\mathbf{0 , 7 7}$ & $\mathbf{0 , 2 1}$ & $\mathbf{0 , 8 6}$ & $\mathbf{- 0 , 1 2}$ & $\mathbf{0 , 8 1}$ & $\mathbf{1 , 0 0}$ \\
\hline
\end{tabular}


Primeiramente, nota-se que a vazão de óleo tem uma correlação desprezível em comparação com todas as outras variáveis, o que pode ser constatado também por uma simples análise visual da Figura 12 - Dados tratados do segundo ciclo de operação do trocador de calor. Isso mostra que essa variável não tem relação com a eficiência da troca térmica do permutador e, portanto, não será utilizada no desenvolvimento do sistema de predição proposto. Por outro lado, a vazão de QAV tem grande correlação com ambas as temperaturas de saída do permutador. Isso evidencia que a degradação dessa vazão, devido à incrustação, afeta negativamente a eficiência da troca térmica.

Um resumo final da análise dos ciclos de operação de novembro de 2011 a março de 2012 do permutador P-27002 pode ser visto na Tabela 6. Em média, os operadores realizam a parada para manutenção quando a efetividade cai para 0,10. Após a limpeza, a efetividade aumenta em média para 0,15, mas existe uma variação considerável entre esses valores.

Tabela 6 - Resumo da análise dos ciclos de operação do P-27002

\begin{tabular}{|c|c|c|c|c|c|c|c|}
\hline Ciclo & $\begin{array}{c}\text { Duração } \\
\text { (dias) }\end{array}$ & $\begin{array}{l}\text { Vazão } \\
\text { inicial } \\
\left(\mathrm{m}^{3} / \mathrm{h}\right)\end{array}$ & $\begin{array}{c}\text { Vazão } \\
\text { final } \\
\left(\mathrm{m}^{3} / \mathrm{h}\right)\end{array}$ & $\begin{array}{l}\text { Efetividade } \\
\text { inicial }\end{array}$ & $\begin{array}{l}\text { Efetividade } \\
\text { final }\end{array}$ & $\begin{array}{l}\text { Índice } \\
\text { inicial }\end{array}$ & $\begin{array}{c}\text { Índice } \\
\text { final }\end{array}$ \\
\hline 1 & 16 & 56,59 & 28,38 & 0,18 & 0,13 & 0,02 & 0,37 \\
\hline 2 & 10 & 44,21 & 19,49 & 0,15 & 0,10 & 0,22 & 0,58 \\
\hline 3 & 13 & 50,03 & 10,49 & 0,18 & 0,10 & 0,03 & 0,54 \\
\hline 4 & 12 & 48,12 & 19,96 & 0,16 & 0,11 & 0,16 & 0,53 \\
\hline 5 & 5 & 39,03 & 19,44 & 0,15 & 0,10 & 0,22 & 0,55 \\
\hline 6 & 5 & 36,79 & 19,77 & 0,15 & 0,10 & 0,19 & 0,55 \\
\hline 7 & 6 & 35,27 & 20,24 & 0,15 & 0,11 & 0,21 & 0,49 \\
\hline 8 & 5 & 27,38 & 16,31 & 0,12 & 0,09 & 0,42 & 0,68 \\
\hline 9 & 7 & 28,43 & 14,04 & 0,12 & 0,08 & 0,42 & 0,74 \\
\hline 10 & 18 & 46,35 & 8,78 & 0,14 & 0,04 & 0,30 & 1,00 \\
\hline Média & 10 & 41,22 & 19,26 & 0,15 & 0,10 & 0,22 & 0,60 \\
\hline $\begin{array}{l}\text { Desvio } \\
\text { padrão }\end{array}$ & 5 & 9,50 & 4,94 & 0,02 & 0,02 & 0,14 & 0,17 \\
\hline
\end{tabular}

Após a análise e tratamento dos dados, foi possível realizar o treinamento da rede neural para o sistema proposto.

\subsection{Definição da Estrutura}

Após a coleta e análise de dados, foi possível definir a estrutura do modelo, ou seja, definir quais variáveis seriam utilizadas como entradas e saídas das redes neurais artificiais. Inicialmente foram feitos experimentos com a arquitetura para predição do número de dias 
até a parada. As entradas utilizadas nesse caso foram as temperaturas de entrada e saída de óleo e de QAV e a vazão de QAV. Mais especificamente, foram testadas quatro alternativas: previsão do número de dias até a parada, de acordo com a duração dos ciclos de treinamento; previsão do número de dias até que a efetividade caísse abaixo de um valor limite; previsão do número de dias até que o índice de incrustação (IF) aumentasse até um valor limite e previsão do número de dias até que a vazão caísse abaixo de um valor limite. Os resultados obtidos com essa arquitetura não foram satisfatórios e, portanto, não serão discutidos mais adiante.

Para a arquitetura de predição da incrustação com saídas recorrentes, foram definidas primeiramente as variáveis de entrada que representam as condições de operação do permutador, para permitir uma predição mais correta. A vazão de óleo poderia ser usada, mas o teste de correlação descrito anteriormente mostrou que essa variável não contém nenhuma informação útil para o problema. A vazão de QAV e as temperaturas de saída do permutador não podem ser utilizadas, pois dependem da incrustação e não é possível determinar seu valor com antecedência. Já as temperaturas de entrada de QAV e de óleo não dependem da incrustação e os operadores são capazes de estimar o valor médio dessas temperaturas para as próximas horas. Atualmente não existe, além dos dados já analisados, nenhum outro sensor conectado diretamente ao P-27002 que possa fornecer alguma informação útil. Portanto, apenas as duas variáveis de temperaturas de entrada do trocador foram escolhidas para representar as condições de operação.

Resta agora definir, para essa arquitetura, qual será a saída da rede neural, ou seja, a variável a ser predita. Foram testadas inicialmente a predição da efetividade e dos índices de incrustação calculados. Os resultados obtidos dessa forma não foram satisfatórios, provavelmente por não utilizarem dados da vazão de QAV, que mostrou ter uma correlação relevante com o desempenho do permutador. Finalmente, optou-se por utilizar a vazão de QAV como variável a ser predita. Essa vazão sofre uma clara degradação ao longo do tempo, causada pela incrustação. Outra vantagem dessa escolha é que a vazão já é monitorada pelos operadores do processo e usada como indicadora da incrustação. Portanto, os valores preditos pelo sistema têm um significado natural para eles. A estrutura final do sistema preditor baseado em redes neurais artificiais pode ser visto na Figura 15. 


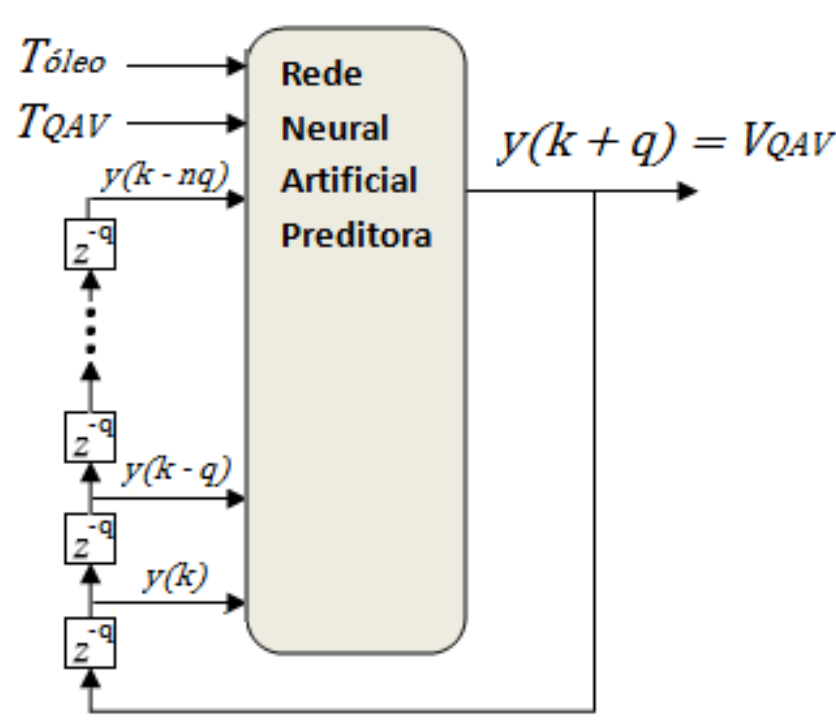

$T_{\text {óleo }}=$ Temperatura de entrada de óleo
$T_{Q A V}=$ Temperatura de entrade de $Q A V$
$V_{Q A V}=$ Vazão de $Q A V$

Figura 15 - Definição do sistema de predição da incrustação

Outros detalhes da estrutura, como o algoritmo de treinamento, número de camadas ocultas e número de atrasos serão discutidos no próximo tópico.

\subsection{Treinamento das Redes Neurais}

O treinamento e teste das redes neurais foram realizados com o auxílio do toolbox para redes neurais artificiais do Matlab ${ }^{\circledR}$. Foram desenvolvidas diversas rotinas para simular as entradas atrasadas e a realimentação de saída das redes neurais. Essas rotinas foram criadas também com o objetivo de facilitar a sua reutilização em trabalhos futuros.

Os dados dos primeiros 5 ciclos foram usados para formar os conjuntos de treinamento e validação. Os ciclos restantes foram usados após o treinamento para testar e verificar se a rede foi capaz de generalizar o conhecimento aprendido.

Em busca do melhor preditor, foram treinadas redes neurais com 2, 4, 6, 12, 24 e 48 atrasos de realimentação. Isso significa que a menor rede deve prever a vazão da próxima hora com base nas vazões das últimas 2 horas (além das temperaturas, como foi explicado anteriormente), enquanto que a maior rede deve prever a vazão com base nos dados das últimas 48 horas. Ainda em busca da melhor arquitetura, foram treinadas redes neurais com 8 , 12, 16, 20 e 24 neurônios. Para cada uma dessas configurações, foram treinadas 10 redes neurais iniciadas com pesos aleatórios. $O$ algoritmo de treinamento utilizado foi o LevenbergMarquardt. 
A Tabela 7 contém as características das melhores redes selecionadas. São informados os erros médios quadráticos para o conjunto de dados usado no treinamento e para o conjunto usado apenas para teste. Na predição de 72 horas, é informado o erro para uma predição contínua das primeiras 72 horas dos ciclos de operação.

Tabela 7 - Informações e erros das melhores redes selecionadas

\begin{tabular}{|c|c|c|c|c|c|}
\hline Atrasos & $\begin{array}{c}\text { Neurônios } \\
\text { na camada } \\
\text { oculta } \\
\text { única }\end{array}$ & $\begin{array}{c}\text { Erro de } \\
\text { treinamento na } \\
\text { predição de 1 hora }\end{array}$ & $\begin{array}{c}\text { Erro de } \\
\text { treinamento na } \\
\text { predição de } 72 \\
\text { horas }\end{array}$ & $\begin{array}{c}\text { Erro de teste na } \\
\text { predição de 1 hora }\end{array}$ & $\begin{array}{c}\text { Erro de teste na } \\
\text { predição de } 72 \\
\text { horas }\end{array}$ \\
\hline 2 & 16 & $1,33 \times 10^{-4}$ & $3,2 \times 10^{-3}$ & $2,12 \times 10^{-4}$ & $6,9 \times 10^{-3}$ \\
\hline 6 & 8 & $1,24 \times 10^{-4}$ & $6,5 \times 10^{-3}$ & $2,90 \times 10^{-4}$ & $1,2 \times 10^{-2}$ \\
\hline 12 & 20 & $1,26 \times 10^{-4}$ & $3,8 \times 10^{-3}$ & $3,00 \times 10^{-4}$ & $4,7 \times 10^{-3}$ \\
\hline
\end{tabular}

Observa-se um maior erro na predição de 72 horas em comparação com a predição de apenas 1 hora. Isso ocorre porque, na predição de 72 horas, o erro de predição é continuamente realimentado pela rede neural para realizar os próximos passos de predição, amplificando esse erro. $\mathrm{O}$ erro de treinamento é menor que o de teste, porque o ajuste dos pesos sinápticos foi feito para se adequar especialmente aos dados de treinamento. Ainda assim, o erro para os dados de teste foi aceitável, mostrando a capacidade de generalização da rede neural.

\subsection{Testes e Simulação da Operação}

A ideia é que, depois de implementado na realidade, o sistema seja utilizado para realizar a predição até um horizonte desejado, a partir de dados passados conhecidos. Um dia depois, o operador pode reinicializar a rede neural com os dados reais mais recentes e obter uma nova predição, e assim por diante. Os testes a seguir foram feitos simulando essa operação real do sistema, para verificar se as redes foram capazes de prever adequadamente.

Para verificar qual o maior horizonte de predição aceitável, foram feitos testes com horizontes diferentes de 1 até 7 dias. As figuras Figura 16 a Figura 25 a seguir mostram a predição das melhores redes neurais selecionadas com 2, 6 e 12 linhas de realimentação, para todos os ciclos de operação identificados de novembro de 2011 a março de 2012. O resultado das redes com outras configurações foi omitido por ser similar ou com maior erro que os apresentados. 
Os pontos dos gráficos em que há uma mudança brusca de valor indicam que a partir deste momento os dados foram preditos pela rede neural inicializada com os dados reais um dia à frente da inicialização da rede neural anterior.
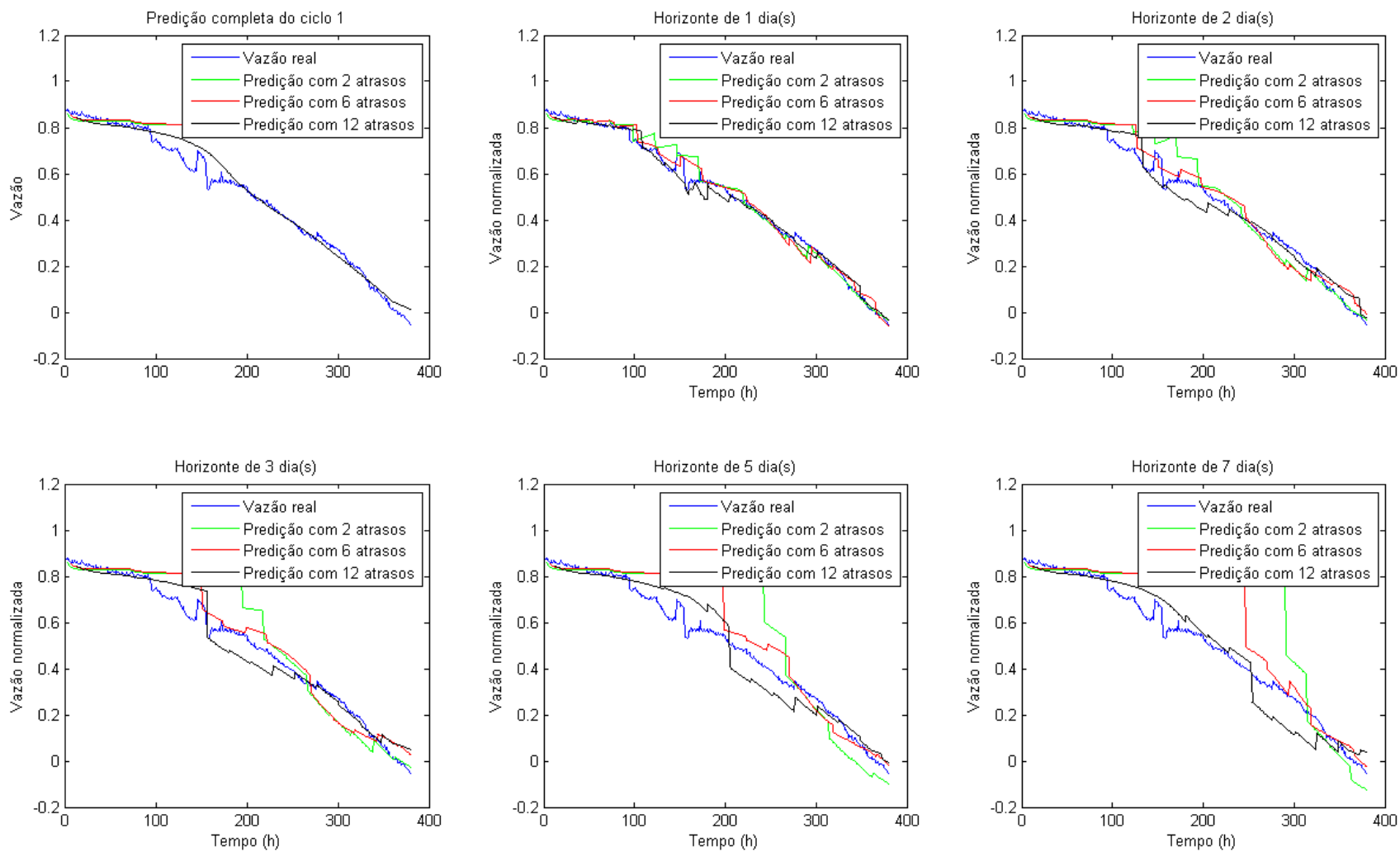

Figura 16 - Teste de predição para o ciclo 1 

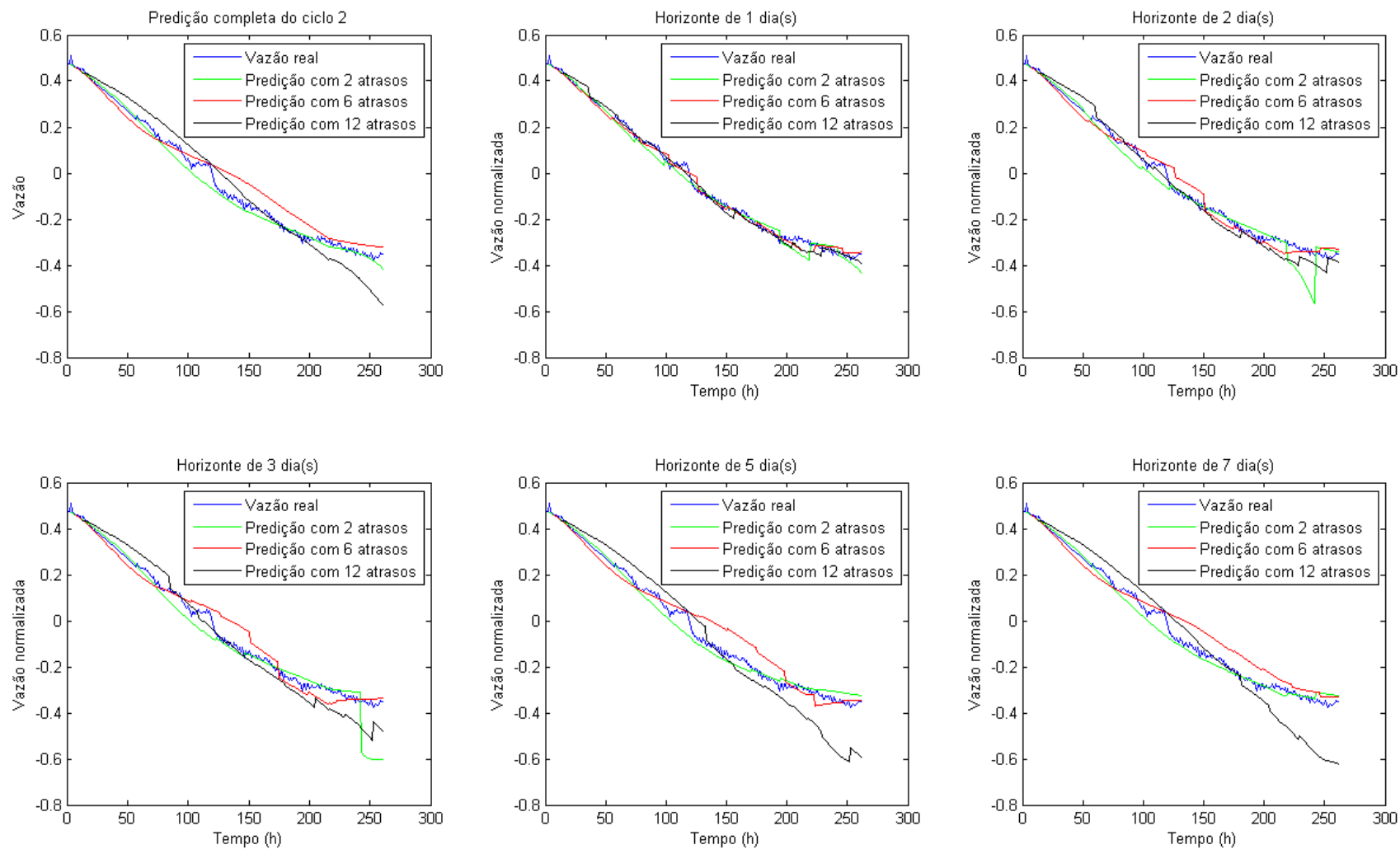

Figura 17 - Teste de predição para o ciclo 2
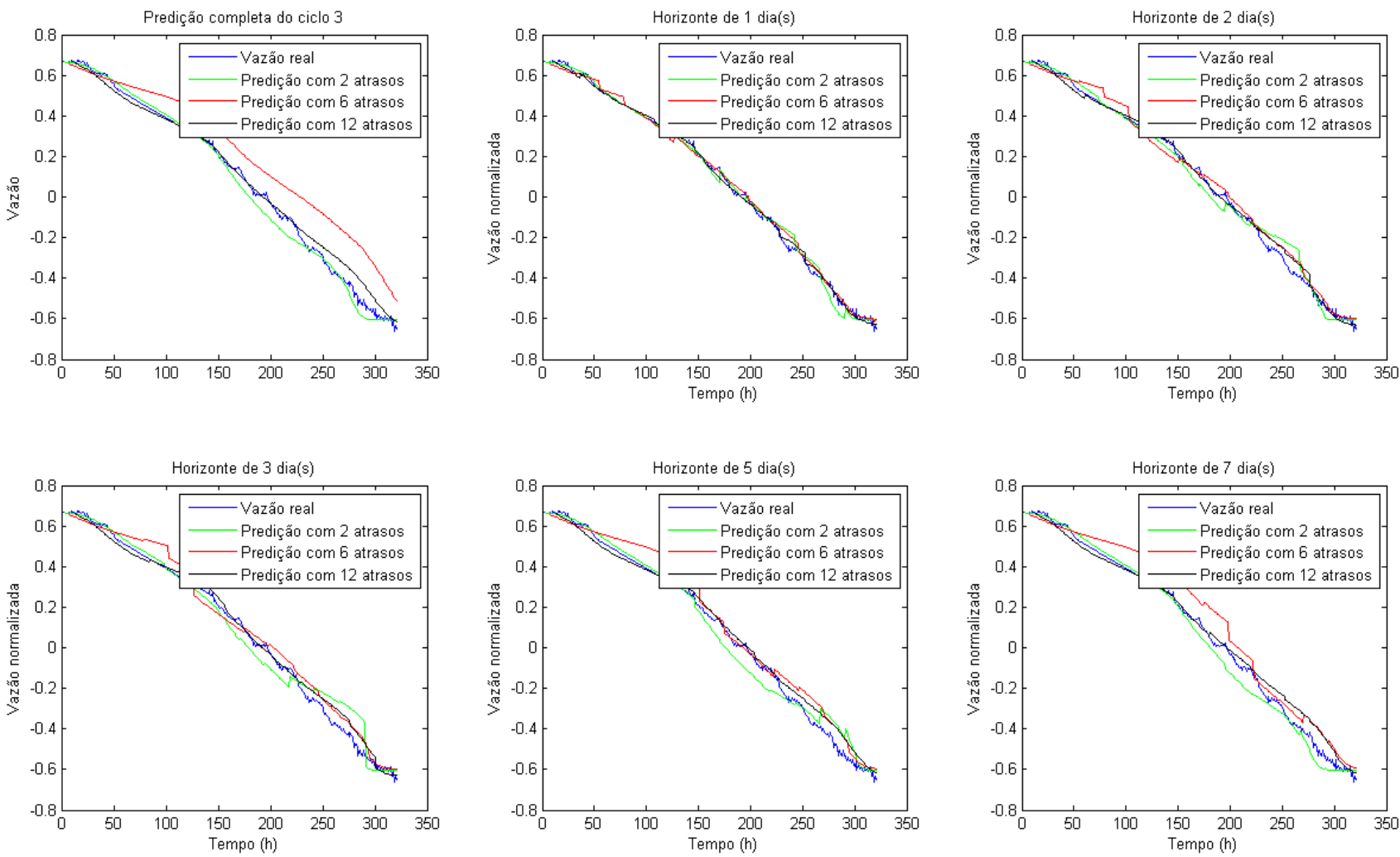

Figura 18 - Teste de predição para o ciclo 3 

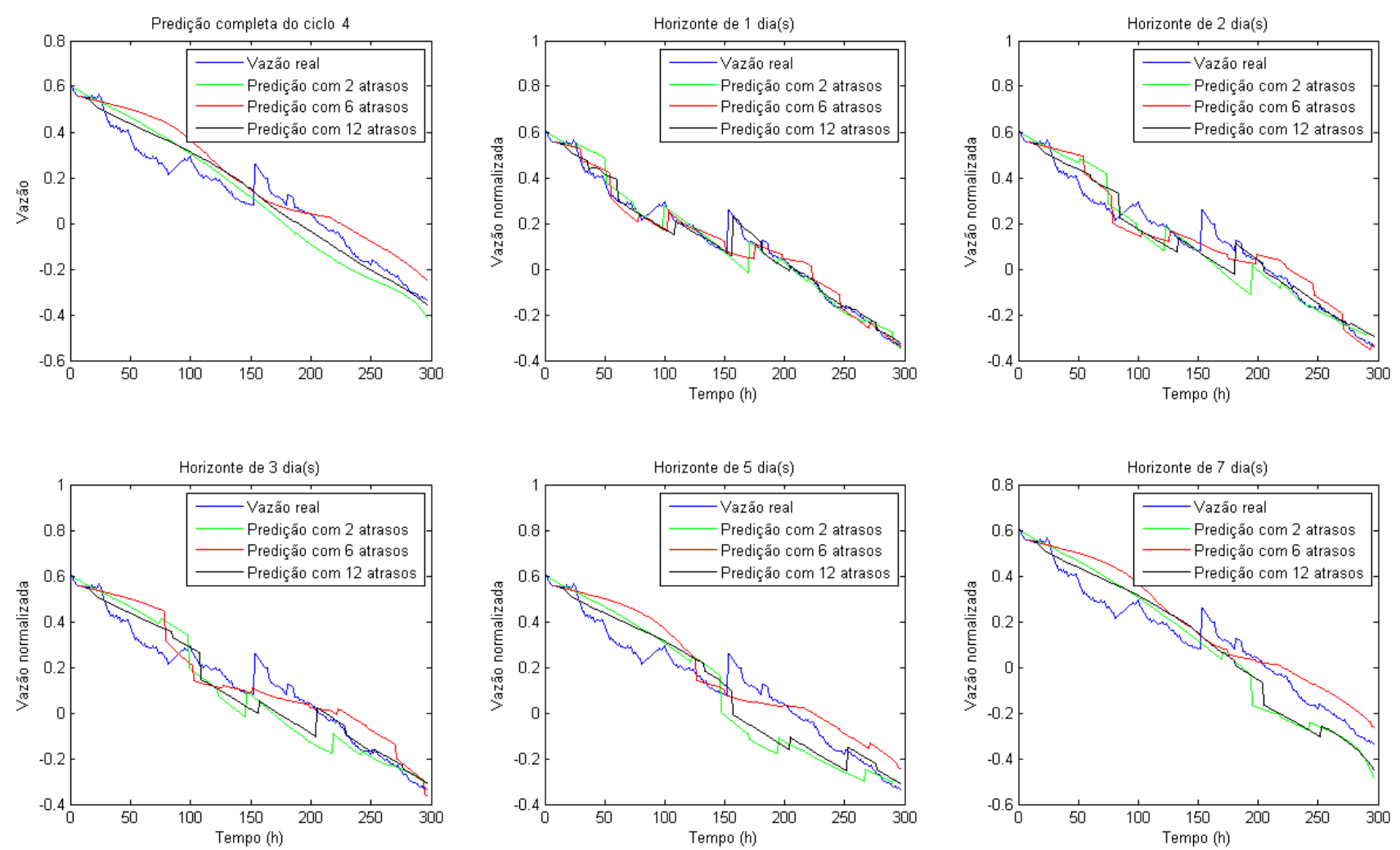

Figura 19 - Teste de predição para o ciclo 4
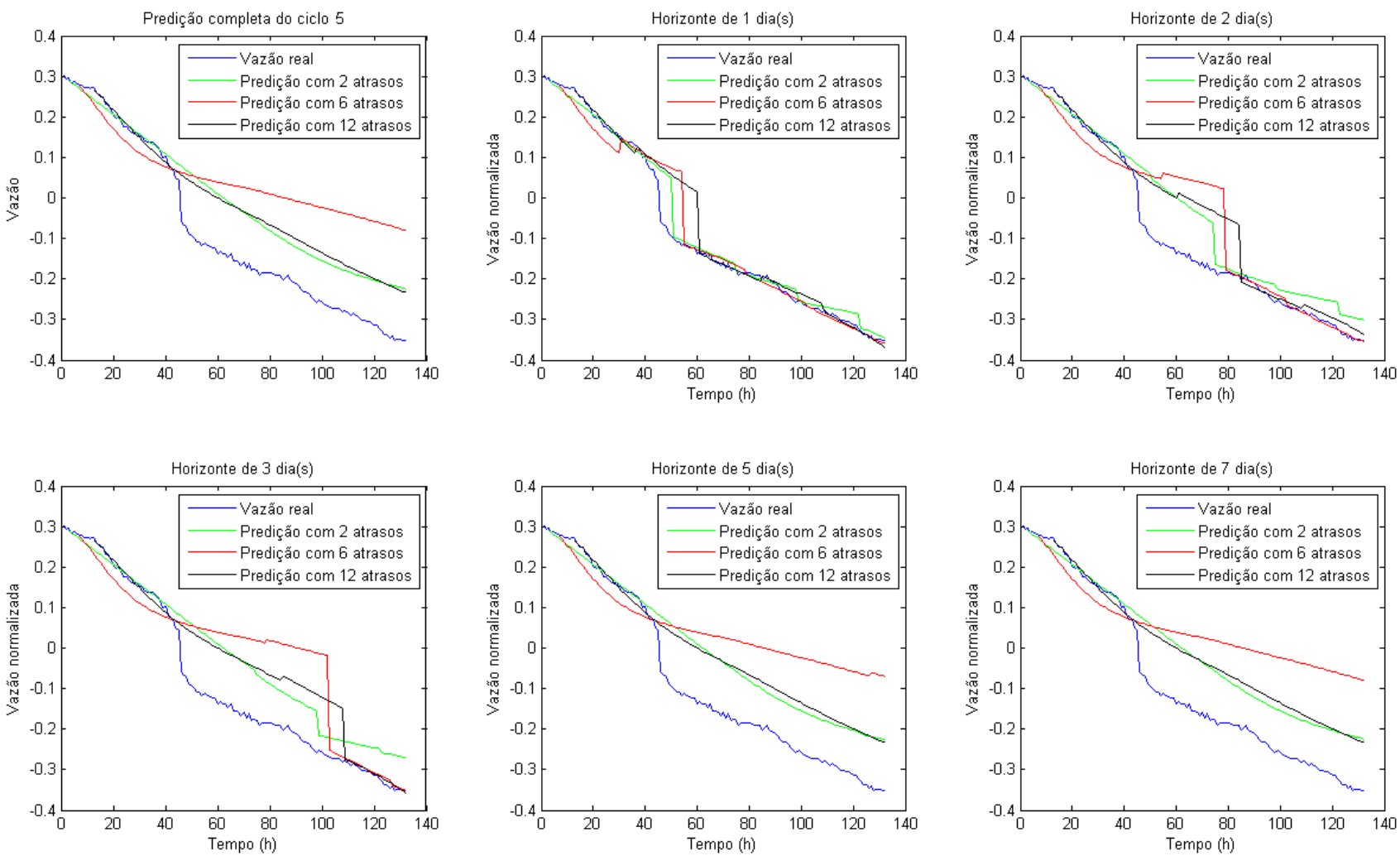

Figura 20 - Teste de predição para o ciclo 5 

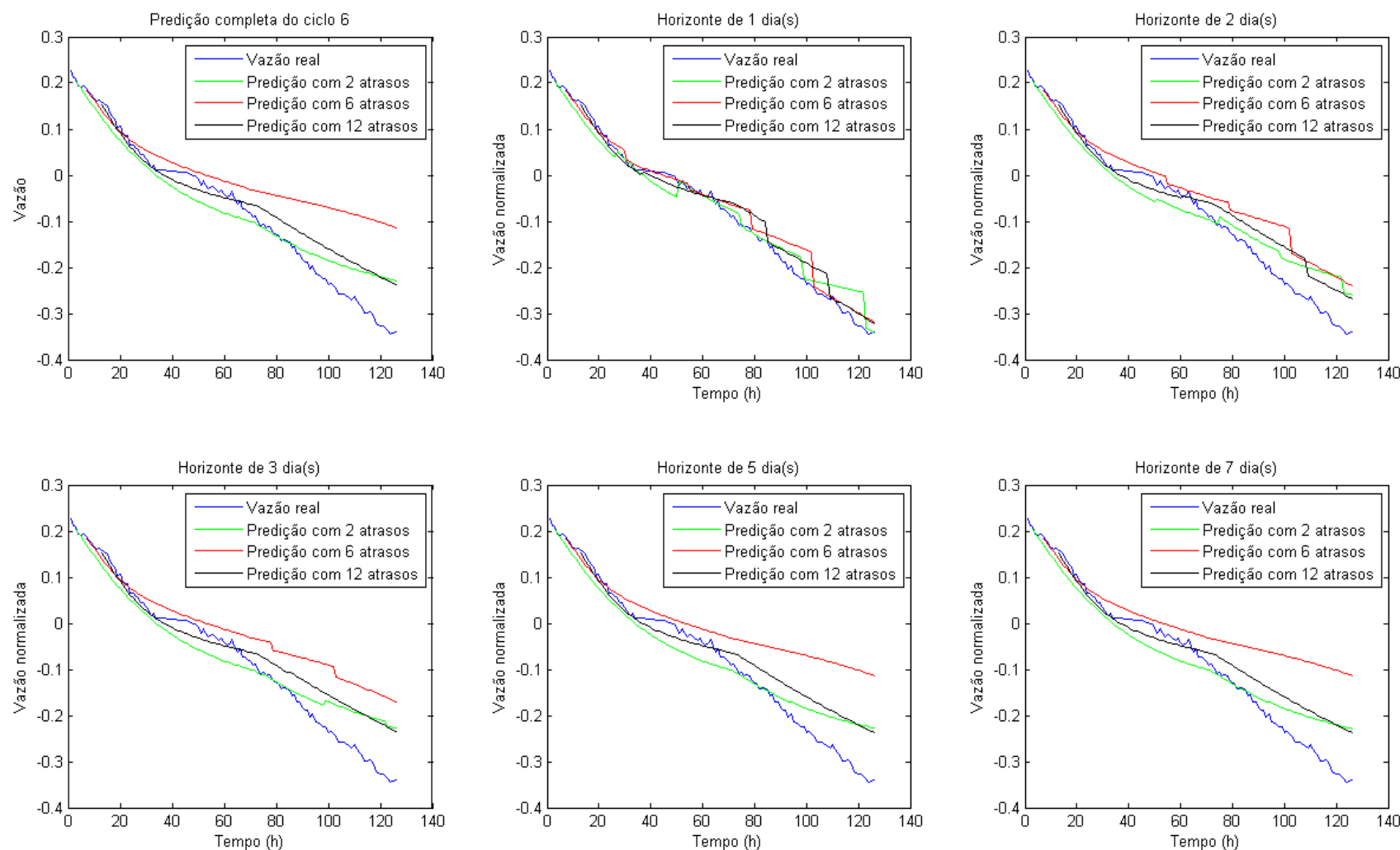

Figura 21 - Teste de predição para o ciclo 6
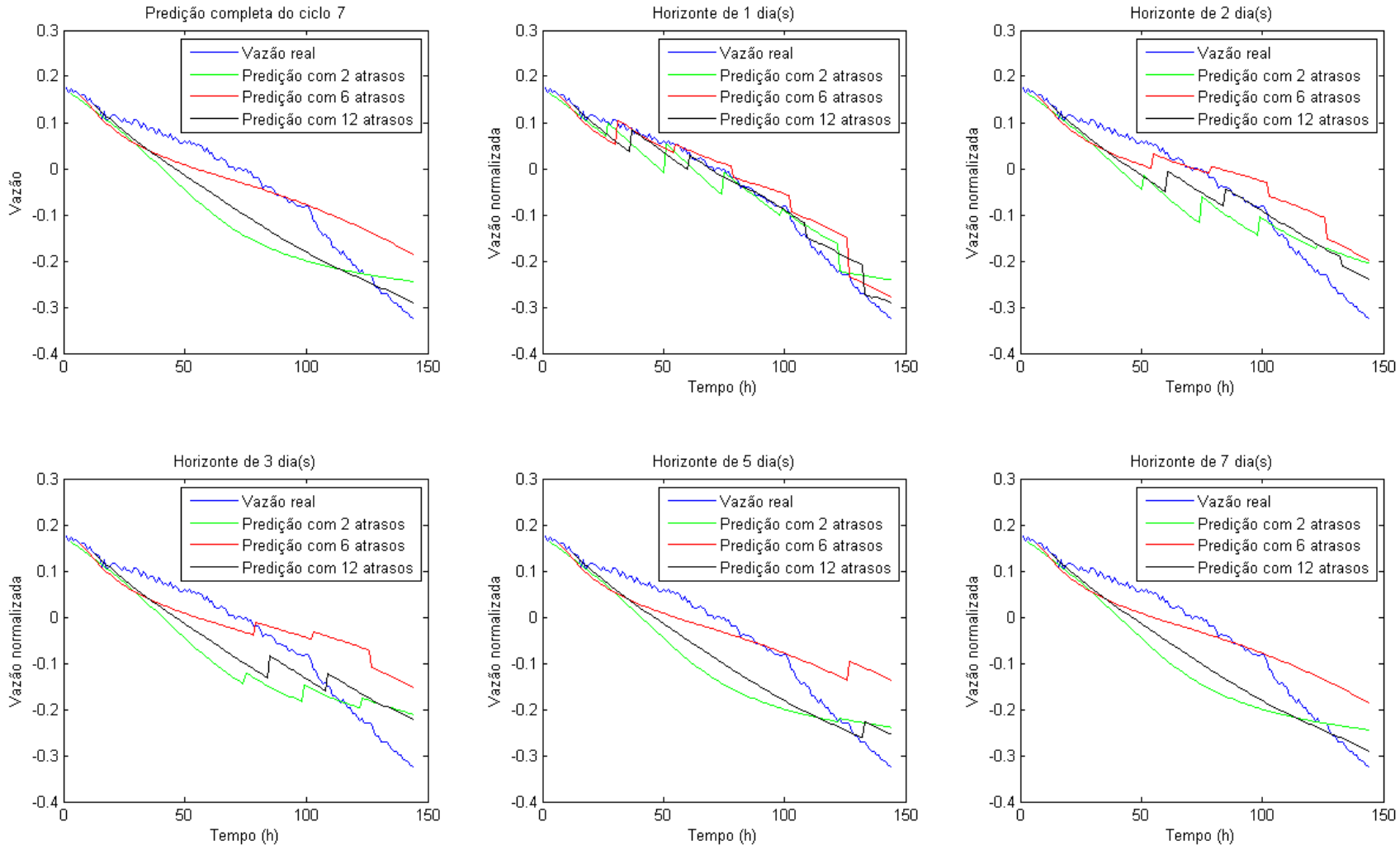

Figura 22 - Teste de predição para o ciclo 7 

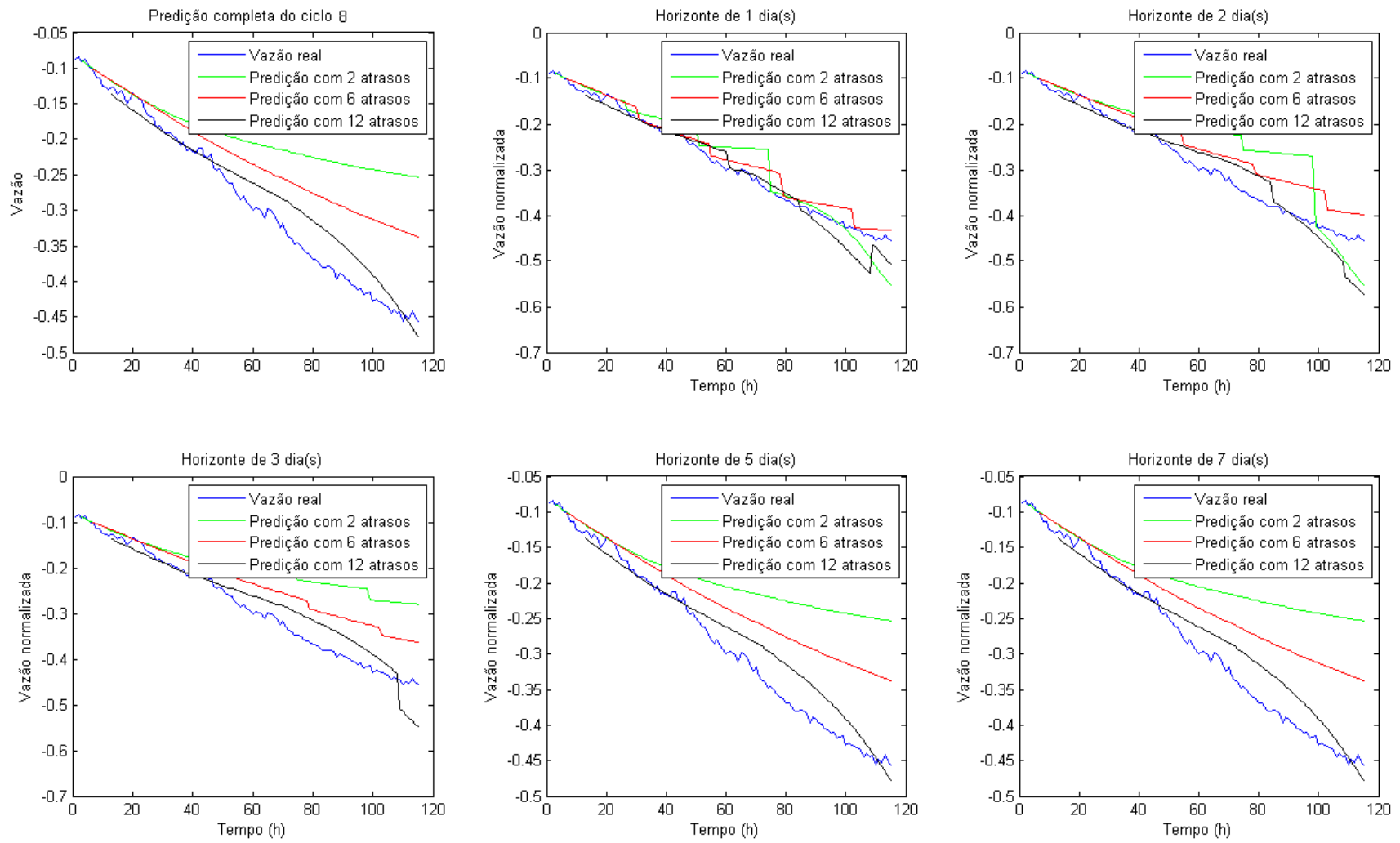

Figura 23 - Teste de predição para o ciclo 8
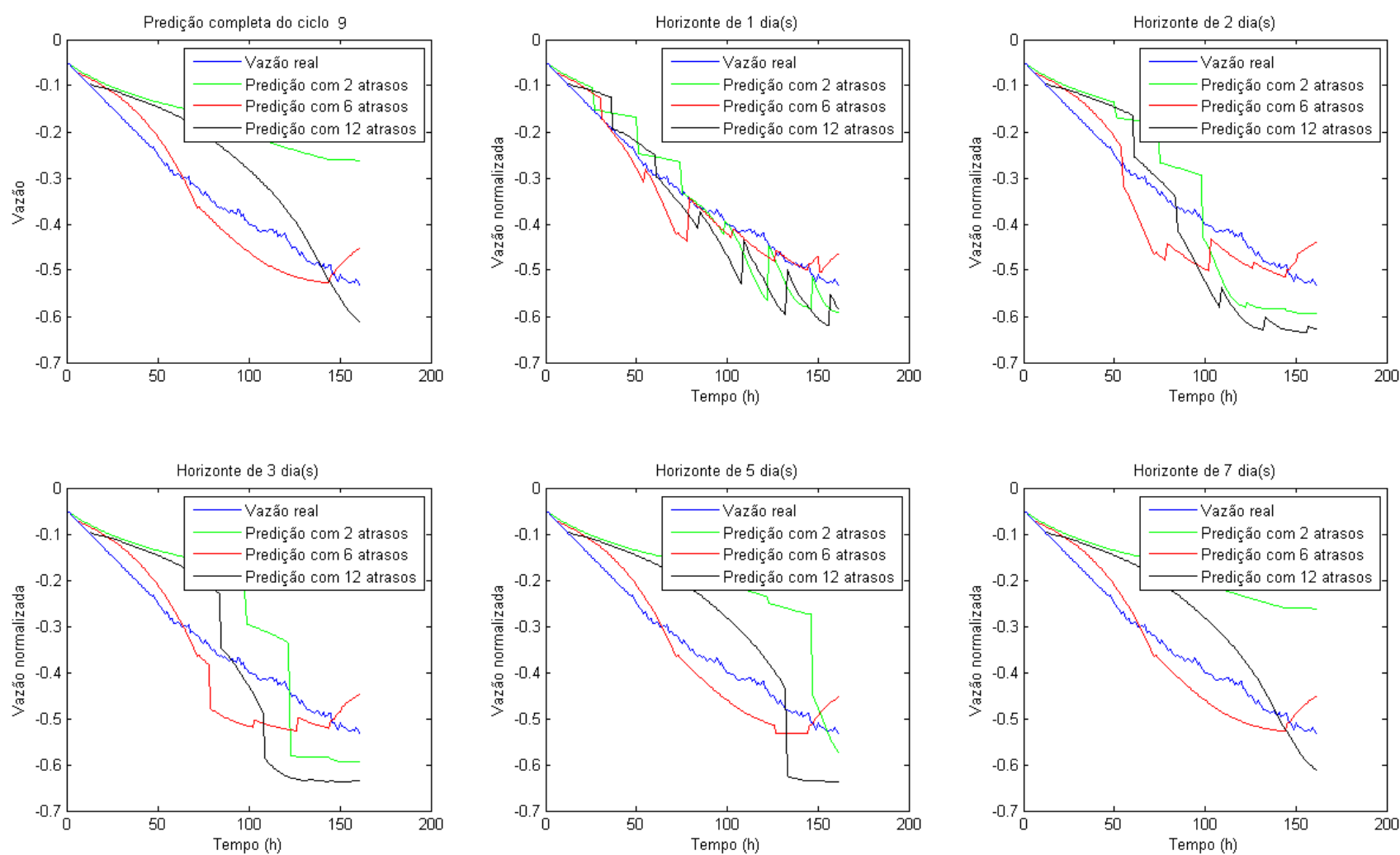

Figura 24 - Teste de predição para o ciclo 9 

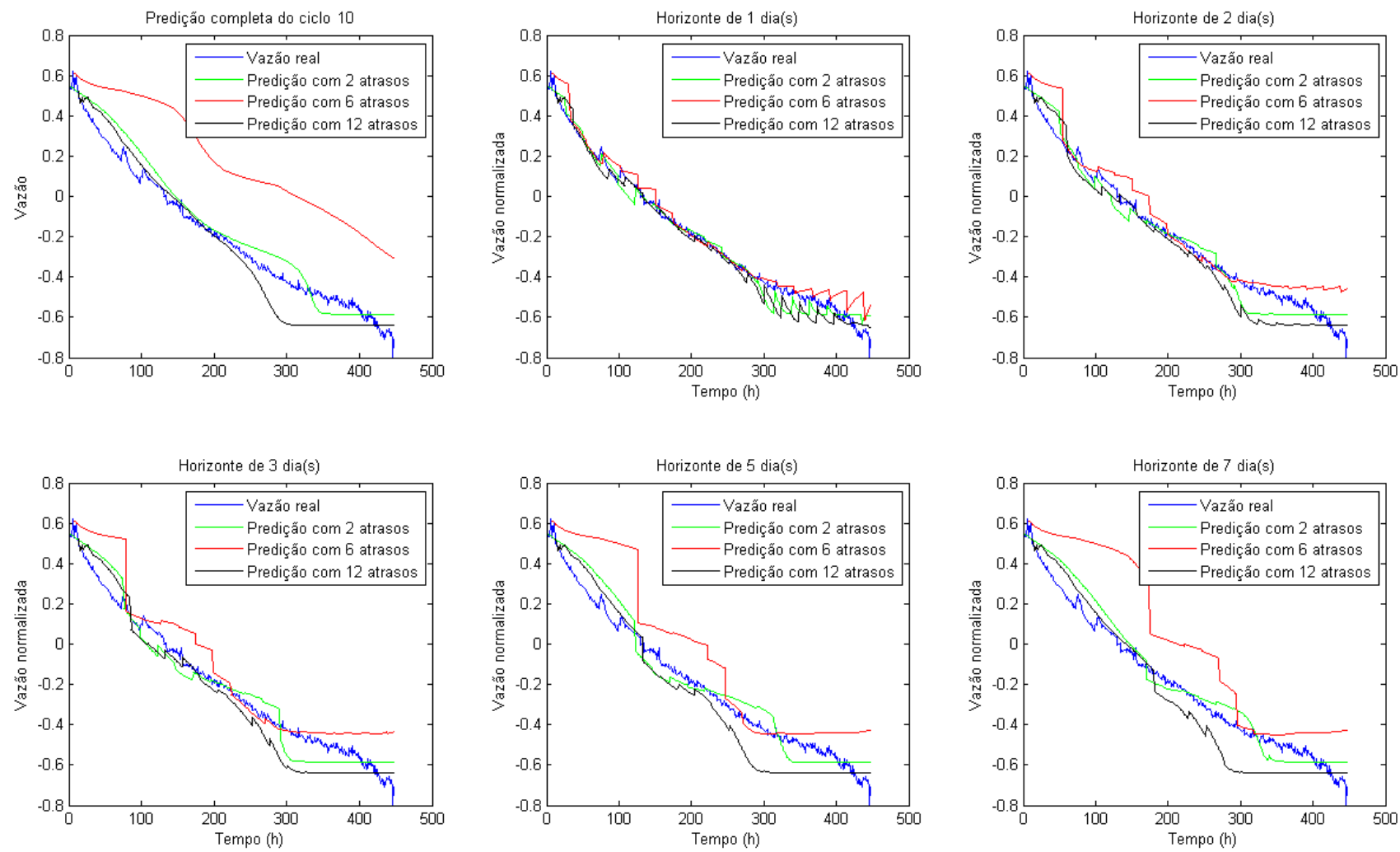

Figura 25 - Teste de predição para o ciclo 10

Os resultados mostram que, quanto maior o horizonte de predição, maior é o erro, como já era esperado. Mesmo assim, a rede neural forneceu em geral uma boa predição de 3 até 5 dias à frente.

Observa-se também que, na maioria dos casos, a rede neural com apenas 2 atrasos teve um desempenho similar ao da rede neural com 12 atrasos. Mas esta última foi mais consistente, como pode ser verificado em particular nos ciclos 1, 8 e 9. Nesses casos, houve uma degradação mais rápida do desempenho da rede neural com 2 atrasos.

Para os primeiros 4 ciclos, o preditor foi capaz de estimar eficientemente a vazão até o final, a partir de uma única inicialização no primeiro dia. Isso se deve ao fato destes terem sido os ciclos usados no treinamento, para os quais a rede se adaptou muito bem. 0 ciclo 5 também foi usado no treinamento, porém houve em certo instante uma grande mudança nas condições de operação (temperaturas de entrada de óleo e de QAV), o que prejudicou o comportamento do preditor. Nesse caso, a reinicialização da rede neural com as novas condições de operação fez com que o preditor voltasse a realizar uma predição adequada.

A predição para os ciclos 6 e 8 forneceu bons resultados até um horizonte de 5 dias, com uma boa predição da degradação gradual da vazão, apesar de um erro um pouco maior 
nos instantes finais dos ciclos. A predição para o ciclo 10 também foi bastante satisfatória até um horizonte de 3 dias, ao longo de todo o ciclo.

Os piores resultados foram observados para os ciclos 7 e 9 . Nesses casos, o comportamento intermediário da vazão não foi predita de maneira adequada para horizontes maiores que 1 dia. Por outro lado, a vazão final, poucas horas antes da parada, foi predita com erro satisfatório.

A Tabela 8 fornece um resumo dos erros médios quadráticos obtidos para cada ciclo de operação, para cada horizonte de predição e para cada número de linhas de realimentação, ou seja, o número de horas passadas que devem ser fornecidas inicialmente à rede neural.

Tabela 8 - Erros de predição para todos os casos

\begin{tabular}{|c|c|c|c|c|c|c|c|c|c|c|c|}
\hline \multicolumn{12}{|c|}{ Erro Médio Quadrático } \\
\hline \multirow[b]{2}{*}{$\begin{array}{c}\text { Horizonte } \\
\text { (dias) }\end{array}$} & \multirow[b]{2}{*}{$\begin{array}{c}\text { Linhas de } \\
\text { atrasos }\end{array}$} & \multicolumn{10}{|c|}{ Ciclo } \\
\hline & & 1 & 2 & 3 & 4 & 5 & 6 & 7 & 8 & 9 & 10 \\
\hline \multirow{3}{*}{1} & 2 & $1,5 e-3$ & $8,0 e-4$ & $8,5 e-4$ & $3,1 \mathrm{e}-3$ & $8,9 e-4$ & $7,4 e-4$ & $1,1 \mathrm{e}-3$ & $1,2 \mathrm{e}-3$ & $2,5 e-3$ & $2,5 e-3$ \\
\hline & 6 & $1,1 \mathrm{e}-3$ & $3,7 e-4$ & $6,0 e-4$ & $2,6 e-3$ & $2,3 e-3$ & $6,3 e-4$ & $1,1 \mathrm{e}-3$ & $4,4 \mathrm{e}-4$ & $1,3 e-3$ & $3,8 \mathrm{e}-3$ \\
\hline & 12 & $0,9 e-3$ & $4,5 e-4$ & $2,9 e-4$ & $1,6 e-3$ & $2,9 e-3$ & $5,9 e-4$ & $6,0 e-4$ & $7,5 e-4$ & $3,5 e-3$ & $2,9 e-3$ \\
\hline \multirow{3}{*}{2} & 2 & $5,4 \mathrm{e}-3$ & $2,6 e-3$ & $1,8 \mathrm{e}-3$ & $7,3 e-3$ & $4,6 e-3$ & $2,2 e-3$ & $4,5 e-3$ & $5,6 e-3$ & $8,4 e-3$ & $4,5 e-3$ \\
\hline & 6 & $2,8 \mathrm{e}-3$ & $1,1 \mathrm{e}-3$ & $1,7 e-3$ & $5,0 e-3$ & $9,1 e-3$ & $3,7 e-3$ & $4,3 e-3$ & $2.2 \mathrm{e}-3$ & $4,5 e-3$ & $1,0 \mathrm{e}-2$ \\
\hline & 12 & $2,2 \mathrm{e}-3$ & $1,6 e-3$ & $7,5 e-4$ & $4,6 e-3$ & $6,2 \mathrm{e}-3$ & $2,0 e-3$ & $2,3 e-3$ & $1,5 e-3$ & $1,1 \mathrm{e}-2$ & $7,3 e-3$ \\
\hline \multirow{3}{*}{3} & 2 & $1,2 \mathrm{e}-2$ & $5,2 e-3$ & $3,9 e-3$ & $1,0 e-2$ & $7,1 \mathrm{e}-3$ & $2,6 e-3$ & $7,0 e-3$ & $1,1 \mathrm{e}-2$ & $1,23-2$ & $6,5 e-3$ \\
\hline & 6 & $5,1 \mathrm{e}-3$ & $2,0 e-3$ & $2,9 e-3$ & $7,3 e-3$ & $1,8 \mathrm{e}-2$ & $7,7 e-3$ & $7,1 \mathrm{e}-3$ & $3,8 \mathrm{e}-3$ & $4,9 e-3$ & $1,8 \mathrm{e}-2$ \\
\hline & 12 & $3,3 e-3$ & $3,7 e-3$ & $1,3 e-3$ & $6,6 e-3$ & $8,8 \mathrm{e}-3$ & $2,7 e-3$ & $4,2 e-3$ & $1,3 e-3$ & $1,3 e-3$ & $9,5 e-3$ \\
\hline \multirow{3}{*}{5} & 2 & $3,0 \mathrm{e}-2$ & $1,1 \mathrm{e}-3$ & $3,0 e-3$ & $1,6 e-2$ & $9,5 e-3$ & $2,3 e-2$ & $7,7 e-3$ & $1,3 e-2$ & $2,2 \mathrm{e}-2$ & $6,7 e-3$ \\
\hline & 6 & $1,2 \mathrm{e}-2$ & $3,1 \mathrm{e}-3$ & $5,6 e-3$ & $1,0 e-2$ & $3,3 e-2$ & $1,2 \mathrm{e}-2$ & $5,5 e-3$ & $5,1 \mathrm{e}-3$ & $2,4 e-3$ & $4,0 \mathrm{e}-2$ \\
\hline & 12 & $5,0 e-3$ & $1,0 \mathrm{e}-2$ & $1,6 e-3$ & $1,1 \mathrm{e}-2$ & $1,1 \mathrm{e}-2$ & $2,6 e-3$ & $4,5 e-3$ & $9,0 e-4$ & $1,1 \mathrm{e}-2$ & $1,2 \mathrm{e}-2$ \\
\hline \multirow{3}{*}{7} & 2 & $6,0 \mathrm{e}-2$ & $9,2 e-4$ & $2,0 \mathrm{e}-3$ & $1,1 \mathrm{e}-2$ & $9,6 e-3$ & $2,2 \mathrm{e}-3$ & $7,6 e-3$ & $1,3 e-2$ & $2,9 e-2$ & $5,9 e-3$ \\
\hline & 6 & $2,8 \mathrm{e}-2$ & $3,0 e-3$ & $7,4 \mathrm{e}-3$ & $9,6 e-3$ & $3,2 \mathrm{e}-2$ & $1,2 \mathrm{e}-2$ & $3,7 e-3$ & $5,1 \mathrm{e}-3$ & $2,3 e-3$ & $6,8 \mathrm{e}-2$ \\
\hline & 12 & $5,8 \mathrm{e}-3$ & $1,1 \mathrm{e}-2$ & $1,9 e-3$ & $9,2 e-3$ & $1,1 \mathrm{e}-2$ & $2,6 e-3$ & $4,2 \mathrm{e}-3$ & $9,0 \mathrm{e}-4$ & $8,1 e-3$ & $1,2 \mathrm{e}-2$ \\
\hline \multirow{3}{*}{$\begin{array}{c}\text { Ciclo } \\
\text { Completo }\end{array}$} & 2 & $1,9 e-1$ & $8,6 e-4$ & $1,5 e-3$ & $7,7 e-3$ & $9,6 e-3$ & $2,2 e-3$ & $7,6 e-3$ & $1,3 e-2$ & $2,9 e-2$ & $6,3 e-3$ \\
\hline & 6 & $1,8 \mathrm{e}-1$ & $2,8 \mathrm{e}-3$ & $2,3 e-2$ & $9,9 e-3$ & $3,2 \mathrm{e}-2$ & $1,2 \mathrm{e}-2$ & $3,7 e-3$ & $5,1 \mathrm{e}-3$ & $2,3 e-3$ & $1,5 \mathrm{e}-1$ \\
\hline & 12 & $1,8 \mathrm{e}-3$ & $4,7 e-3$ & $1,7 \mathrm{e}-3$ & $4,7 e-3$ & $1,1 \mathrm{e}-2$ & $2,6 e-3$ & $4,2 e-3$ & $9,0 \mathrm{e}-4$ & $8,1 e-3$ & $1,0 \mathrm{e}-2$ \\
\hline
\end{tabular}




\section{Conclusão e Perspectivas}

Esse trabalho teve o objetivo de desenvolver um sistema capaz de prever a incrustação do trocador de calor P-27002 da refinaria da Petrobras, na cidade de Guamaré-RN. Esse permutador é bastante afetado pela incrustação e a predição pode ser útil para auxiliar os operadores a planejar com mais eficiência as paradas para limpeza, pois eles teriam uma indicação de como o permutador iria operar alguns dias à frente.

Foram coletados, em parceria com a Petrobras, dados reais do P-27002 referentes aos meses de novembro de 2011 até março de 2012. Esses dados correspondem a todas as variáveis medidas diretamente no permutador, sendo elas a vazão de QAV e de óleo e as temperaturas de entrada e saída de QAV e de óleo, totalizando 6 variáveis. Os dados foram tratados para eliminar diversos problemas como valores espúrios, congelamento de valores e perda de informação. Além dessas 6 variáveis, outras duas puderam ser calculadas a partir de equações da literatura, sendo elas a efetividade e o fator de incrustação do permutador. A análise também permitiu separar 10 ciclos de operação do permutador. Cada ciclo corresponde ao início da operação do equipamento logo após a limpeza, com gradual aumento da incrustação ao longo dos dias seguintes, até a parada seguinte para manutenção.

Os dados tratados foram analisados e foi definida uma arquitetura para o sistema preditor da incrustação. A melhor indicação da incrustação é a vazão de QAV. Assim, redes neurais artificiais recorrentes foram desenvolvidas com o objetivo de prever a vazão e, por consequência, a incrustação. As redes foram modeladas de forma a prever o comportamento futuro dessa variável com base nas condições de operação do permutador, representadas pelas temperaturas de entrada de óleo e de QAV estimadas para os próximos dias, e nos dados passados reais da vazão, referentes às últimas horas de operação.

Em busca da melhor solução, foram treinadas várias redes com diferentes regressores e números de neurônios. Os melhores modelos treinados possuíram uma camada oculta com 16 ou 20 neurônios e foram capazes de prever com um erro aceitável a vazão até 5 dias à frente, com base nos dados reais das últimas 12 horas de operação.

As redes neurais artificiais treinadas aprenderam as características não lineares do processo da incrustação especificamente para o permutador P-27002. Caso ocorram alterações significativas no processo como, por exemplo, na qualidade do óleo, nas temperaturas médias de operação ou nas vazões fornecidas, será necessário realizar uma nova 
coleta de dados e treinamento do sistema. Se for implementado na realidade, também seria interessante realizar outro treinamento ao término de cada novo ciclo de operação. Isso permitiria ao sistema adquirir sempre novas informações e melhorar a sua capacidade de generalização, diminuindo o erro na predição para ciclos futuros. Essa é, inclusive, uma das maiores vantagens do uso de redes neurais artificiais: a sua capacidade de aprendizagem e fácil adaptação a novas situações.

Outro resultado secundário desse trabalho foi o desenvolvimento de um conjunto de rotinas que permitem preparar os dados para treinamento e simulação de redes neurais com realimentação, usando também o toolbox nativo do Matlab ${ }^{\circledR}$. Essas rotinas foram escritas de modo geral e podem ser reutilizadas com facilidade em outros trabalhos.

Neste trabalho foram utilizados dados de 5 meses, de novembro de 2011 a março de 2012. Trabalhos futuros poderiam coletar dados referentes a um período de tempo ainda maior. O treinamento com um maior número de ciclos potencialmente melhoraria a capacidade de generalização do sistema, tornando a predição mais confiável para novos ciclos de operação. No entanto, seria importante analisar também se houve alguma grande alteração no processo em algum instante de tempo. Por exemplo, a instalação de novos filtros, dessalgadores ou outros equipamentos podem alterar significativamente o comportamento da incrustação no trocador de calor. Os dados mais antigos, coletados antes dessa alteração, não contribuiriam para o treinamento do preditor e iriam somente piorar o seu desempenho ou aumentar a sua complexidade. Reuniões técnicas com a empresa que fornecerá os dados são a melhor maneira de descobrir a existências de tais alterações no processo.

A arquitetura do sistema projetado neste trabalho não está limitada ao permutador P27002. A mesma arquitetura poderia ser utilizada em trabalhos futuros em outros trocadores de calor reais, bastando ser feita a coleta e tratamento de dados de maneira adequada.

Seria interessante estudar a melhor maneira de implementar e testar esse sistema para a operação em tempo real em plantas reais. $O$ treinamento das redes neurais, por ser mais matematicamente complexo, é mais bem efetuado em modo offline, com o auxílio de um software matemático ou de uma linguagem de operação. Por outro lado, já existem trabalhos descrevendo como implementar redes neurais já treinadas em CLPs e redes industriais.

Outras perspectivas para trabalhos futuros incluem um estudo mais detalhado dos processos da refinaria para a identificação de outras variáveis significativas ao problema da incrustação. Talvez existam outras medições da planta que não estejam ligadas diretamente ao 
permutador de calor, mas que de algum modo influenciem a incrustação. Exemplos de variáveis interessantes para estudos futuros são a dosagem de produtos químicos adicionados ao petróleo desde os poços produtores até as estações de tratamento, principalmente o sequestrante de $\mathrm{H}_{2} \mathrm{~S}$, e a vazão de água nas dessalgadoras. Esses novos dados poderiam ser incluídos no sistema preditor para melhorar sua confiabilidade, ou poderia ser estudado um sistema de controle visando manipular essas variáveis para reduzir a incrustação e manter a especificação dos produtos da coluna de destilação, prolongando o tempo entre as limpezas.

A análise de custo da coluna de destilação é outro ponto de grande interesse para indústria, para definir qual o melhor período para efetuar a limpeza. É sabido que a incrustação no trocador de calor afeta o rendimento da coluna principalmente devido ao aumento da sua temperatura de topo. Um estudo poderia ser feito para verificar, em longo prazo, o que seria mais vantajoso financeiramente: diminuir o tempo entre as paradas para limpeza, fazendo com que a coluna opere com maior rendimento, ou fazer com que a coluna opere com eficiência mais baixa, com um tempo mais longo entre as paradas. Mais especificamente, essa análise poderia definir qual o valor da vazão de QAV correspondente ao melhor momento para efetuar a limpeza.

Finalmente, é interessante observar que um grande desafio no desenvolvimento de trabalhos relacionados à coluna de destilação é a impossibilidade de manipular variáveis e realizar experimentos com a planta real. Uma simulação dinâmica do processo seria uma excelente ferramenta no desenvolvimento de trabalhos futuros. 


\section{Referências Bibliográficas}

AGUIRRE, L. A. (2004). Introdução à identificação de sistemas: técnicas lineares e não-lineares aplicadas a sistemas reais. Editora UFMG, 2 ed., Belo Horizonte - MG, Brasil.

AKBARI, S., SIMONSON, C. J., BESANT, R. W. (2012). Application of neural networks to predict the transient performance of a Run-Around Membrane Energy Exchanger for yearly non-stop operation. International Journal of Heat and Mass Transfer, vol. 55, ed. 21-22, pp. 5403-5416.

BEALE, M. H., HAGAN, M. T., DEMUTH, H. B. (2012). Neural Network Toolbox ${ }^{T M}$ User's Guide. Mathworks.

Disponível em: http://www.mathworks.com/help/pdf_doc/nnet/nnet_ug.pdf

FERNANDES, R. G. (2007). Detecção e Isolamento de Falhas em Sistemas Dinâmicos Baseados em Redes Neurais. Dissertação de Mestrado, Universidade Federal do Rio Grande do Norte.

FORTUNA, L., GRAZIANI, S., RIZZO, A., XIBILIA, M. G. (2007). Soft Sensors for Monitoring and Control of Industrial Processes. Springer-Verlag, Londres.

GANG, W., WANG, J. (no prelo, 2013). Predictive ANN models of ground heat exchanger for the control of hybrid ground source heat pump systems. Applied Energy.

GONÇALVES, J. C. (2007). Estudo de Corrosão em Sistemas de Topo de Unidades de Destilação de Petróleo - Avaliação em Laboratório de Inibidor de Corrosão Comercial e Agentes Neutralizantes. Dissertação de Mestrado, Universidade Federal do Rio de Janeiro.

HAYKIN, S. (2000). Redes Neurais: Princípios e Prática. Bookman, 2 ed..

HOU, D., ZHOU, Z. (2005). A Novel Measurement Scheme for Periodic Fouling in Recipe Alternation Based on Hybrid Fuzzy Neural Network. IEEE International Conference on Systems, Man and Cybernetics. 
JeRÓNIMO, M. A. S., MELO, L. F., BRAGA, A. S., FERREIRA, P. J. B. F., MARTINS, C. (1997). Monitoring the thermal efficiency of fouled heat exchanger - a simplified method. Experimental Thermal and Fluid Science, vol. 14, pp. 455-463.

JONSSON, G. R., LALOT, S., PALSSON, O. P., DESMET, B. (2007). Use of extended Kalman filtering in detecting fouling in heat exchangers. International Journal of Heat and Mass Transfer, vol. 50, ed. 13-14, pp 2643-2655.

KASHANI, M. N., AMINIAN, J., SHAHHOSSEINI, S., FARROKHI, M. (2012). Dynamic crude oil fouling prediction in industrial preheaters using optimized ANN based moving window technique. Chemical Engineering Research and Design, vol. 90, ed. 7, pp. 938-949.

KHAN, M. S., HUSNIL, Y. A., GETU, M., LEE, M. (2012). Modeling and Simulation of Multi-stream Heat Exchanger Using Artificial Neural Network. Computer Aided Chemical Engineering, Elsevier, vol. 31, pp. 1196-1200.

LANG, K. J., HINTON, G. E. (1988).The development of the time-delay neural network architecture for speech recognition. Technical report CMU-CS-88-152, Carnegie-Mellon University, Pittsburgh, Pennsylvania, Estados Unidos.

LEONDES, T. L. (2006). Control and dynamic systems - neural network systems techniques and applications. Academic Press, San Diego, California, Estados Unidos.

LINHARES, L. L. S. (2010). Sistema Híbrido de Inferência Baseado em Análise de Componentes Principais e Redes Neurais Artificiais Aplicado a Plantas de Processamento de Gás Natural. Dissertação de Mestrado, Universidade Federal do Rio Grande do Norte.

LJUNG, L. (1998). System identification: theory for the user. Prentice Hall, 2 ed., Upper Saddle River, New Jersey, Estados Unidos.

MACKAY, D. J. C. (1992). A Practical Bayesian Framework for Backpropagation Networks. Neural Computation, vol. 4, n. 3, pp. 415 to 447. 
NARENDRA, K. S., PARTHASARATHY, K. (1990). Identification and control of dynamical systems using neural networks. IEEE Transactions on Neural Networks, vol. 1, n. 1, pp 4-27.

NELLES, O. (2005). Nonlinear system identification: from classifcal approaches to neural networks and fuzzy models. Springer-Verlag, Berlin, Alemanha.

NORGAARD, M., RAVN, O., POULSEN, N. K., HANSEN, L. K. (2006). Neural networks for modelling and control of dynamic systems. Springer-Verlag, Berlin, Alemanha.

RADHAKRISHNAN, V.R., RAMASAMY, M., ZABIRI, H., DO THANH, V., TAHIR, N. M., MUKHTAR, H., HAMDI, M. R., RAMLI, N. (2007). Heat exchanger fouling model and preventive maintenance scheduling tool. Applied Thermal Engineering, vol. 27, ed. 1718.

REBOUÇAS, D. L. (2009). Sistema de Inferência Neural e Processamento Estatístico Multivariável Aplicado á Indústria do Petróleo. Monografia de Graduação, Universidade Federal do Rio Grande do Norte.

REBOUÇAS, D. L. (2011). Utilização de redes neurais artificiais para detecção e diagnóstico de falhas. Dissertação de Mestrado, Universidade Federal do Rio Grande do Norte.

SHANRANG, Y., ZHIMING, X. LINGFANG, S. (2004). Heat Exchanger Fouling and Its Countermeasure. Pequim, Science Press, ed. 2.

SHAOSHENG, F., JU, W. (2007). Application of Diagonal Recurrent Neural Network for Measuring Fouling in Condenser. 2nd IEEE Conference on Industrial Electronics and Applications ICIEA.

SILVA, I. N., SPATTI, D. H., FLAUZINO, R. A. (2010). Redes Neurais Artificiais para engenheria e ciências aplicadas. Artliber, São Paulo - SP, Brasil.

SONG, T. W. (1997). Condições de processo num trocador de calor. Revista de Graduação da Engenharia Química, São Paulo, vol. 1, n. 1, pp. 29-42. 
SUN, L., CAI, H., ZHANG, Y., YANG, S., QIN, Y. (2008a). Research on the Fouling Prediction of Heat Exchanger Based on Wavelet Neural Network. IEEE 3rd International Conference on Cybernetics and Intelligent Systems (CIS).

SUN, L., ZHANG, Y., SAQI, R. (2009). Research on the Fouling Prediction of Heat Exchanger Based on Support Vector Machine Optimized by Particle Swarm Optimization Algorithm. Proceedings of the IEEE International Conference on Mechatronics and Automation.

SUN, L., ZHANG, Y., ZHENG, X., YANG, S., QIN, Y. (2008b). Research on the Fouling Prediction of Heat exchanger Based on Support Vector Machine. IEEE International Conference on Intelligent Computation Technology and Automation.

SUYKENS, K., VANDEWALLE, J. P. L., DE MOOR, B. L. (2001). Artificial neural networks for modeling and control of non linear systems. Springer-Verlag, Berlin, Alemanha.

THYAGARAJAN, T., MALAR, R. S. M. (2009). Modeling of Quadruple Tanks System Using Soft Computing Techniques. European Journal of Scientific Research, vol. 29, n. 2, pp. 249-264.

TONIN, P. C. (2003). Metodologia para Monitoramento do Desempenho Térmico de Redes de Trocadores de Calor. Dissertação de Mestrado, Centro Federal de Educação Tecnológica do Paraná.

TONIN, P. C., NEGRÃO, C. O. R. (2003). Monitoramento da Performance Térmica de Trocadores de Calor e Redes de Trocadores de Calor. 2을 Congresso Brasileiro de P\&D em Petróleo \& Gás, Rio de Janeiro. Anais do 2o Congresso Brasileiro de P\&D em Petróleo \& Gás, 2003. vol. 1. pp. 1-10.

VASICKANINOVÁ, A., BAKOSOVÁ, M., MÉSZÁROS, A., KLEMES, J. J. (2011). Neural network predictive control of a heat exchanger. Applied Thermal Engineering, vol. 31, ed. 13 , pp. 2094-2100 
VIJAYSAI, P., OSBORN, M. D., AU, S. S., REDDY, K. R. C., SHAH, S. S., VORA, N.P., GRYSCAVAGE, A. (2006). Predictive Performance Assessment of Heat Exchangers for Proactive Remediation. IEEE International Conference on Industrial Technology (ICIT).

WALLHÄUßER, E., HUSSEIN, M. A., BECKER, T. (2012). Detection methods of fouling in heat exchangers in the food industry. Food Control, vol. 27, ed. 1, pp. 1-10.

WANG, X., PENG, G. (2003). Modeling and control for pneumatic manipulator based on dynamic neural network. IEEE International Conference on Systems, Man and Cybernetics, vol 3., pp 2231-2236.

WERLE, L. O. (2009). Implementação de Sensores de Software em Colunas de Destilação com Aquecimento Distribuído. Qualificação de Doutorado, Universidade Federal de Santa Catarina.

WIJAYASEKARA, D., MANIC, M., SABHARWALL P., UTGIKAR, V. (2011). Optimal artificial neural network architecture selection for performance prediction of compact heat exchanger with the EBaLM-OTR technique. Nuclear Engineering and Design, vol. 241 , ed. 7, pp. 2549-2557.

ZANATA, D. R. P. (2005). Desenvolvimento de Sensor Virtual Empregando Redes Neurais para Medição da Composição em uma Coluna de Destilação. Dissertação de Mestrado, Escola Politécnica da Universidade de São Paulo. 